\title{
Is There a Histone Code for Cellular Quiescence?
}

OPEN ACCESS

Edited by:

Guang Yao,

University of Arizona, United States

Reviewed by:

Venkata Chalamcharla,

Centre for Cellular \& Molecular

Biology (CCMB), India

Mary Ann Osley,

University of New Mexico Health

Sciences Center, United States

*Correspondence:

Hilary A. Coller

hcoller@ucla.edu

tThese authors have contributed equally to this work and share first authorship

FThese authors have contributed equally to this work and share last authorship

Specialty section:

This article was submitted to Cell Growth and Division,

a section of the journal

Frontiers in Cell and Developmental

Biology

Received: 12 July 2021

Accepted: 17 September 2021

Published: 29 October 2021

Citation:

Bonitto K, Sarathy K, Atai K,

Mitra $M$ and Coller HA (2021) Is There

a Histone Code for Cellular

Quiescence?

Front. Cell Dev. Biol. 9:739780.

doi: 10.3389/fcell.2021.739780

\author{
Kenya Bonitto ${ }^{1 \dagger}$, Kirthana Sarathy ${ }^{1 \dagger}$, Kaiser Atai ${ }^{1,2,3}$, Mithun Mitra ${ }^{1,3 \neq}$ and \\ Hilary A. Coller ${ }^{1,3,4 * \neq}$
}

\begin{abstract}
'Department of Molecular, Cell, and Developmental Biology, University of California, Los Angeles, Los Angeles, CA, United States, ${ }^{2}$ Molecular Biology Interdepartmental Doctoral Program, University of California, Los Angeles, Los Angeles, CA, United States, ${ }^{3}$ Department of Biological Chemistry, David Geffen School of Medicine, University of California, Los Angeles, Los Angeles, CA, United States, ${ }^{4}$ Molecular Biology Institute, University of California, Los Angeles, Los Angeles, CA, United States
\end{abstract}

Many of the cells in our bodies are quiescent, that is, temporarily not dividing. Under certain physiological conditions such as during tissue repair and maintenance, quiescent cells receive the appropriate stimulus and are induced to enter the cell cycle. The ability of cells to successfully transition into and out of a quiescent state is crucial for many biological processes including wound healing, stem cell maintenance, and immunological responses. Across species and tissues, transcriptional, epigenetic, and chromosomal changes associated with the transition between proliferation and quiescence have been analyzed, and some consistent changes associated with quiescence have been identified. Histone modifications have been shown to play a role in chromatin packing and accessibility, nucleosome mobility, gene expression, and chromosome arrangement. In this review, we critically evaluate the role of different histone marks in these processes during quiescence entry and exit. We consider different model systems for quiescence, each of the most frequently monitored candidate histone marks, and the role of their writers, erasers and readers. We highlight data that support these marks contributing to the changes observed with quiescence. We specifically ask whether there is a quiescence histone "code," a mechanism whereby the language encoded by specific combinations of histone marks is read and relayed downstream to modulate cell state and function. We conclude by highlighting emerging technologies that can be applied to gain greater insight into the role of a histone code for quiescence.

Keywords: histone post translational modification, quiescence, histone methylation, histone acetylation, metabolism, histone code

\section{CELLULAR QUIESCENCE: A STATE OF REVERSIBLE CELL CYCLE EXIT}

To maintain physiological homeostasis, many tissues contain a population of cells that can exit the proliferative cell cycle and enter a quiescent state of temporary cell division arrest in response to anti-proliferative cues (Li and Clevers, 2010; Cheung and Rando, 2013; Nakamura-Ishizu et al., 2014; Dhawan and Laxman, 2015; Sun and Buttitta, 2017; Sagot and Laporte, 2019a; Marescal and Cheeseman, 2020). This non-dividing state of cellular quiescence is defined by its reversibility, that is, quiescent cells can reenter the cell cycle upon receiving proliferative signals. Quiescent 
cells can be distinguished from other types of non-dividing cells such as senescent or terminally differentiated cells by their temporary exit from the cell cycle and high likelihood of proliferating in response to a triggering stimulus (Sang and Coller, 2009; Cheung and Rando, 2013; Terzi et al., 2016). Quiescent cells must therefore preserve the ability to proliferate at a later time, and protect themselves from entering irreversible states (Coller et al., 2006; Sang and Coller, 2009; Sang et al., 2010; Bjornson et al., 2012).

Cellular quiescence has been studied experimentally in multiple systems including yeast, cultured primary cells, and stem cells (Mitra et al., 2018a; Spain et al., 2018; Yang and Chi, 2018) (Table 1). Some of the gene expression, signaling, and functional changes observed with quiescence are likely specific for a cell type, while others are shared. Transcriptional changes with quiescence have been analyzed using cDNA libraries (Schneider et al., 1988; Coppock et al., 1993), microarrays (Venezia et al., 2004; Coller et al., 2006; Suh et al., 2012; Johnson et al., 2017), next generation sequencing (van Velthoven et al., 2017; Mitra et al., 2018b; Srivastava et al., 2018), and single-cell RNA sequencing methods (Kalakonda et al., 2008; Coller, 2019a). These studies demonstrated widespread gene expression changes with quiescence, some of which are functionally important for the quiescent state (Suh et al., 2012; Johnson et al., 2017; Lee H.N. et al., 2018; Mitra et al., 2018b). These gene expression changes include downregulation of genes involved in cell cycle progression and upregulation of stress response genes (Lemons et al., 2010; Legesse-Miller et al., 2012; Valcourt et al., 2012; Coller, 2019b). Other gene expression changes allow the cell to re-organize metabolic pathways in quiescent cells to better match the availability of nutrients and the metabolic needs of the cell (Lemons et al., 2010; Valcourt et al., 2012; Coller, 2019b). Disruption of these cellular mechanisms can contribute to the occurrence and progression of pathologies related to aging, developmental defects, and cancer (Tumpel and Rudolph, 2019).

In addition to gene expression changes, quiescence is also associated with changes in the packaging of DNA into chromatin. Eukaryotic chromatin can take on two forms-a more condensed and transcriptionally silent form called heterochromatin and a less condensed and more transcriptionally active form called euchromatin (DesJarlais and Tummino, 2016). Within these states, the extent of compaction can vary, for instance, mitotic chromosomes are extremely condensed. Studies using imaging, flow cytometry, Hi-C, and other methods have shown that entry to a quiescent state involves changes in nuclear size, chromatin compaction and 3D genome architecture (Bridger et al., 2000; Evertts et al., 2013a; Guidi et al., 2015; Criscione et al., 2016; Swygert et al., 2019, 2021). In yeast, the transition from exponential phase growth to stationary phase, a quiescent state achieved when yeast deplete their nutrients, is associated with downregulation of gene expression, a more condensed chromatin state (Martinez et al., 2004; Schafer et al., 2008), and more long-range chromosomal interactions (Swygert et al., 2019). In mammals, activation of quiescent lymphocytes is associated with an unpacking of condensed chromatin in a process that can be visualized with electron microscopy (Tokuyasu et al., 1968; Dardick et al., 1983; Setterfield et al., 1983; Grigoryev et al., 2004).
Using circular dichroism, Chiu and Baserga reported a likely change to a more open chromatin structure as quiescent fibroblasts re-enter the cell cycle (Chiu and Baserga, 1975). In contrast, in one study, bovine fibroblasts were reported to have a more relaxed chromatin state in $\mathrm{G}_{0}$ (quiescent) compared with $\mathrm{G}_{1}$ cells (Kallingappa et al., 2016).

In addition to changes in gene expression and chromatin compaction, quiescence is also associated with a change in the positioning of chromosomes within the nucleus. In yeast, hyperclustering of telomeres has been reported with quiescence (Guidi et al., 2015; Laporte et al., 2016). When serum was removed from the culture medium of human fibroblasts, chromosomes were repositioned within $15 \mathrm{~min}$ in a process that required ATP, actin polymerization, and myosin (Mehta et al., 2010). In another study in human dermal fibroblasts, gene-poor chromosome 18 was found near the edge of the nucleus and gene-rich chromosome 19 was found in the center of the nucleus in proliferating cells. In serum-starved, quiescent fibroblasts, chromosome 18 shifted to a more central location in the nucleus, and there was no longer a difference in the positioning of chromosomes 18 and 19 (Bridger et al., 2000). Taken together, these findings demonstrate changes in gene expression, chromatin compaction and chromosome positioning within the nucleus in quiescent cells.

\section{HISTONE POST-TRANSLATIONAL MODIFICATIONS AS A POSSIBLE BIOLOGICAL CODE}

\section{Nucleosome Structure and Histone Marks}

Eukaryotic genomic DNA is tightly packed inside the nucleus. For mammalian chromosomes, this tight packing results in a 10,000-fold reduction in length (Kornberg and Lorch, 2020). The DNA in chromatin forms complexes with histone proteins that assemble the DNA strands into nucleosomes in a structure that resembles "beads on a string" with the nucleosomes (beads) representing the basic repeating unit of chromatin (Cutter and Hayes, 2015; Zhou et al., 2019; Ghoneim et al., 2021). Each core nucleosome consists of $\sim 147$ base pairs (bp) of DNA in a left-handed super-helical conformation wrapped around an octamer of histone proteins (Zhou et al., 2019). The octamer consists of two copies each of histone proteins $\mathrm{H} 2 \mathrm{~A}, \mathrm{H} 2 \mathrm{~B}, \mathrm{H} 3$, and $\mathrm{H} 4$ with each of the two dimers of $\mathrm{H} 2 \mathrm{~A}-\mathrm{H} 2 \mathrm{~B}$ interacting with either end of a $(\mathrm{H} 3-\mathrm{H} 4)_{2}$ tetramer $(\mathrm{H} 4-\mathrm{H} 3: \mathrm{H} 3-\mathrm{H} 4)$. The core nucleosome is flanked by $10-70$ bp of linker DNA and usually a linker histone (H1) (Cutter and Hayes, 2015). The disordered $\mathrm{N}$-terminal tails of all four histone proteins as well as the C-terminal tail of $\mathrm{H} 2 \mathrm{~A}$ protrude out from the nucleosome core and are sites of diverse post translational modifications (PTMs) or marks such as lysine and arginine methylation, lysine acetylation, and serine and threonine phosphorylation (Bannister and Kouzarides, 2011; Greer and Shi, 2012; Cutter and Hayes, 2015). These histone tails modulate charge, hydrophobicity, and steric access to chromatin (Ghoneim et al., 2021). Histone PTMs 
TABLE 1 | List of in vitro and in vivo quiescence models.

\begin{tabular}{|c|c|c|c|}
\hline Quiescence model & Type & Model conditions & References \\
\hline Yeast & Cell culture & Stationary phase isolation & Allen et al., 2006 \\
\hline Fission yeast & Cell culture & Nitrogen-induced starvation; Glucose deprivation & Hayashi et al., 2018; Zahedi et al., 2020 \\
\hline Human dermal fibroblasts & Cell culture & Serum-starvation; Contact-inhibition & Evertts et al., 2013a; Mitra et al., 2018a \\
\hline Human lung fibroblasts & Cell culture & $\begin{array}{l}\text { Mitogen withdrawal; Contact inhibition; Loss of } \\
\text { adhesion }\end{array}$ & Coller et al., 2006; Dai et al., 2015 \\
\hline Bovine fibroblasts & Cell culture & Serum starvation & Meng et al., 2020; Kallingappa et al., 2016 \\
\hline Human/mouse embryonic stem cells & Cell culture & Isolation from inner cell mass of blastocyst & Khoa et al., 2020 \\
\hline Mouse hematopoietic stem cells & Tissue & Isolation from fetal liver, bone marrow, cord blood & Vizán et al., 2020; Tie et al., 2020 \\
\hline Mouse neural stem cells & Tissue & Isolation from ventricular-subventricular zone of brain & Kalamakis et al., 2019; Obernier et al., 2018 \\
\hline Mouse muscle skeletal cells & Tissue & Isolation from muscle of 2 month-old mice & Boonsanay et al., 2016; Ryall et al., 2015 \\
\hline Human primary myoblasts & Cell culture & Methylcellulose culture medium & Cheedipudi et al., 2015 \\
\hline Mouse hair follicle stem cells & Tissue & Isolation from back, belly, or scalpskin & $\begin{array}{l}\text { Kang et al., 2020; Lee et al., 2016; } \\
\text { Lien et al., } 2011\end{array}$ \\
\hline Human Breast cancer MCF-7 cells & Cell culture & Hormone starvation; Serum starvation & Liu et al., 2017; Bierhoff et al., 2014 \\
\hline Mouse T cells & Tissue & Isolation from spleen & Rawlings et al., 2011 \\
\hline Mouse Fibroblasts & Cell culture & Serum deprivation & Grigoryev et al., 2004 \\
\hline
\end{tabular}

are added and removed by enzymatic proteins referred to as "writers" and "erasers," respectively (Soshnev et al., 2016; Hyun et al., 2017; Husmann and Gozani, 2019). Histone PTMs serve as recognition sites for proteins ("readers") that site-specifically bind to chromatin. In some cases, a single protein contains multiple domains and can act as both a reader for one type of PTM and a writer for another PTM (Smeenk and Mailand, 2016). The amino acid residues in the histone globular core can also be post-translationally modified and these core PTMs likely modulate interactions between histones and between histones and DNA (Tessarz and Kouzarides, 2014).

\section{What Are the Properties or Functions of Histone Marks?}

Histone H3K4me3, H3K36me3, and H3K79me3 and ubiquitylation of $\mathrm{H} 2 \mathrm{~B}$ marks are often associated with active transcription (Black et al., 2012; Hyun et al., 2017), whereas H3K9me3, H3K27me3, H2A ubiquitylation on lysine 119, and H4K20 methylation are indicators of a silenced chromatin state with reduced gene expression (Black et al., 2012; Hyun et al., 2017). These properties of histone marks are related to the way they interact with chromatin and chromatin binding proteins. Histone PTMs can be envisioned to function by at least two broad categories of mechanisms (Bannister and Kouzarides, 2011). The first involves direct structural effects on the biomechanical properties of DNA (Bannister and Kouzarides, 2011). In this role, histone PTMs can affect the accessibility of DNA, and thus the binding of transcription factors or other proteins that bind enhancers and affect transcription (Bannister and Kouzarides, 2011). Such effects can occur, for instance, when histone PTMs disrupt electrostatic interactions between histones and DNA. Nucleosome core particle has an overall charge of -150 electrons that is contributed by DNA (-294 electrons) and histones (+ 144 electrons) (Norton et al., 1989; Cortini, 2016; Prakash and Fournier, 2018). Some histone PTMs that are associated with a more open chromatin state and increased gene expression reduce the positive charges on histones thereby leading to less effective screening of the negative charges on DNA (Prakash and Fournier, 2018). Acetylation, in particular, impairs the affinity of histones for DNA by neutralizing the positive charges and disrupting the ionic interactions between histones and DNA. This results in increased histone mobility and a more open chromatin conformation (Allfrey et al., 1964; Cosgrove et al., 2004). An open chromatin conformation facilitates access to transcription factors and other chromatin binding proteins (Bannister and Kouzarides, 2011). While some modifications such as acetylation may be expected to alter the ionic charge and thus chromatin compaction, others, including methylation, may have more modest impacts on charge and chromatin structure (Bannister and Kouzarides, 2011).

The second way in which histone PTMs can exert a functional effect is by regulating the binding of different chromatin factors. As one example, proteins with PHD fingers and Tudor family of domains can bind lysine methylations (Maurer-Stroh et al., 2003; Champagne and Kutateladze, 2009; Bannister and Kouzarides, 2011). In some cases, multiple different domains can recognize the same lysine methylation (Bannister and Kouzarides, 2011). Another example of histone PTM recognition is the binding of dimeric Heterochromatin Protein 1 (HP1) to the H3K9me3 mark via the chromodomain. This is associated with repressive architecture and chromatin compaction (Bannister et al., 2001; Lachner et al., 2001; Bannister and Kouzarides, 2011).

Genome-wide studies of histone marks have revealed that combinations of histone marks can be used to classify chromatin into different states (Black et al., 2012). In Arabidopsis, four chromatin states were identified (Roudier et al., 2011); in Drosophila, 5-9 states have been reported (Kharchenko et al., 2011; Riddle et al., 2011); while in human cells, up to 51 chromatin states have been defined (Ernst and Kellis, 2010). In human cells, chromatin states include promoter-associated, 
transcription-associated, active intergenic, large-scale repressed, and repeat-associated states, each of which have distinct histone marks and biological roles (Ernst and Kellis, 2010). Different promoter states were defined by patterns of H3K4 methylation, H3K79 methylation, H4K20 methylation, and acetylation (Black et al., 2012). One particular chromatin state that involves a specific combination of histone marks is the bivalent mark (Bernhart et al., 2016). Bivalent marks are often found in the promoters of developmentally regulated genes (Bernstein et al., 2006; Lesch et al., 2013), and are defined by the simultaneous presence of activating marks such as $\mathrm{H} 3 \mathrm{~K} 4 \mathrm{me} 1$ or H3K4me3, and the repressive chromatin mark H3K27me3 (Voigt et al., 2013). Genes with bivalent marks are repressed, but pre-loaded with RNA polymerase that is "poised" for rapid expression in response to a relevant trigger (Mikkelsen et al., 2007; Margaritis and Holstege, 2008; Gaertner et al., 2012). More recent studies have identified combinatorial marks that establish zones within the nucleus that can be identified by combinations of proteins and histone marks (Takei et al., 2021). These nuclear zones include nuclear speckles, active chromatin, heterochromatin zones and zones within the nucleolus (Takei et al., 2021). The active chromatin zone, for example, was characterized by histone H3K9ac, H3K27ac, H4K16ac, RNA polymerase II serine 5 phosphorylation, and SF3A66 (Takei et al., 2021).

Consistent with the concept of nuclear zones, histone marks may allow for the patterning of chromatin into regions of approximately 0.5-1 megabases with similar properties, termed topological domains as identified by the Hi-C technique (Prakash and Fournier, 2018). Histone modifications have been found to cluster at the genome scale as DNA tends to fold into domains in which the all of the DNA in that domain is labeled with similar histone marks (Dixon et al., 2012; Rao et al., 2014; Barbieri et al., 2017). For instance, H3K4me3-rich, H3K27me3rich and $\mathrm{H} 3 \mathrm{~K} 9 \mathrm{me} 3$ rich regions have been found to segregate from each other, and to mark active genes, repressed genes and inactive chromatin, respectively (Prakash and Fournier, 2018). Thus, histone PTMs may be associated with multiple aspects of chromatin including the extent of local compaction, the extent of gene expression and the formation of chromatin domains.

\section{Do Histone Marks Create a Histone Code?}

Biological codes that have been previously described include an input system that is translated into an output via adaptors (Prakash and Fournier, 2018). As one example, the genetic code translates sequences of nucleotide codons (input) into a sequence of amino acids (output) using the protein translation apparatus (adapter) (Prakash and Fournier, 2018). Histone PTMs have also been suggested to establish a biological code (Strahl and Allis, 2000; Allis and Jenuwein, 2016). According to the histone code hypothesis, the presence of specific histone marks, and in some cases, possible combinations of histone marks (inputs), provides information to reader proteins (adapters) that interpret the marks or combinations of marks to produce outputs such as gene activation or silencing, chromatin compaction, repair of DNA damage, cell division or differentiation (Strahl and
Allis, 2000; Jenuwein and Allis, 2001; Turner, 2002; Smeenk and Mailand, 2016). Given that histone marks tend to be rapidly reestablished after cell division (Evertts et al., 2013a,b), information about a cell's state can be transmitted to descendant cells. Misreading of histone marks has been associated with cancer and developmental defects (Wang and Allis, 2009; Chi et al., 2010; Hyun et al., 2017).

One potential advantage of a histone code would be that combinations of histone marks could provide increased robustness to a system in which different inputs result in specific outcomes (Prakash and Fournier, 2018). Robustness can be achieved with cooperation and redundancy (Prakash and Fournier, 2018). A histone code has been hypothesized to provide a level of proofreading needed so that genes are not turned on or off inappropriately (Prakash and Fournier, 2018). If there are multiple independent histone marks that work in concert to achieve an outcome, then loss of one mark would have only a modest effect on the associated phenotypes (Prakash and Fournier, 2018). Further, comparing the use of histone marks in different species shows that histone modifications have evolutionarily conserved functions and play a similar functional role across eukaryotes (Ho et al., 2014; Prakash and Fournier, 2018).

Generating chromatin states with combinations of histone marks may reflect instances in which the presence of one histone PTM affects the recruitment of enzymes that create another PTM in the same or different histone tails resulting in reproducible output patterns (Figure 1). This can be achieved by multi-domain proteins that recognize the histone PTM through the reader domain and utilize a different domain for recruiting a histone writer. As one example, double-stranded DNA breaks serve as a signal to the ATM kinase, which leads to phosphorylation of the H2A variant H2A.X on its C terminal tail (Rogakou et al., 1998; Smeenk and Mailand, 2016). The presence of this mark, called $\gamma$-H2AX, creates binding sites for a reader for this mark, Mediator of DNA Damage Checkpoint Protein 1 (MDC1), a protein that recruits factors to the DNA damage site (Stucki et al., 2005), including E3 ligases that ubiquitinate histones (Huen et al., 2007; Kolas et al., 2007; Mailand et al., 2007; Doil et al., 2009). Histone ubiquitin modifications create recruitment platforms for DNA repair factors (Huen et al., 2007; Kolas et al., 2007; Mailand et al., 2007; Doil et al., 2009). Thus, histone modifications can transmit information about the site-specific presence of double strand breaks to affect an outcome, in this case, DNA repair.

Another example in which the presence of a histone mark affects the likelihood of other marks being added occurs during the mitosis phase of the cell cycle. Phosphorylation of Ser10 of histone $\mathrm{H} 3$ regulates transcription during interphase (Shimada et al., 2008) and chromosome condensation during mitosis (Wei et al., 1999). Histone H3S10 phosphorylation prevents phosphorylation of Thr6 and Thr11 on the same histone (Cosgrove, 2012; Liokatis et al., 2012). This hierarchy may ensure that phosphorylation of Ser10 during mitosis, which is required for chromosome condensation and separation, does not lead to subsequent formation of dually labeled histones with H3S10 phosphorylation and Thr6 or Thr11 phosphorylation during mitosis (Cosgrove, 2012; Liokatis et al., 2012). This example 

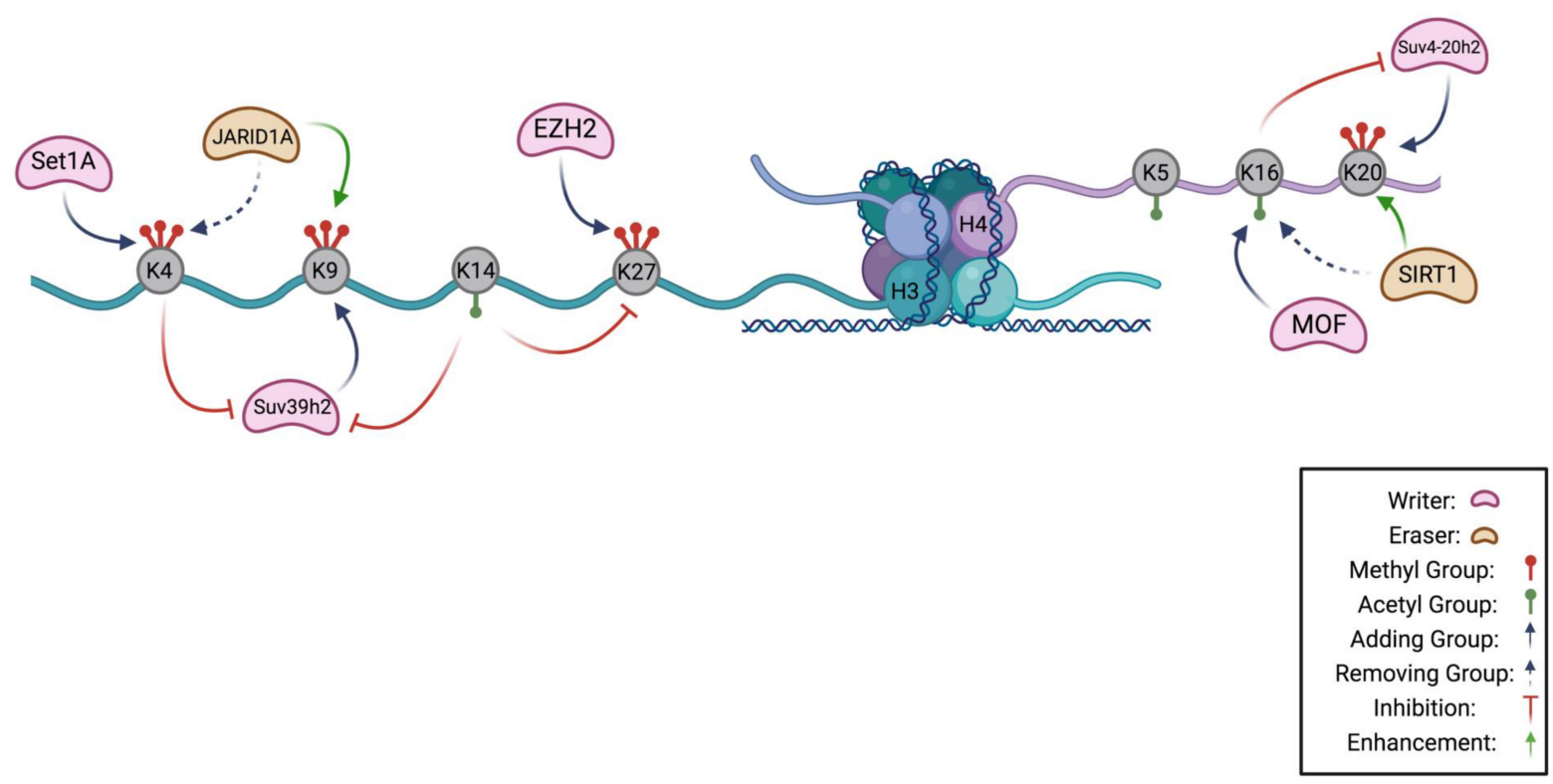

FIGURE 1 | Histone Code Hypothesis. A schematic highlighting the known interactions between chromatin modifying enzymes on the H3 and H4 tail as a potential hypothesis of the histone code in quiescence. Lysines that can be methylated or acetylated are gray, and are indicated to have methyl groups (red) or acetyl groups (green). H3K4 can be methylated by methyltransferase, Set1A, and demethylated by JARID1A, a demethylase. Methylation of lysine 4 prevents the methylation of H3K9 by inhibiting Suv39h2, the methyltransferase of lysine 9. Suv39h2 activity can also be prevented by acetylation of H3K14. Removal of H3K4 methylation by JARID1A enhances H3K9 methylation. On the H4 tail, MOF acetylates lysine 16 which inhibits activity of Suv4-20h2 in methylating H4K20. Removal of an acetyl group from H4K16 by SIRT1 enhances H4K20 methylation (Figure made in BioRender).

provides an instance in which histone marks antagonize each other, and combinations of histone marks are required to ensure a robust functional response.

Histone codes that lead to biologically significant outcomes have been suggested to play a role in neural plasticity (Farrelly and Maze, 2019), genome structure (Prakash and Fournier, 2018), and cancer (Godley and Le Beau, 2012). In neurons, serotonylation of histone $\mathrm{H} 3$ glutamine 5 works in conjunction with nearby H3K4me3 marks to regulate transcription (Farrelly et al., 2019; Farrelly and Maze, 2019). The dual H3K4(me3)(Q5serotonin) mark was found to enhance binding of interacting proteins, including the transcription factor complex TFIID (Lauberth et al., 2013; Farrelly et al., 2019; Farrelly and Maze, 2019). In this way, the combination of histone marks results in increased transcription of specific nearby genes.

On the other hand, it is important to note that the model that specific combinations of histone tail PTMs lead to defined biological outcomes has been challenged (Henikoff and Shilatifard, 2011; Morgan and Shilatifard, 2020). One central argument is whether histone modifications are the cause of different transcriptional states or, instead, are formed as a consequence of transcription and other dynamic processes. It has been difficult to resolve this controversy because studying the direct role of a histone PTM is challenging. Traditional genetic tools such as knockdown or overexpression are not sufficient to differentiate the direct versus indirect effects of targeting a histone modifying enzyme that adds or removes a PTM because the enzyme may also act on non-histone substrates (Henikoff and Shilatifard, 2011; Cornett et al., 2019; Corvalan and Coller, 2021).
An alternative strategy to directly assess the role of a histone PTM is to mutate the amino acid residue that bears the PTM. While this strategy can be effective in some organisms such as yeast, it is not practical for higher eukaryotes due to the presence of multiple copies of the genes encoding the most frequently modified histones (Tripputi et al., 1986; Henikoff and Shilatifard, 2011; Soshnev et al., 2016; Corvalan and Coller, 2021).

Debate about the existence of a histone code has also centered on the nature of the histone code. The original paper describing a histone code suggested a code that has been described as hardwired and deterministic (Jenuwein and Allis, 2001), like the genetic code (Morgan and Shilatifard, 2020). With time, an alternative and more complex relationship between histone marks and functional outcomes has been described (Morgan and Shilatifard, 2020). In this potential representation, histone PTMs convey information in a context-dependent manner (Morgan and Shilatifard, 2020). A histone mark can have multiple potential outcomes, and the specific path would depend on multiple factors including the three-dimensional folding of the genome, the local chromatin environment, and the concentrations of the possible downstream effector molecules (Morgan and Shilatifard, 2020).

\section{Is There a Histone Post-translational Modification Code for Quiescence?}

Does a histone code exist for quiescence? Are there specific patterns of histone tail PTMs that dictate or are associated with entry, exit, maintenance, or depth of a quiescent state? If so, do these histone PTMs modulate the physical properties 
of the DNA? Do these histone marks directly alter the chromatin accessibility of gene promoters and enhancers to induce molecular and phenotypic changes with quiescence? Alternatively, do these histone PTMs serve as binding sites for readers that recognize the PTMs and effect cellular changes during quiescence? If the histone marks serve as recognition sites, what are the most important effectors and what aspects of quiescence do they control? In this review, we address these questions and compare the findings from multiple experimental models of quiescence (Table 1). Advances in ChIP-seq technology (O'Geen et al., 2011) such as CUT\&RUN (Hainer and Fazzio, 2019), CUT\&Tag (Kaya-Okur et al., 2019), and HiChIP (Yan et al., 2014) have enabled fine resolution mapping of the genomic position of different histone tail marks (Table 2). Mass spectrometry can be used to measure histone epigenetic mark abundance and dynamics in a multiplexed, parallel manner (Volker-Albert et al., 2018) (Table 2). Further, advances in imaging such as combining immunofluorescence

TABLE 2 | Methods to study histone marks.

\begin{tabular}{|c|c|c|c|c|c|c|}
\hline Approach & Method(s) & Description & $\begin{array}{l}\text { Amount of } \\
\text { material }\end{array}$ & $\begin{array}{l}\text { Bulk or } \\
\text { single-cell }\end{array}$ & $\begin{array}{l}\text { Global } \\
\text { pattern? }\end{array}$ & References \\
\hline PCR & ChIP-qPCR & $\begin{array}{l}\text { Chromatin is cross-linked, fragmented, } \\
\text { and immunoprecipitated (ChIP). DNA is } \\
\text { isolated and purified and undergoes } \\
\text { PCR }\end{array}$ & $\begin{array}{l}5 \times 10^{5}-5 \times 10^{6} \\
\text { cells }\end{array}$ & Bulk & No & $\begin{array}{l}\text { Milne et al., } \\
2009\end{array}$ \\
\hline \multirow[t]{6}{*}{ High-throughput sequencing } & ChIP-seq & $\begin{array}{l}\text { Following ChIP, Next-generation } \\
\text { sequencing (NGS) is used to identify } \\
\text { DNA fragments and map them against } \\
\text { entire genome }\end{array}$ & $\begin{array}{l}10^{5}-5 \times 10^{5} \text { cells } \\
\text { per antibody }\end{array}$ & Bulk & Yes & $\begin{array}{l}\text { O'Geen et al., } \\
2011\end{array}$ \\
\hline & CUT\&RUN & $\begin{array}{l}\text { Recombinant protein A-micrococcal } \\
\text { nuclease fusion recruited to the } \\
\text { antibody targeting chromatin protein of } \\
\text { interest; DNA fragments near antibody } \\
\text { sites are cleaved, released, and } \\
\text { sequenced }\end{array}$ & $5 \times 10^{5}$ cells & Bulk & Yes & $\begin{array}{l}\text { Hainer and } \\
\text { Fazzio, } 2019\end{array}$ \\
\hline & CUT\&Tag & $\begin{array}{l}\text { A-Tn5 transposase fusion protein } \\
\text { bound to antibody; transposase } \\
\text { generates fragment libraries for } \\
\text { sequencing }\end{array}$ & $\begin{array}{l}100,000-500,000 \\
\text { cells }\end{array}$ & Bulk & Yes & $\begin{array}{l}\text { Kaya-Okur } \\
\text { et al., } 2019\end{array}$ \\
\hline & $\begin{array}{l}\text { Joint RNA-seg and } \\
\text { CUT\&Tag } \\
\text { (Paired-Tag) }\end{array}$ & $\begin{array}{l}\text { CUT\&Tag followed by RNA-seq: } \\
\text { profiling of histone modifications and } \\
\text { transcripts in single cells; generates } \\
\text { maps of chromatin state and transcript } \\
\text { in various tissues by cell type }\end{array}$ & $\begin{array}{l}\sim 10,000 \text { cells per } \\
\text { antibody }\end{array}$ & Single-cell & Yes & Zhu et al., 2021 \\
\hline & $\mathrm{HiCHIP}$ & $\begin{array}{l}\text { Comprehensive analysis of single-end } \\
\text { and paired-end ChIP-seq reads for } \\
\text { protein-DNA interactions }\end{array}$ & $\begin{array}{l}10^{6}-15 \times 10^{6} \\
\text { cells }\end{array}$ & Bulk & Yes & Yan et al., 2014 \\
\hline & RNA-seq & $\begin{array}{l}\text { RNA is isolated from sample and } \\
\text { converted into cDNA libraries which } \\
\text { undergo NGS. }\end{array}$ & $\begin{array}{l}5 \times 10^{4}-5 \times 10^{6} \\
\text { cells }\end{array}$ & $\begin{array}{l}\text { Bulk and } \\
\text { single-cell }\end{array}$ & Yes & $\begin{array}{l}\text { Wang et al., } \\
2009 ; \\
\text { Svensson et al., } \\
2018\end{array}$ \\
\hline \multirow[t]{2}{*}{ Imaging } & $\begin{array}{l}\text { Multicolor IF-based } \\
\text { single cell analysis }\end{array}$ & $\begin{array}{l}\text { Using directly labeled histone } \\
\text { modification-specific antibodies to } \\
\text { monitor histone levels in single cells }\end{array}$ & & & No & $\begin{array}{l}\text { Hayashi- } \\
\text { Takanaka et al., } \\
2020\end{array}$ \\
\hline & $\begin{array}{l}\text { Stochastic Optical } \\
\text { Reconstruction } \\
\text { Microscopy } \\
\text { (STORM) }\end{array}$ & $\begin{array}{l}\text { Single fluorophores blink individually } \\
\text { and randomly, enabling precise location } \\
\text { of photons, eventually forming full } \\
\text { images }\end{array}$ & & & No & Xu et al., 2018 \\
\hline Mass spectrometry & LC-MS/MS & $\begin{array}{l}\text { Allows for quantification of histone } \\
\text { modifications and combinations of } \\
\text { modifications }\end{array}$ & $10^{6}-10^{7}$ cells & single-cell & Yes & $\begin{array}{l}\text { Volker-Albert } \\
\text { et al., } 2018\end{array}$ \\
\hline Flow cytometry & FACS & $\begin{array}{l}\text { Cells are prepared accordingly for } \\
\text { high-throughput flow cytometry, and } \\
\text { gated based on phenotype of interest; } \\
\text { allows for investigation of multiple } \\
\text { phenotypes in complex samples }\end{array}$ & $10^{5}-10^{6}$ cells & single-cell & Yes & $\begin{array}{l}\text { Zahedi et al., } \\
2020\end{array}$ \\
\hline Western blot & & $\begin{array}{l}\text { Protein is isolated from sample, } \\
\text { separated by weight and probed for on } \\
\text { gel with specific antibodies }\end{array}$ & & & No & $\begin{array}{l}\text { Egelhofer et al., } \\
2011\end{array}$ \\
\hline
\end{tabular}


with directly labeled histone modification-specific antibodies to monitor histone levels in single cells (Hayashi-Takanaka et al., 2020), sequential fluorescence in situ hybridization analysis (Takei et al., 2021), and improved imaging with Stochastic Optical Reconstruction Microscopy (STORM) (Xu et al., 2018), have permitted detailed analysis of the global and site-specific organization of histone marks (Takei et al., 2021). It is important to note that in this review we focus on the most intensively studied histone PTMs, but these are not the only possible candidates by which histones or a histone code could contribute to the changes observed with quiescence. For instance, there may be new histone marks that are specific for quiescence and have not yet been observed, despite mass spectrometry-based histone tail analysis (Evertts et al., 2013a). There are also linker histones and variants of core histones that affect nucleosome structure and function, and consequently chromatin architecture (Kurumizaka et al., 2021). Changes in the compositions of histones and histone linkers could potentially contribute to the functional attributes of quiescent cells, and these are not reviewed here. We conclude by identifying areas for future studies and methodologies that can be used to address existing gaps in our knowledge.

\section{DIFFERENT QUIESCENCE MODEL SYSTEMS FOR STUDYING HISTONE MARKS}

\section{Yeast Models of Quiescence}

Multiple model systems have been used to study the molecular mechanisms of quiescence including yeast, mouse and human cells (Table 1), all of which have different genomes, limiting our ability to make direct comparisons about histone modifications in specific genomic regions. Further, the signals that induce quiescence, and the quiescent state achieved in these model systems differs, which may contribute to differences in the levels of specific histone modifications (Valcourt et al., 2012; Coller, 2019a). Among these model systems, each has advantages and disadvantages, for instance, budding yeast in a haploid state contain only one copy each of the major core histone genes (Eriksson et al., 2012). In haploid yeast, it is possible to alter a single amino acid to test the importance of a specific histone PTM, thus making yeast a particularly attractive model system for such studies.

Budding yeast, such as the well-studied strain Saccharomyces cerevisiae (S. cerevisiae), participate in both symmetric mitotic cell divisions during the budding process, and meiotic cell divisions during yeast sporulation (Neiman, 2011). All microorganisms, including yeast, spend a majority of their life-cycle in a quiescent state due to a lack of resources in their natural environment (De Virgilio, 2012; Sagot and Laporte, 2019b). Diploid yeast cells can enter a quiescent state in response to nutrient depletion, stress, and even cell wall damage (Miles et al., 2019). Saccharomyces cerevisiae initiate quiescence following the exhaustion of nutrients, especially glucose, and have been widely used to study quiescence. Quiescent yeast share some similarities to the quiescent state of mammals (Gray et al., 2004; Dhawan and Laxman, 2015; Miles et al., 2021). When grown in the laboratory, yeast consume glucose present in their growth medium and when available nutrients have been depleted, the yeast undergo a change termed diauxic shift (Chu and Barnes, 2016) as their metabolic profiles transition from fermentation to respiration, resulting in a decreased growth rate. When no other carbon sources are readily available, the yeast enter stationary phase or quiescence (Galdieri et al., 2010). By fractionating the cells based on differing densities, the non-proliferating stationary phase yeast have been separated into a denser population that is long-lived, and a less dense subpopulation that has been termed "non-quiescent" (Allen et al., 2006). Differences in the accumulation of trehalose and lipids may contribute to the different densities of these populations (Sagot and Laporte, 2019 b). Fractionation protocols that purify quiescent yeast have allowed for comparisons of histone modifications in quiescent and proliferative yeast samples (Mews et al., 2014). In budding yeast that initiate quiescence following nutrient exhaustion, there is a genomewide shift in gene expression, with transcriptional repression of genes involved in growth and proliferation including ribosomal genes (Werner-Washburne et al., 1996; Gray et al., 2004; Radonjic et al., 2005; McKnight et al., 2015).

Yeast can also form spores, which can serve as another model for quiescence. When diploid yeast cells undergo meiosis, the meiotic products can differentiate into dormant spores during the process of sporogenesis (Greig, 2009; Duina et al., 2014). The state achieved in dormant microbial spores shares some similarities to the quiescent state achieved by nutrient depletion in S. cerevisiae (Greig, 2009; Duina et al., 2014). For instance, spore formation, like quiescence, is reversible as spores germinate to form haploid cells when exposed to nutrients. Spores are distinguished from a quiescent state because quiescent cells maintain some metabolic capacity, maintain membrane potential and do not undergo a morphological differentiation (Rittershaus et al., 2013). Spore formation is characterized by a dramatic decrease in global transcription levels (Xu et al., 2012). As described below, both nutrient limitation and spore formation have been used as models to probe the role of histone PTMs in quiescence in S. cerevisiae.

Fission yeast like Schizosaccharomyces pombe (S. pombe) are also an excellent model for quiescence (Su et al., 1996). During meiosis in fission yeast, asymmetric division takes place in which inheritance of the mother cell's components give rise to four different, unique daughter cells (Higuchi-Sanabria et al., 2014). Removing nitrogen from $S$. pombe causes the yeast to mate with yeast of the opposite mating type followed by replication through meiosis (Freese et al., 1982). However, if there is only one mating type of yeast in the population, the fission yeast arrest in G1phase and enter quiescence (Nurse and Bissett, 1981; Gangloff et al., 2017). These nitrogen-deprived fission yeast can remain viable for months. Quiescent fission yeast cells are metabolically active, engage stress-responsive signaling and are efficient in DNA damage repair (Su et al., 1996; Mochida and Yanagida, 2006; Ben Hassine and Arcangioli, 2009; Marguerat et al., 2012; Gangloff and Arcangioli, 2017). When fission yeast enter a state of quiescence as non-dividing spores, a gene regulatory program 
is activated that includes upregulation of genes needed to adapt to the quiescent state (Su et al., 1996; Sajiki et al., 2009; Takeda and Yanagida, 2010), the nucleus undergoes changes in chromatin compaction, and histone modifications are altered (Neiman, 2011). For all of these reasons, fission yeast represents a valuable model system for studying epigenetic changes with quiescence.

\section{Fibroblast Models of Quiescence}

In multicellular organisms, there are multiple different types of quiescent cells, such as quiescent fibroblasts, immune cells, and stem cells, that serve as model systems for the study of quiescence at the molecular level (Mitra et al., 2018a). Fibroblasts, which are normally quiescent in vivo, contribute to the physical form and biomechanics of tissue by secreting growth factors and extracellular matrix proteins. Fibroblasts are organizers of the wound healing process as they can proliferate and replenish dead cells at the wound site and secrete extracellular matrix proteins that contribute to the formation of granulation tissue and scars (Lynch and Watt, 2018). Fibroblasts isolated from different tissues such as skin or lung are relatively easy to culture, and quiescence can easily be achieved by serum starvation, contact inhibition, or loss of adhesion (Coller et al., 2006; Mitra et al., 2018a). When fibroblasts enter a quiescent state, there is a dramatic change in gene expression in which a large fraction of the genome is differentially regulated (Coller et al., 2006; Suh et al., 2012; Mitra et al., 2018b). This change in gene expression is accompanied by significant changes in the abundance and activity of microRNAs (Suh et al., 2012; Johnson et al., 2017), transcript decay rates (Johnson et al., 2017; Mitra et al., 2018b), splicing (Mitra et al., 2018b), and the use of proximal versus distal polyadenylation sites (Mitra et al., 2018b). Fibroblasts are a heterogeneous population of cells. They can be isolated from different locations within the skin including hair follicles, and locations within the dermal layer, such as the papillary and reticular dermis (Sorrell and Caplan, 2004), and they differ based on their location within tissue (Sorrell and Caplan, 2004; Lynch and Watt, 2018). Further, fibroblasts isolated from skin from different anatomical sites have distinct and characteristic transcriptional programs that include extracellular matrix synthesis, lipid metabolism and signaling pathways (Chang et al., 2002). Single-cell sequencing data has shed light on the heterogeneity of fibroblasts (Muhl et al., 2020). While the tissue of origin represents an important contributing factor to the differences among fibroblasts, single cell sequencing has also shown intra-organ heterogeneity (Muhl et al., 2020). Different fibroblast subpopulations have distinct characteristics and the contributions of each fibroblast population to physiology is being actively elucidated (Muhl et al., 2020).

\section{Stem Cell Models of Quiescence}

Adult stem cells are another widely used quiescence model. Stem cells have been used to study quiescence in the context of the tissue-specific niche in which they are located. Many types of stem cells are largely quiescent unless activated to proliferate and differentiate in order to maintain tissue homeostasis and tissue regeneration (Li and Bhatia, 2011; Cheung and Rando, 2013; Coller, 2019b; Urbán and Cheung, 2021). Dysregulation or loss of stem cell quiescence can result in depletion of a stem cell pool, which can impede tissue regeneration (Cheung and Rando, 2013). Cellular quiescence has been studied in different types of adult stem cells such as hair follicle stem cells (HFSCs) within the skin (Lien et al., 2011; Lee et al., 2016; Rodriguez and Nguyen, 2018), hematopoietic stem cells (HSCs) from bone marrow (Nakamura-Ishizu et al., 2014), neural stem cells (NSCs) in the brain (Basak et al., 2018), and skeletal muscle stem cells (MuSCs) (Fukada et al., 2007). In the skin, the hair follicles that anchor hair to the skin progress through a cycle. During the anagen phase, there is rapid cell proliferation and growth of a new hair follicle. In the catagen phase that follows, the hair stops growing and detaches from the blood supply. Finally, in the telogen phase or resting phase, a new hair grows beneath the existing hair. Quiescent, non-proliferative hair follicle stem cells, which can be identified with cell surface markers including CD34 and CD49 (Garza et al., 2011), reside within a portion of the hair follicle called the bulge during the hair follicle's resting stage, the telogen phase. During the transition from telogen to anagen, HFSCs are activated, exit the bulge and proliferate downward, creating a trail of rapidly proliferating cells (Nowak et al., 2008). These proliferating cells terminally differentiate to give rise to cells that form the new hair shaft and its channel. Hair follicle stem cells have been an important model system for understanding quiescence, including the epigenetics of quiescence.

Another important model system for understanding quiescence is the hematopoietic stem cell (HSC) compartment. HSCs are the stem cells that give rise to other blood cells including both myeloid and lymphoid lineages. In adult animals, hematopoiesis occurs in the bone marrow and the stem cells are only a small fraction of all of the cells present. The HSCs with the greatest capacity for self-renewal in the mouse bone marrow are quiescent HSCs (Wilson et al., 2008; Tesio et al., 2015) which are long-term label retaining and are in a deeply quiescent state (Foudi et al., 2009; Tesio et al., 2015). They are reported to divide only 5 times per lifetime (Foudi et al., 2009; Tesio et al., 2015). In response to infection or chemotherapy, these cells enter the cell cycle and start to proliferate to replenish damaged or lost cells (Wilson et al., 2008; Tesio et al., 2015). HSCs can be identified and isolated from surrounding cells by combinations of cell surface markers, including the presence of CD34 and an absence of markers for specific cell lineages (Sieburg et al., 2006; Dykstra et al., 2007; Kent et al., 2007).

Neural stem cells (NSCs) are present in the developing brain where they generate neurons (Ma et al., 2009). In adult animals, specific regions in the brain contain NSCs that have the capacity to proliferate and generate new neurons, thereby allowing adults to learn and acquire new skills, for instance, the ability to smell new odors (Ma et al., 2009; Obernier et al., 2018; Kalamakis et al., 2019). Like quiescent HFSCs, NSCs in vivo are thought to be slowly dividing and can be identified based on their label retention (Ma et al., 2009). These NSCs are depleted as organisms age (Obernier et al., 2018), and recent studies in single cells have shown an increase in quiescent NSCs in older mice compared with younger mice (Kalamakis et al., 2019). Markers for NSCs include expression of glial fibrillary acidic protein and 


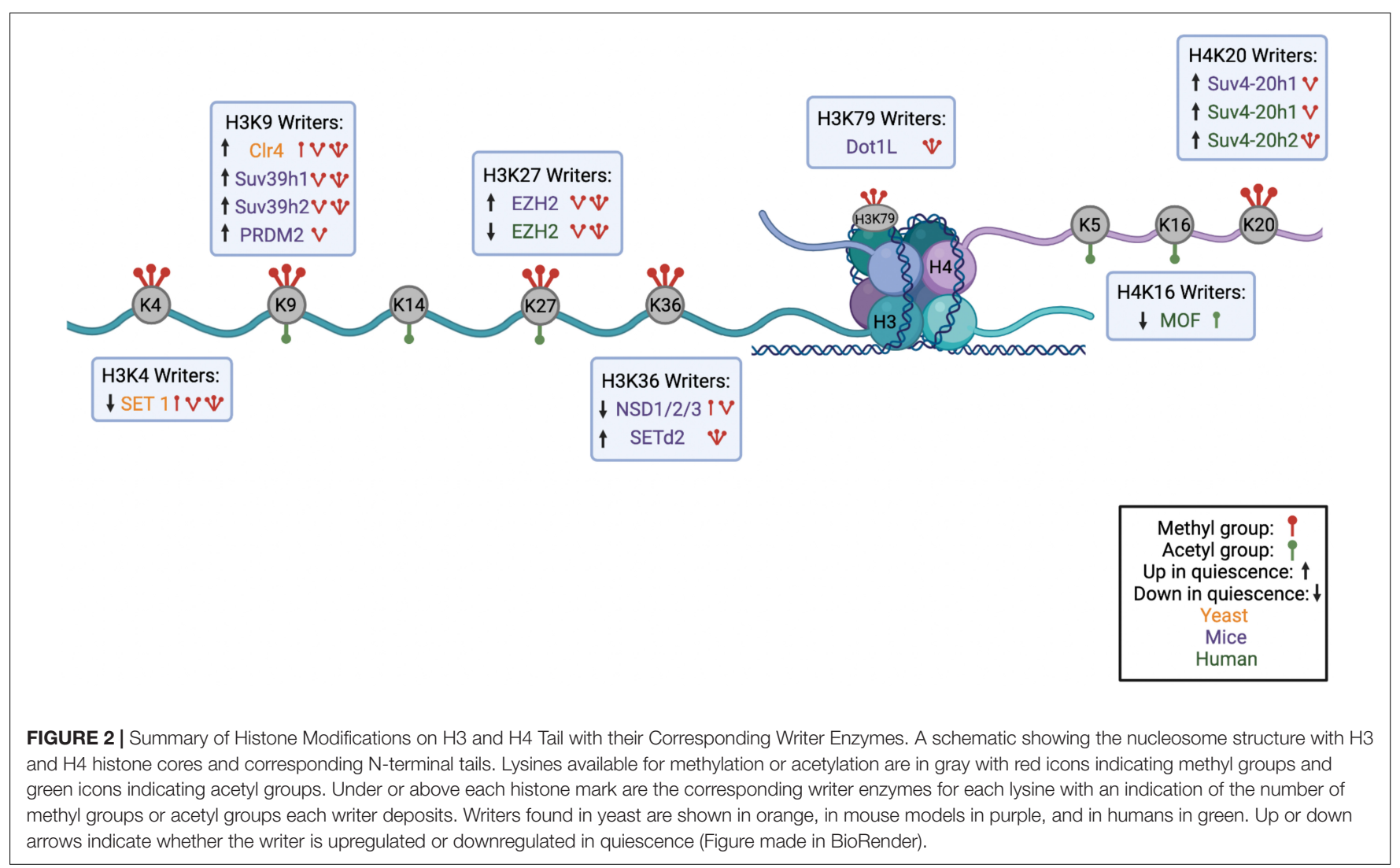

glycoprotein CD133, along with an absence of differentiated cell markers (Ma et al., 2009).

Finally, muscle stem cells (MuSCs), or muscle satellite cells, represent another valuable quiescence model as MuSCs are mostly quiescent in uninjured tissue (Cheung et al., 2012). Muscle stem cells are crucial for the process of regenerating skeletal muscle (Boonsanay et al., 2016). Upon muscle injury, quiescent satellite cells are activated to re-enter the cell cycle and proliferate (Yin et al., 2013). The proliferating progeny of the muscle satellite cells can differentiate into myotubes that form muscle fibers (Dumont et al., 2015; Boonsanay et al., 2016). Other MuSCs return to quiescence and are available to assist in the repair of subsequent muscle injury events (Yin et al., 2013). In vivo analysis of MuSCs has revealed that MuSCs are primed for activation (van Velthoven et al., 2017). The quiescent state of MuSCs has been reported to be an "idling" state for stem cells because widespread, low-level transcription was observed and hypothesized to serve as a means to ensure that the transcription machinery is ready to respond when required (van Velthoven et al., 2017).

Stem cells in these different models are normally found in a quiescent state that is maintained by specific niches that are tightly regulated by intrinsic and extrinsic factors (So and Cheung, 2018). Within these complex niches and diverse tissue compartments, quiescent stem cells are identified by their low RNA content and lack of proliferative markers (Fukada et al., 2007). In many cases, quiescent stem cells can be isolated from the tissue of interest by monitoring the presence and levels of cell-surface markers with fluorescence-activated cell sorting (FACS), and label-incorporation assays that identify cells that haven't divided for an extended time (Cheung and Rando, 2013; Nakamura-Ishizu et al., 2014). While this general pattern of quiescent stem cells is reported in multiple tissues, it is important to note that not all stem cells are quiescent, and in some tissues, stem cells are proliferative (Barker et al., 2007).

\section{H3 METHYLATION WITH QUIESCENCE}

Histone $\mathrm{H} 3 \mathrm{~h}$ has more potential methylation sites than any other histone in the histone octamer. Lysine residues 4, 9, 27, and 36 within the tail region of $\mathrm{H} 3$ are the most frequently methylated amino acids (Hyun et al., 2017; Jambhekar et al., 2019). In addition, H3K79, a lysine located within the globular domain of the histone, rather than on the tail, can also be methylated (Farooq et al., 2016). Each of the H3 lysines can be mono- (me), di- (me2), or tri-methylated (me3) by histone methyltransferases (writers) (Husmann and Gozani, 2019), and the methylation marks can be removed by histone demethylases (erasers). Histone methyltransferases, with the exception of DOT1L, contain a Suppressor of variegation, Enhancer of zeste, and Trithorax (SET) domain that catalyzes methylation of the lysine $\varepsilon$-amino group (DesJarlais and Tummino, 2016). Methylations of different histone lysines have characteristic deposition patterns that support a possible role for them in establishing different types of chromatin either by modulating the accessibility of the DNA to proteins, or by serving as a binding site for readers that act as 
effectors. Below we discuss the evidence that each of these marks plays a role individually and in combination in quiescence. Many of these marks have been investigated individually, but not in combination, and thus in many instances, our understanding of how they contribute to a histone code is limited.

\section{H3K4 Methylation}

$\mathrm{H} 3 \mathrm{~K} 4 \mathrm{me} 1 / \mathrm{me} 2 / \mathrm{me} 3$ are usually associated with gene activation (Jambhekar et al., 2019). H3K4me1, me2, and me3 methylation marks are enriched in enhancers, the 5' ends of genes, and promoters, respectively (Hyun et al., 2017; Jambhekar et al., 2019). Methylation of H3K4 is associated with gene activation and the presence and absence of $\mathrm{H} 3 \mathrm{~K} 4$ methylation marks provides insight into the genome-wide patterns of active and inactive genes, respectively. Changes in genome-wide H3K4 methylation patterns with quiescence provide insights into gene activation and repression with quiescence. Whether these changes are functionally important for the changes in gene expression with quiescence, or are only correlated with quiescence, and whether $\mathrm{H} 3 \mathrm{~K} 4$ marks act alone or in combination with other marks or effector proteins, is the subject of active investigation in multiple model systems.

Young and colleagues investigated these questions in budding yeast $S$. cerevisiae by inducing the yeast into quiescence by glucose depletion (diauxic shift) and analyzing the yeast at 7 and 14 days. Overall levels of H3K4me2 were similar between $\log$ (proliferating cells) and stationary phase cells containing a mixture of quiescent and non-quiescent cells (Table 3) (Young et al., 2017). Levels of H3K4me3 decreased about $50 \%$ in quiescent and non-quiescent stationary phase cells compared with proliferating cells in these studies (Young et al., 2017). In another study focused on cell cycle entry from quiescence, $S$. cerevisiae were maintained in a nutrient depleted environment and then restimulated with complete medium (Mews et al., 2014). In this study, Mews and colleagues found that overall levels of H3K4me1, H3K4me2 and H3K4me3 were similar in log and a mixture of quiescent and non-quiescent stationary phase cells (Mews et al., 2014).

While H3K4me3 levels were similar or changed by $50 \%$ in the two studies comparing proliferating and stationary phase budding yeast, there was an observed difference in transcription rate between these two populations of cells. Levels of RNA Pol II CTD residues phospho-Ser5 and phosphoSer2, which are indicators of transcriptional initiation and elongation, respectively, were high in day 3 post-diauxic cells, and subsequently decreased in day 5 post-diauxic cells (Young et al., 2017). In both proliferating and quiescent cells, H3K4me3 and RNA polymerase II were found at gene promoters, but the distribution of the $\mathrm{H} 3 \mathrm{~K} 4 \mathrm{me} 3$ mark among promoters shifted with quiescence (Young et al., 2017). H3K4me3 was more abundant at the promoters of growth-associated genes in log phase yeast (Mews et al., 2014). Genes that retained the H3K4me3 mark and RNA Pol II at their promoters in quiescent yeast included genes responsible for stress response, protein catabolism, and energy production (Mews et al., 2014; Young et al., 2017). Thus, an association was observed between the presence of the $\mathrm{H} 4 \mathrm{~K} 3 \mathrm{me} 3$ histone mark and activation of genes with quiescence, but further studies would be needed to determine whether this constitutes a "code" and if so, what the functional consequences of this mark are for quiescence.

Further studies have evaluated the functional importance of $\mathrm{H} 3 \mathrm{~K} 4$ methylation for quiescence in strains of $S$. cerevisiae. S. cerevisiae were genetically engineered so that lysine 4 of histone $\mathrm{H} 3$ was mutated to alanine. These mutant strains lost reproductive capacity over time, after being introduced into stationary phase, to a greater extent than wild-type yeast (Walter et al., 2014; Young et al., 2017). Further, in this mutant strain, the proportion of non-quiescent cells in the stationary phase increased (Walter et al., 2014; Young et al., 2017). These results indicate that methylation of $\mathrm{H} 3 \mathrm{~K} 4$ is required for the establishment or maintenance of a quiescent state initiated in response to nutrient depletion.

The effects of removal of $\mathrm{H} 3 \mathrm{~K} 4$ methylation marks (demethylation) have also been characterized in $S$. cerevisiae during spore production. In S. cerevisiae spores, which have very low transcription rates, there is an accumulation of the highly conserved H3K4 demethylase JARID1-family histone 2 (JHD2) during sporulation ( $\mathrm{Xu}$ et al., 2012) (Figure 1). The spores of JHD2 mutant yeast strain, $j h d 2 \Delta$, show a $\sim 2$-fold increase in $\mathrm{H} 3 \mathrm{~K} 4 \mathrm{me} 3$ and reduced levels of $\mathrm{H} 3 \mathrm{~K} 4 \mathrm{me} 1 / \mathrm{me} 2$ compared to wild-type spores, suggesting that absence of JHD2 leads to the conversion of $\mathrm{H} 3 \mathrm{~K} 4 \mathrm{me} 1 / \mathrm{me} 2$ to $\mathrm{H} 3 \mathrm{~K} 4 \mathrm{me} 3$ (Xu et al., 2012). Studies with wild-type and $j h d 2 \Delta$ mutant strains indicated that JHD2 demethylases reduce intergenic transcription induced by $\mathrm{H} 3 \mathrm{~K} 4 \mathrm{me} 3$ during spore differentiation, promoted protein coding gene transcription, and repressed nucleosome accumulation at transcription start sites (TSSs) of a large subset of ribosomal protein-coding genes. Mutants of $j h d 2$ exhibited precocious differentiation and the spores formed were sensitive to stress. Since JHD2 needs alpha-ketoglutarate from the TCA cycle for enzymatic function, it is possible that this family of proteins can sense carbon metabolism activity, which in turn regulates transcription in response to nutrient availability (Xu et al., 2012). These findings, taken together, suggest that $\mathrm{H} 3 \mathrm{~K} 4 \mathrm{me} 3$ may be a mark that can transform information about nutrient availability into a complex pattern of gene expression that has distinct effects on protein coding genes, ribosomal genes and non-coding RNAs.

The role of $\mathrm{H} 3 \mathrm{~K} 4$ methylation has been studied in the context of quiescent mammalian cells as well. Kallingappa and colleagues compared chromatin states of proliferating bovine adult ear skin fibroblasts in the G1 phase of the cell cycle with chromatin composition of serum-starved, quiescent $\left(\mathrm{G}_{0}\right)$ fibroblasts (Kallingappa et al., 2016). With fluorescence microscopy, quiescent nuclei were found to have a more relaxed or less compact chromatin state, and half the levels of $\mathrm{H} 3 \mathrm{~K} 4 \mathrm{me} 3$ compared to G1 nuclei (Kallingappa et al., 2016). In mouse $B$ cells, there was a dramatic shift in histone H3K4 methylation with quiescence, with much lower H3K4me2 levels in quiescent mouse B cells compared to cycling mouse B cells (Baxter et al., 2004). Reduction of $\mathrm{H} 3 \mathrm{~K} 4 \mathrm{me} 3$ levels was also observed in quiescent mouse HSCs in late catagen stage in comparison to proliferating HSCs in early anagen stage (Lee et al., 2016; Kang et al., 2020). Based on ChIP-seq, the H3K4me3 signal generally decreased 
TABLE 3 | Levels of histone marks in different quiescence systems.

\begin{tabular}{|c|c|c|c|c|c|}
\hline Histone mark & $\begin{array}{l}\text { General } \\
\text { location }\end{array}$ & $\begin{array}{l}\text { Generally } \\
\text { associated with } \\
\text { gene activation } \\
\text { or repression? }\end{array}$ & Present within yeast & Up with quiescence & Down with quiescence \\
\hline H3K4me2 & Euchromatin & Gene activation & $\begin{array}{l}\text { Saccharomyces cerevisiae (S. } \\
\text { cerevisiae) Schizosaccharomyces } \\
\text { pombe (S. pombe) }\end{array}$ & & $\begin{array}{l}\text { Decreased in sporulating yeast (Xu } \\
\text { et al., 2012), mouse skin and } \\
\text { HFSCs (Lee et al., 2016), and } \\
\text { mouse B lymphocytes (Baxter } \\
\text { et al., 2004) }\end{array}$ \\
\hline H3K4me3 & Euchromatin & Gene activation & S. cerevisiae S. pombe & $\begin{array}{l}\text { Increase in adult mouse } \\
\text { muscle stem cells (Liu } \\
\text { et al., 2013) }\end{array}$ & $\begin{array}{l}\text { Decrease in quiescent yeast (Xu } \\
\text { et al., 2012; Young et al., 2017), } \\
\text { sporulating yeast (Xu et al., 2012), } \\
\text { bovine fibroblasts (Kallingappa } \\
\text { et al., 2016), and in HFSCs (Kang } \\
\text { et al., 2020) }\end{array}$ \\
\hline H3K9me2 & Heterochromatin & Gene repression & S. pombe & $\begin{array}{l}\text { increased in muscle } \\
\text { quiescent stem cells } \\
\text { (Cheedipudi et al., 2015) }\end{array}$ & $\begin{array}{l}\text { reduced in yeast (Oya et al., 2019) } \\
\text { and bovine fibroblasts (Kallingappa } \\
\text { et al., 2016) }\end{array}$ \\
\hline H3K9me3 & Heterochromatin & Gene repression & S. pombe & $\begin{array}{l}\text { increased in MuSCs } \\
\text { (Boonsanay et al., 2016) }\end{array}$ & $\begin{array}{l}\text { reduced in mouse skin and HFSCs } \\
\text { (Lee et al., 2016), yeast (Oya et al., } \\
\text { 2019), and bovine fibroblasts } \\
\text { (Kallingappa et al., 2016) }\end{array}$ \\
\hline H3К9ac & Euchromatin & Gene activation & S. cerevisiae S. pombe & & $\begin{array}{l}\text { Global decrease in yeast (Mews } \\
\text { et al., 2014) }\end{array}$ \\
\hline H3K14ac & & Gene activation & S. cerevisiae S. pombe & & $\begin{array}{l}\text { Decreased in muscle quiescent } \\
\text { stem cells and yeast (Cheedipudi } \\
\text { et al., 2015; Young et al., 2017) }\end{array}$ \\
\hline H3K27me3 & Heterochromatin & Gene repression & & & $\begin{array}{l}\text { Decrease in skin and hair stem cells } \\
\text { for growth (Kang et al., 2020), in } \\
\text { mouse skin and HFSCs (Lee et al., } \\
\text { 2016), and in bovine fibroblasts } \\
\text { (Kallingappa et al., 2016) }\end{array}$ \\
\hline H3K27ac & Euchromatin & Gene activation & S. cerevisiae S. pombe & $\begin{array}{l}\text { Increase in neural stem } \\
\text { cells (Martynoga et al., } \\
\text { 2013) }\end{array}$ & \\
\hline H3K36me1/me2/me3 & Euchromatin & Gene activation & S. cerevisiae S. pombe & $\begin{array}{l}\text { me3 increase in mouse } \\
\text { bone marrow cells (Zhou } \\
\text { et al., 2018) }\end{array}$ & $\begin{array}{l}\text { reduced in bovine fibroblasts (Meng } \\
\text { et al., 2020) }\end{array}$ \\
\hline H3K79me1/me2 & Heterochromatin & & S. cerevisiae S. pombe & & loss in yeast (Young et al., 2017) \\
\hline $\mathrm{H} 4 \mathrm{~K} 5 \mathrm{ac}$ & Euchromatin & Gene activation & S. cerevisiae S. pombe & & $\begin{array}{l}\text { Global decrease in yeast (Mews } \\
\text { et al., 2014) }\end{array}$ \\
\hline H4K16ac & Euchromatin & Gene activation & S. cerevisiae S. pombe & & $\begin{array}{l}\text { decreased in skeletal muscle stem } \\
\text { cells and ESCs (Ryall et al., 2015; } \\
\text { Kang et al., 2020) }\end{array}$ \\
\hline H4K20me3 & Heterochromatin & Gene repression & S. pombe & $\begin{array}{l}\text { increased in primary human } \\
\text { dermal fibroblasts (Evertts } \\
\text { et al., 2013a), in MuSCs } \\
\text { (Boonsanay et al., 2016) }\end{array}$ & \\
\hline
\end{tabular}

at transcription start sites and overall in quiescent compared with proliferating HSCs, although there was no clear correlation between H3K4me3 marks and gene expression changes with proliferation or quiescence (Lee et al., 2016). These findings suggest that $\mathrm{H} 3 \mathrm{~K} 4$ methylation may have other roles in addition to transcriptional regulation. Indeed, a recent article re-evaluating the role of histone-modifying enzymes argues that histone $\mathrm{H} 3 \mathrm{~K} 4$ methylation only has a minor role in transcriptional regulation (Rickels et al., 2017; Morgan and Shilatifard, 2020), but that H3K4 methylation has been associated with DNA recombination, repair, and replication (Daniel and
Nussenzweig, 2012; Acquaviva et al., 2013; Kantidakis et al., 2016).

Similar results were observed in MuSCs where neither the number nor the identify of genes marked by $\mathrm{H} 3 \mathrm{~K} 4 \mathrm{me} 3$ at their transcription start site changed in activated compared with quiescent stem cells, and quiescence-specific genes retained their H3K4me3 mark at their transcription start site even upon activation (Liu et al., 2013). The authors conclude that H3K4me3 marks genes for transcriptional activation but its presence is not sufficient to determine whether a gene will be expressed (Liu et al., 2013). 
Evidence for the importance of $\mathrm{H} 3 \mathrm{~K} 4$ demethylation as a regulator of quiescence is derived from studies of Retinoblastoma binding protein 2 (RBP2), which can demethylate all the methylation states of $\mathrm{H} 3 \mathrm{~K} 4$ in vivo (Klose et al., 2007). In vitro, RBP2 can processively remove the me 3 and me 2 marks on H3K4 to return the histone to a singly methylated state, but it cannot demethylate the mel mark (Klose et al., 2007). Hematopoietic stem cells (HSCs) and myeloid progenitors isolated from $R b p 2$ knockout mice $\left(R b p 2^{-/-}\right)$contain a higher proportion of cells exiting quiescence compared to WT. Further, in $R b p 2^{-/-}$cells, genes encoding cytokines were marked with higher levels of H3K4me3 and were expressed at higher levels, which could promote proliferation of the HSCs (Klose et al., 2007). In addition to the JmjC domain that is responsible for the demethylase activity, KDM5A/RBP2 also contains 2-3 plant homeodomain (PHD) domains (Klose et al., 2007). Binding of the PHD domain to unmodified $\mathrm{H} 3$ peptide activates the KDM5A/RBP2 catalytic activity and results in removal of methyl marks from histone H3K4me3 from a nearby nucleosome (Torres et al., 2015). By coupling the KDM5A/RBP2's ability to read unmodified H3K4 with demethylation of nearby $\mathrm{H} 3 \mathrm{~K} 4 \mathrm{me} 3$, results in a positive feedback loop that allows the spreading of a chromatin state of demethylated histones (Torres et al., 2015).

The data that are currently available suggest that methylation of H3K4 may play a role in aspects of quiescence, including potentially transcription, but whether this mark is a determinant of gene expression or simply associated with an activated promoter is not yet clear. H3K4 methylation could also contribute to quiescence through its roles in replication, repair or recombination. Establishing whether $\mathrm{H} 3 \mathrm{~K} 4$ methylation affects quiescence entry or maintenance through direct effects on the biomechanical properties of the DNA or through readers, whether it is part of a histone code, and how this affects functional aspects of quiescence will require additional studies.

\section{H3K9 Methylation}

H3K9 methylation marks are primarily associated with gene repression in heterochromatin regions (Saksouk et al., 2015). H3K9me3 associates with regions of constitutive heterochromatin such as repeat regions of telomeres and centromeres (Saksouk et al., 2015). H3K9me3 is also deposited at some genomic regions in a tissue-specific manner and plays a role in cell identity (Ninova et al., 2019). Given the observation that in some systems, chromatin is more compact in quiescent than proliferating cells (Bridger et al., 2000; Evertts et al., 2013a; Guidi et al., 2015; Criscione et al., 2016; Swygert et al., 2019, 2021), H3K9 methylation is of particular interest as a potential regulator of chromatin compaction with quiescence.

In fission yeast, there is only one H3K9 methyltransferase, Clr4/Suv39H, which adds H3K9me1, me2, and me3 marks (Figure 1, Table 4). Inactivation of $\mathrm{Clr} 4$ resulted in viability similar to wild-type cells when nutrients were present, but reduced viability when quiescence was initiated following nitrogen starvation or glucose deprivation (Joh et al., 2016). This trend was also observed in yeast cells with a mutation that converted histone $\mathrm{H} 3$ lysine 9 to an alanine, suggesting that H3K9 methylation is important for survival during quiescence (Joh et al., 2016). Global ChIP-seq analysis showed that as fission yeast enter quiescence, the cells accumulate Clr4-dependent H3K9me2 and $\mathrm{H} 3 \mathrm{~K} 9 \mathrm{me} 3$ marks at euchromatic genes whose transcriptional regulation has been shown to be important for establishing quiescence including genes involved in metabolism, ribosomal genes, cell cycle genes and stress response genes (Joh et al., 2016). In this study, a strong correlation was observed between genes with $\mathrm{H} 3 \mathrm{~K} 9 \mathrm{me} 2$ marks and the set of genes repressed in $\mathrm{G}_{0}$ (Joh et al., 2016). The enrichment of H3K9 methylation marks in euchromatic gene regions upon quiescence entry required the small RNAs (sRNAs) associated with RNA interference (RNAi) factor Argonaute (Ago1). Quiescent yeast had a distinct profile of these sRNAs (Joh et al., 2016). Before H3K9 is deposited in these euchromatic regions in quiescent yeast, Agol-associated sRNAs are expressed from these regions (Joh et al., 2016), and these sRNAs may serve as guides for the deposition of H3K9 methylation marks (Joh et al., 2016). This may reflect a mechanism for regulating the expression of specific genes as yeast enter quiescence. In contrast to euchromatic regions, the levels of $\mathrm{H} 3 \mathrm{~K} 9 \mathrm{me} 2$ in constitutive heterochromatic regions decline early during quiescence ( $8 \mathrm{~h}$ and $24 \mathrm{~h}$ after starvation) (Oya et al., 2019). These findings support the possibility of a combined histone-RNA code that controls gene expression and viability during quiescence. Surprisingly, the authors observed relatively little overlap between the $\mathrm{H} 3 \mathrm{~K} 9 \mathrm{me} 3$-enriched genes

TABLE 4 | The relationship of histone writers with quiescence.

\begin{tabular}{|c|c|c|c|c|}
\hline $\begin{array}{l}\text { Histone writers } \\
\text { (HGNC ids) }\end{array}$ & Histone mark & Model & $\begin{array}{l}\text { Relationship with cell } \\
\text { quiescence }\end{array}$ & References \\
\hline SET1 & $\mathrm{H} 3 \mathrm{~K} 4 \mathrm{me} 1 / 2 / 3$ & Fission Yeast & Downregulated in quiescence & Young et al., 2017 \\
\hline Clr4 & $\mathrm{H} 3 \mathrm{~K} 9 \mathrm{me} 1 / 2 / 3$ & Fission Yeast & Upregulated in quiescence & Joh et al., 2016 \\
\hline Suv39h1 & $\mathrm{H} 3 \mathrm{~K} 9 \mathrm{me} / 3$ & Mouse Primary Keratinocytes & Upregulated in quiescence & Lee et al., 2016 \\
\hline Suv39h2 & H3K9me2/3 & Mouse Primary Keratinocytes & Upregulated in quiescence & Lee et al., 2016 \\
\hline PRDM2 & H3K9me2 & Mouse Myoblasts & Upregulated in quiescence & Cheedipudi et al., 2015 \\
\hline $\mathrm{EZH} 2$ & H3K27me2/3 & Mouse Primary Keratinocytes & Upregulated in quiescence & Lee et al., 2016 \\
\hline NSD1/2/3 & H3K36me1/2 & Murine Adult Hematopoietic Stem Cells & Downregulated in quiescence & Zhou et al., 2018 \\
\hline SETD2 & H3K36me3 & Murine Adult Hematopoietic Stem Cells & Upregulated in quiescence & Zhou et al., 2018 \\
\hline MOF & H4K16ac & Human Embryonic Stem Cells & Downregulated in quiescence & Khoa et al., 2020 \\
\hline \multirow[t]{2}{*}{ Suv4-20h1 } & H4K20me2 & Mouse Skeletal Muscle Stem Cells & Upregulated in quiescence & Boonsanay et al., 2016 \\
\hline & & Primary Human Dermal Fibroblasts & Upregulated in quiescence & Evertts et al., 2013a \\
\hline Suv4-20h2 & H4K20me3 & Primary Human Dermal Fibroblasts & Upregulated in quiescence & Evertts et al., 2013a \\
\hline
\end{tabular}


in quiescent cells and the genes that are repressed by $\mathrm{Clr} 4$ in quiescence based on RNA-seq analysis of wild-type and clr4deleted yeast strains (Joh et al., 2016). This disconnect between the two genesets shows that additional studies will be needed to clearly determine whether $\mathrm{H} 3 \mathrm{~K} 9$ methylation plays a role in regulating transcription with quiescence, whether transcriptional regulation by $\mathrm{H} 3 \mathrm{~K} 9$ is crucial for viability in the quiescent state, and whether the effects of H3K9 in conjunction with short RNAs constitute part of a quiescence histone code.

Similar to the findings in fission yeast, in hair follicles, quiescent HFSCs that were isolated from the late catagen stage of the hair follicle cycle contained considerably lower levels of the $\mathrm{H} 3 \mathrm{~K} 9 \mathrm{me} 3$ mark compared to proliferating HFSCs isolated from the early anagen stage of the hair follicle cycle (Lee et al., 2016; Kang et al., 2020) (Table 3). In contrast to other studies, Boonsanay et al. found no change in the levels of $\mathrm{H} 3 \mathrm{~K} 9 \mathrm{me} 3$ between proliferating and quiescent mouse MuSCs (Boonsanay et al., 2016). This study did not measure the global distribution of $\mathrm{H} 3 \mathrm{~K} 9$ methyl marks, and thus the genomic regions where $\mathrm{H} 3 \mathrm{~K} 9$ methyl marks are found or how they are redistributed in proliferating and quiescent MuSCs is not known (Boonsanay et al., 2016).

Studies of fibroblasts have also revealed differences in the levels of H3K9 methyl marks with quiescence although the changes observed varies in fibroblasts from different sources. In adult ear skin fibroblasts, overall levels of H3K9me 2 and me3 were roughly halved in quiescent cells compared to the same fibroblasts in the G1 phase of the cell cycle, while the levels of $\mathrm{H} 3 \mathrm{~K} 9 \mathrm{me} 1$ were slightly elevated in quiescent relative to G1 cells (Kallingappa et al., 2016). In contrast, levels of H3K9me3 were modestly elevated in quiescent human dermal fibroblasts compared to proliferating fibroblasts (Evertts et al., 2013a), while levels of $\mathrm{H} 3 \mathrm{~K} 9 \mathrm{me} 2$ and $\mathrm{H} 3 \mathrm{~K} 9 \mathrm{me} 1$ were similar (Evertts et al., 2013a). In mouse B lymphocytes, the levels of H3K9me2 and me3 were lower in quiescent cells compared to activated cells (Baxter et al., 2004). Thus, in different quiescence model systems, changes in the levels of $\mathrm{H} 3 \mathrm{~K} 9$ methylation states are altered, but the specific changes reported have been different depending on the model system, and thus a consistent quiescence program of H3K9 methylation changes has not been observed.

In mammals, there are multiple methyltransferases that add methyl groups to histone $\mathrm{H} 3$ lysine 9 including the 17 members of the PRDM family of proteins (Steele-Perkins et al., 2001; Hyun et al., 2017). One of these members, PR domain-containing$2 / \mathrm{Rb}$ interacting zinc finger protein (PRDM2/RIZ) is expressed at high levels in quiescent mouse MuSCs in vivo (Cheedipudi et al., 2015) (Table 4). Knockdown and overexpression studies of PRDM2/RIZ indicated that in quiescent MuSCs, PRDM2/RIZ prevents lineage commitment and irreversible cell cycle arrest (Cheedipudi et al., 2015). Global analysis using ChIP coupled with DNA microarray (ChIP-Chip) showed that PRDM2 was associated with $>4400$ gene promoters in quiescent muscle cells that initiate quiescence in suspension culture, that is, loss of adhesion. Approximately $50 \%$ of these promoters were also marked with H3K9me2 (Cheedipudi et al., 2015). The PRDM2associated genes were enriched for differentiation, cell cycle, and developmental regulators (Cheedipudi et al., 2015). The levels of H3K9 methylation marks (me1, me2, and me3) did not change overall upon knockdown of PRDM2 (Cheedipudi et al., 2015). However, $\mathrm{H} 3 \mathrm{~K} 9 \mathrm{me} 2$ levels were reduced at the MyoG promoter in $G_{0}$ cells, while PRDM2 knockdown cells showed reduced H3K9me2 at the same locus, suggesting that PRDM2 may add methyl groups to generate $\mathrm{H} 3 \mathrm{~K} 9 \mathrm{me} 2$ at $\mathrm{MyoG}$ (Cheedipudi et al., 2015). Further, increased H3K14Ac was observed at the MyoG promoter upon PRDM2 knockdown, supporting a role for PRDM2 in regulating the expression of MyoG, a critical molecule for muscle differentiation (Cheedipudi et al., 2015). These findings support a model in which PRDM2 activation in $\mathrm{G}_{0}$ ensures that two distinct possible outcomes-myogenesis and cell cycle progression-are poised for reactivation. The findings implicate H3K9 methylation, possibly in combination with other histone marks, in muscle stem cell quiescence and renewal (Cheedipudi et al., 2015).

Thus, while quiescence is generally associated with a reduction in transcription and number of active genes based on $\mathrm{H} 3 \mathrm{~K} 4$ methylation status as well as other markers, surprisingly in most, but not all, studies, there was not an increase in the $\mathrm{H} 3 \mathrm{~K} 9 \mathrm{me} 2$ and $\mathrm{H} 3 \mathrm{~K} 9 \mathrm{me} 3$ marks that might be expected. $\mathrm{H} 3 \mathrm{~K} 9 \mathrm{me} 3$ is associated with constitutive heterochromatin (Saksouk et al., 2015) and it is possible that the increase in heterochromatin with quiescence reflects an increase in facultative heterochromatin. Nevertheless, even though $\mathrm{H} 3 \mathrm{~K} 9 \mathrm{me} 2 / 3$ are not consistently observed to increase with quiescence, in yeast, there is evidence that these marks may be functionally important for the viability of quiescent cells as perturbations that reduce their levels reduce viability of quiescent cells with little effect on cells in full nutrient conditions. The data taken together support a possible role for $\mathrm{H} 3 \mathrm{~K} 9$ marks as contributors to changes that ensure the viability of quiescent cells, but these effects may be mediated through mechanisms other than transcriptional changes.

\section{H3K27 Methylation}

The H3K27me3 mark is found in multiple model organisms including Arabidopsis, Drosophila, worms, and the filamentous fungus Neurospora crassa, but not yeast (Jamieson et al., 2013). $\mathrm{H} 3 \mathrm{~K} 27 \mathrm{me} 3$ is a reversible mark of facultative heterochromatin, chromatin that can become compact or open depending upon the circumstance and is not repetitive (Trojer and Reinberg, 2007). H3K27me3 decorates genes that are developmentally regulated and are switched on and off depending upon the stage of development (Jambhekar et al., 2019). The Enhancer of Zeste 1 (EZH1) and EZH2 histone lysine methyltransferases trimethylate $\mathrm{H} 3 \mathrm{~K} 27$, and are constituents of Polycomb Repressive Complex 2 (PRC2) (Margueron and Reinberg, 2011) (Figures 1, 2, Table 4), while PRC1 stabilizes PRC2 binding to H3K27 and catalyzes monoubiquitination of histone H2A lysine 119 (Margueron and Reinberg, 2011). This ubiquitination mark represses transcription (Lavarone et al., 2019) and promotes chromatin compaction (Wiles and Selker, 2017; Lavarone et al., 2019). The Embryonic Ectoderm Development (EED) protein subunit of the PRC2 complex binds to H3K27me3 and this interaction increases the methyltransferase activity of the complex, resulting in a positive feedback loop that establishes 
zones of repressed chromatin (Margueron et al., 2009; Des)arlais and Tummino, 2016).

In some studies, H3K27me3 levels were reduced with quiescence. In bovine fibroblasts, which exhibit more open chromatin with quiescence, H3K27me3 levels were reduced by approximately a half when the fibroblasts entered quiescence in response to serum starvation (Kallingappa et al., 2016). Similarly, protein levels of the members of PRC2-EZH2, EED, and Suppressor of Zeste 12 (SUZ12) -were reduced by about half in $G_{0}$ nuclei (Kallingappa et al., 2016). Proteins in the PRC1 polycomb complex were also reduced in quiescent bovine fibroblasts, specifically Polyhomeotic Homolog (PHC1) and Ring Finger Protein 2 (RING2) (Kallingappa et al., 2016). H3K27me3 levels are also reduced in quiescent mouse B lymphocytes compared to activated and cycling B lymphocytes (Baxter et al., 2004).

In contrast, murine chondrocytes (cartilage cells) that entered into a quiescent state by the application of physiological hydrostatic pressure had lower levels of $\mathrm{H} 3 \mathrm{~K} 9 \mathrm{me} 3$ and higher levels of H3K27me3 compared to control cells that were not subjected to hydraulic pressure (Maki et al., 2021). In primary human dermal fibroblasts, a mass spectrometry-based analysis of histone post-translational modifications revealed higher levels of H3K27me3 in contact-inhibited, quiescent fibroblasts than proliferating fibroblasts (Evertts et al., 2013a). Further dissection of the H3K27me3 signal revealed that levels were particularly high when $\mathrm{H} 3 \mathrm{~K} 27 \mathrm{me} 2$ was found in combination with H3K36me2 or if H3K27me3 was found on the same histone tail as H3K36me1 and H3K36me2 (Evertts et al., 2013a). This pattern of histone modifications may reflect the fact that H3K36me3 can inhibit the ability of PRC2 to methylate H3K27 (Schmitges et al., 2011; Yuan et al., 2011).

H3K27me3 levels have been observed to be reduced in multiple quiescence model systems involving stem cells. Quiescent mouse HFSCs isolated in the late catagen (quiescent) stage experienced a global decrease in the levels of H3K27me3 along with a decrease in $\mathrm{H} 3 \mathrm{~K} 4 \mathrm{me} 3$ and $\mathrm{H} 3 \mathrm{~K} 9 \mathrm{me} 3$, as mentioned in the sections above, compared to cycling HFSCs in earlyanagen stage. This hypomethylation of quiescent HFSCs was confirmed using immunofluorescence, western blotting, and ChIP-seq methods (Lee et al., 2016). The levels of H3K27me3 were reduced in $64 \%$ of promoters with quiescence in HFSCs (Lee et al., 2016). Surprisingly, the changes in the levels of histone methylation marks, overall, did not correlate with changes in the levels of transcripts for the associated genes in quiescent versus proliferating hair follicle cells (Lee et al., 2016). There were exceptions: a larger than expected fraction of genes highly expressed at all hair cycle stages in the bulge had an increase in the levels of H3K27me3 and a set of genes defined as cell cycle regulators and tumor suppressors had almost no H3K27me3 in quiescent and proliferating HFSCs (Lee et al., 2016). To explore a possible role for decreased histone methylation levels during catagen, the bone morphogenetic protein (BMP) signal which normally maintains quiescence in vivo was inhibited, resulting in elevated levels of $\mathrm{H} 3 \mathrm{~K} 4 / \mathrm{K} 9 / \mathrm{K} 27$ me3 in quiescent bulge HFSCs (Lee et al., 2016). These findings demonstrate that quiescent HFSCs in the bulge require active BMP signaling in order to maintain a hypomethylated H3 state (Lee et al., 2016). When keratinocytes, skin epithelial cells, were serum-starved in culture, transcript levels of several histone methyltransferases including EZH2 (forms H3K27me3), SUV39H1 and SUV39H2 (H3K9me3), decreased (Lee et al., 2016), while transcript levels of multiple histone demethylases increased (Lee et al., 2016). The latter include JMJD2a which catalyzes demethylation of histone H3 lysines 9 and 36 (Kim T.D. et al., 2012), UTX which demethylates H3K27me3 (Tang et al., 2017), and JARID1, which acts as a demethylase for H3K4me3 and H3K4me2 (Lee et al., 2016). After chemically inhibiting demethylases specific to the $\mathrm{K} 4, \mathrm{~K} 9$, and $\mathrm{K} 27$ me3 marks with a cocktail applied to the mouse's skin, cells at the catagen stage failed to generate new hair follicles in the following hair cycle. Thus, the reduction in the H3K4/K9/K27 me3 levels observed in quiescent HFSCs was necessary for the ability of quiescent cells to re-enter the cell cycle (Lee et al., 2016). While these data support the importance of histone demethylation for the quiescent state of HFSCs, it remains unclear whether one, two or all of these marks was required for a functional state, whether these marks maintain chromatin structure or serve as binding sites for effectors, and whether the absence of the methylation marks affected the activity of other marks such as acetylation marks.

Three different studies have investigated the role of H3K27 methylation in quiescent mouse MuSCs (Liu et al., 2013; Cheedipudi et al., 2015; Boonsanay et al., 2016). Liu et al. found that H3K27me3 levels were low in quiescent MuSCs and dramatically increased in activated stem cells (Liu et al., 2013) (Table 3). The transcription start sites of genes expressed at high levels in quiescent stem cells were marked with $\mathrm{H} 3 \mathrm{~K} 4 \mathrm{me}$, but not H3K27me3 (Liu et al., 2013). The 2,019 genes that were marked by $\mathrm{H} 3 \mathrm{~K} 27 \mathrm{me} 3$ at their transcription start site in quiescent stem cells displayed very low expression levels (Liu et al., 2013). Upon activation, there was a dramatic increase in $\mathrm{H} 3 \mathrm{~K} 27 \mathrm{me} 3$ in the gene body and intergenic regions (Liu et al., 2013). Boonsanay and colleagues, in contrast, reported that the levels of H3K27me3 were not different between quiescent and proliferating MuSCs (Boonsanay et al., 2016).

Both Boonsanay et al. and Liu et al. discovered changes in the levels of writers and erasers of $\mathrm{H} 3 \mathrm{~K} 27 \mathrm{me} 3$ as quiescent mouse MuSCs were activated. Liu and colleagues reported that the increase in $\mathrm{H} 3 \mathrm{~K} 27 \mathrm{me} 3$ marks with activation was associated with higher transcript levels of Ezh2 and lower levels of the demethylase Jmjd3 (Liu et al., 2013). Boonsanay and colleagues also found higher levels of PRC2-Ezh2 in proliferating MuSCs and higher levels of PRC2-Ezh1 in the quiescent MuSCs (Boonsanay et al., 2016). These findings would be consistent with a study by Margueron and colleagues that showed that Ezh2 is more closely associated with proliferation, while Ezh1 is more abundant in non-proliferative adult tissues (Margueron et al., 2008). Margueron and colleagues discovered that PRC2-Ezh2 effectively catalyzes the formation of H3K27me2/3, while PRC2-Ezh1 directly represses transcription and compacts chromatin. Additional studies would be needed to determine whether the differences in expression of these methyltransferases results in changes in the genome-wide 
distribution of $\mathrm{H} 3 \mathrm{~K} 27 \mathrm{me} 2 / 3$, whether there is a direct effect on transcription or chromosome compaction, or whether the shift in the relative abundance of these methyltransferases is functionally important for establishing, maintaining or reversing quiescence in MuSCs.

Cheedipudi and colleagues focused on H3K27me3 levels in MuSCs in the context of their co-existence with $\mathrm{H} 3 \mathrm{~K} 4 \mathrm{me} 3$ and $\mathrm{H} 3 \mathrm{~K} 9 \mathrm{me} 2$ and their co-regulation by the H3K9 methyltransferase PRDM2/RIZ. As described in the H3K9 methylation section above, PRDM2/RIZ, an H3K9 methyltransferase, is enriched in quiescent muscle cells in vitro, where it participates in stalling differentiation and cell cycle programs, while also maintaining genes involved in differentiation and proliferation poised for future activation (Cheedipudi et al., 2015). Cheedipudi and colleagues found that knocking down PRDM2 resulted in a reduction of $\mathrm{H} 3 \mathrm{~K} 4 \mathrm{me} 3$ and $\mathrm{H} 3 \mathrm{~K} 9 \mathrm{me} 2$, and higher levels of $\mathrm{H} 3 \mathrm{~K} 27 \mathrm{me} 3$ at the cyclin A2 promoter in $\mathrm{G}_{0}$ MuSCs (Cheedipudi et al., 2015). They conclude that PRDM2 may block the deposition of H3K27me3 silencing marks at the cyclin $A 2$ promoter in $G_{0}$, thereby preserving the gene's potential for reactivation (Cheedipudi et al., 2015). These studies highlight the combinatorial nature of the histone marks during the transition between proliferation and quiescence.

Thus, taken together, substantial changes in H3K27me3 have been observed in different models of quiescence. H3K27me3 may contribute to transcriptional repression in quiescent cells and may contribute to a poised quiescent state, characterized by an ability to re-enter the cell cycle. However, additional studies that probe the genomic location of $\mathrm{H} 3 \mathrm{~K} 27 \mathrm{me} 3$ in proliferating and quiescent cells in different model system and their functional importance for quiescence will be needed to fully understand the specific role of $\mathrm{H} 3 \mathrm{~K} 27$ methylation individually or in combination with other marks in quiescence.

\section{H3K36 Methylation}

H3K36 methylation marks are usually deposited across the entire gene body (Hyun et al., 2017; Jambhekar et al., 2019), and are associated with transcriptional activation, dosage compensation, transcriptional repression, and DNA repair (Wagner and Carpenter, 2012). In the study by Young and colleagues described above, quiescent budding yeast S. cerevisiae had similar levels of H3K36me2 and H3K36me3 marks compared to proliferating cells (Young et al., 2017). However, the levels of SET Domain containing 2 (Set2) which deposits all three (mono, di, and tri) methylation marks in budding and fission yeast (Morris et al., 2005; Wagner and Carpenter, 2012), were reduced as the cells entered a quiescent state. These findings indicated that H3K36me3 marks were deposited prior to quiescence entry, concomitant with the activity of RNA Pol II.

While yeast has only one $\mathrm{H} 3 \mathrm{~K} 36$ methyltransferase, humans have eight, including SETD2, the human ortholog of yeast Set2, that generates the H3K36me3 mark in vivo, and enzymes of the Nuclear Receptor-binding Set Domain (NSD) family (NSD1/2/3) that deposit H3K36me1 and H3K36me2 marks (Wagner and
Carpenter, 2012) (Figure 2 and Table 4). The trimethylation of H3K36 by SETD2 is highly efficient on an unmethylated H3K36 compared to a H3K36me2 substrate (Husmann and Gozani, 2019). In Setd2 conditional knockout mice with HSCspecific Setd2 inactivation, there is a reduction of the number of HSCs in a quiescent state (Zhou et al., 2018). Setd2 knockout HSCs had a reduced $\mathrm{G}_{0}$ fraction and increased $\mathrm{G} 1$ and $S / G 2 / \mathrm{M}$ phases of the cell cycle (Zhou et al., 2018). In addition, knockout HSCs also exhibited higher levels of apoptosis, reduced stem cell identity, increased differentiation toward progenitors and reduced multiple-lineage terminal differentiation potential (Zhou et al., 2018). Setd2 knockout mice had mild bone marrow fibrosis, increased erythroid progenitors, but a decreased population of other bone marrow progenitors. As a result, the HSCs from Setd2 conditional knockout mice were less able to repopulate the hematopoietic system upon transplantation (Zhou et al., 2018). Setd2 knockout HSCs showed significant reduction of $\mathrm{H} 3 \mathrm{~K} 36 \mathrm{me} 3$, increased levels of $\mathrm{H} 3 \mathrm{~K} 36 \mathrm{me} / \mathrm{me} 2$, and increased Nsd1/2/3 at both transcript and protein levels (Zhou et al., 2018). The levels of H3K4me3, H3K79me2, and phosphorylation of Ser2 residue of RNA pol II, all of which are associated with transcriptional elongation, increased in Setd2 knockout cells. Based on these studies, the authors proposed a model in which, in the absence of SETD2, NSD proteins promote the phosphorylation and elongation of RNA pol II on specific genes, leading to a loss of quiescence (Zhou et al., 2018). The findings support an important role for SETD2 in maintaining the quiescent state of HSCs (Zhou et al., 2018). It is unclear whether SETD2 plays this role through H3K36me3 or non-enzymatic functions such as by affecting cryptic transcription (Carvalho et al., 2013) or alternative splicing (Bhattacharya et al., 2021).

\section{H3K79 Methylation}

In contrast to the previously discussed histone marks that are located on the histone $\mathrm{H} 3$ tail, the H3K79 methylation mark is located in the globular domain of H3 (Farooq et al., 2016). H3K79me2 and H3K79me3 are mainly found in the bodies of active genes and are associated with transcription elongation (Mueller et al., 2007). H3K79me2/3 can also maintain enhancerpromoter interactions at a subset of enhancers (Godfrey et al., 2019). H3K79 methylation has also been implicated in telomere silencing (Singer et al., 1998), recombination, DNA repair and cell cycle progression (Nguyen and Zhang, 2011). Monomethylation and trimethylation of $\mathrm{H} 3 \mathrm{~K} 79$ has been associated with gene activation and gene repression, respectively, in some studies (Barski et al., 2007). Disruptor of Telomere Silencing-Dot1 in yeast and DOT1L in humans-is the only enzyme responsible for methylation of H3K79 in S. cerevisiae, Drosophila, and humans as knockout of DOT1 in these organisms results in a loss of H3K79 methylation (van Leeuwen et al., 2002; Lee S. et al., 2018) (Figure 2 and Table 4). Both Dot1 and DOTL1 can catalyze mono-, di- and trimethylation (Frederiks et al., 2008). Dot1 is the only known non-SET domain-containing methyltransferase (Farooq et al., 2016). S. cerevisiae Dot1 does not methylate free histones, only histones in chromatin, in contrast to other histone methyltransferases (Lacoste et al., 2002; Lee S. et al., 2018). 
Yeast Dot1 also has histone chaperone activity and is particularly important for nucleosome dynamics and chromatin accessibility on transcribed regions of long genes (Lee S. et al., 2018).

After diauxic shift in $S$. cerevisiae, despite the general shut down of transcription, both the quiescent and non-quiescent yeast populations contained higher levels of the H3K79me3 mark than proliferating yeast cells (Young et al., 2017). However, the quiescent population had reduced $\mathrm{H} 3 \mathrm{~K} 79 \mathrm{me} 1$ and H3K79me2 levels compared with the non-quiescent population (Young et al., 2017). Levels of Dot1 decreased by day 3 post-starvation and remained low throughout the time course that ended at day 7 (Young et al., 2017). The elevated levels of H3K79me3 and reduced levels of $\mathrm{H} 3 \mathrm{~K} 79 \mathrm{me} 1 / 2$, while Dot1 was reduced could reflect that $\mathrm{H} 3 \mathrm{~K} 79 \mathrm{me} 3$-containing nucleosomes were not turned over, or that demethylases were activated (Young et al., 2017). H3K79me3 was enriched in gene bodies in transcripts expressed specifically in growing cells or specifically in quiescent cells, with no redistribution to non-canonical locations in genes or intergenic regions (Young et al., 2017). Log and quiescent cells contained similar numbers of gene binding sites for H3K79me3 (Young et al., 2017). These marks were established soon after the shift to diauxic growth and then retained in quiescent cells even as transcription was reduced (Young et al., 2017). There was not a strong correlation between RNA polymerase II occupancy and H3K79me3 marks on specific genes in proliferating or quiescent cells (Young et al., 2017).

Mutant S. cerevisiae strains that are no longer able to methylate histone $\mathrm{H} 3 \mathrm{~K} 4$ or ubiquitinate histone $\mathrm{H} 2 \mathrm{~B}$ showed a shorter chronological lifespan, indicative of reduced ability to re-enter the cell cycle (Young et al., 2017). In contrast, a higher proportion of yeast entered quiescence upon glucose deprivation in H3K79 mutant, and the yeast with H3K79 mutations showed enhanced ability to re-enter the cell cycle (Young et al., 2017). The findings suggest that the presence of a lysine that can be methylated at H3K79 makes cells less able to re-enter the cell cycle after glucose deprivation, and surprisingly, makes the quiescent yeast less fit (Young et al., 2017).

The H3K79 mark has also been implicated in the quiescence of mouse HSCs. In a study described above, knockout of Setd2, a histone methyltransferase involved in the addition of the H3K36me 3 mark, led to the loss of bone marrow reconstitution after transplantation, with the mouse HSCs exhibiting loss of quiescence, increased apoptosis, and inability to differentiate into multiple lineages (Zhou et al., 2018). When studying the changes at the histone level, it was found that knockout of Setd2 led to increased expression of NSD1/2/3, which are also H3K36 methyltransferases that generate H3K36mel and H3K36me2 marks (Zhou et al., 2018). Loss-of-function in SetD2, combined with gain-of-function NSD1/2/3, led to an increase in the H3K79me2 mark through recruitment of DOTL1, the H3K79 methyltransferase (Zhou et al., 2018). Together with increased recruitment of histone acetylase Brd4, which recruits the Super Elongation Complex (SEC), DOT1L enhanced RNA Polymerase II elongation and expression of target genes that promote apoptosis and differentiation of quiescent cells (Zhou et al., 2018). This resulted in increased expression of genes including Myc, as inhibiting Brd4 or Dot1l reduced markers of transcription elongation and Myc expression (Zhou et al., 2018). The findings support a model where multiple histone-modifying enzymes are co-regulated to affect the choice between quiescence and differentiation (Zhou et al., 2018).

These studies, taken together, suggest H3K79 methylation may play a role in quiescence through mechanisms that involve transcription initiation or elongation, or alternative processes. In yeast, this mark reduces the ability of nutrient-starved cells to proliferate when provided nutrients. In mammalian HSCs, data support H3K79 methylation as part of a complex regulatory code that affects transcription elongation and the fate of quiescent HSCs.

\section{H4 METHYLATION WITH QUIESCENCE}

While the $\mathrm{N}$-terminus of $\mathrm{H} 3$ tails exit the nucleosome near DNA entry and exit sites, the tails of histone H4 (residues 120) stick out from the nucleosome's face on either side (Ghoneim et al., 2021). DNA breathing dynamics are altered upon removal of either the $\mathrm{H} 3$ or $\mathrm{H} 4$ tail, suggesting that there is cross-talk between the $\mathrm{H} 3$ and $\mathrm{H} 4$ tails (Ghoneim et al., 2021). The region encompassing residues $16-23$ of $\mathrm{H} 4$ contains a high density of arginine and lysine residues that constitutes a basic patch (Ghoneim et al., 2021). In crystal structures, this H4 basic patch interacts with DNA or the cluster of acidic residues called the $\mathrm{H} 2 \mathrm{~A} / \mathrm{H} 2 \mathrm{~B}$ acidic patch on the same or nearby nucleosomes (Ghoneim et al., 2021). Histone H4 is mainly methylated at residue $\mathrm{K} 20$ in mammalian cells. The methylation of K20 requires the acidic patch, as $\mathrm{H} 4 \mathrm{~K} 20$ monomethylation is not detected in nucleosomes with a defective acidic patch (Ho et al., 2021). H4K20 methylation is conserved from fission yeast $S$. pombe to humans (Jorgensen et al., 2013). Histone H4K20me1 has been observed in budding yeast $S$. cerevisiae (Edwards et al., 2011).

H4K20me1 can act both as a repressive and an activating mark (Huang et al., 2021). On one hand, H4K20me1 causes chromatin condensation (Lu et al., 2008; Oda et al., 2009), and in mammalian cells, can recruit L3MBTL1, a H4K20me1 reader that can induce nucleosome compaction (Trojer et al., 2007). On the other hand, in the genomes of some mammalian cells, H4K20me1 correlates with gene activation (Barski et al., 2007; Wang et al., 2008; Cui et al., 2009). H4K20me3 has been implicated in heterochromatin maintenance (Kourmouli et al., 2004), and localizes to telomeres (Kourmouli et al., 2004; Schotta et al., 2004; Benetti et al., 2007; Mikkelsen et al., 2007; Marion et al., 2011) and repeated elements, including transposable elements (Martens et al., 2005; Mikkelsen et al., 2007; Montoya-Durango et al., 2009; Rhodes et al., 2016). In addition, H4K20me3 has also been discovered in zinc fingers (Nelson et al., 2016), and promoters of E2F responsive genes (Abbas et al., 2010), histones (Abbas et al., 2010), inflammatory genes (Stender et al., 2012), and ribosomal genes (Bierhoff et al., 2014).

A ChIP-seq study in murine ESCs found that H4K20me3 colocalizes with transcriptionally active marks like $\mathrm{H} 3 \mathrm{~K} 4 \mathrm{me} 3$ and H3K36me3 (Xu and Kidder, 2018). This bivalent placement of H4K20me3 with activating histone marks suggest a potential combinatorial histone code for a "poised" state. These "poised" 
states have been suggested to allow for rapid activation of RNA pol II (Bernstein et al., 2006) during cell state transitions. Sims and colleagues report on another combinatorial code involving H4K20, but in conjunction with H3K9 (Sims et al., 2006). They found that $\mathrm{H} 4 \mathrm{~K} 20 \mathrm{me} 3$ and $\mathrm{H} 3 \mathrm{~K} 9 \mathrm{me} 3$ were both enriched in pericentric heterochromatin. H4K20me1 and H4K20me2 were found together with $\mathrm{H} 3 \mathrm{~K} 9 \mathrm{me} 1$ and $\mathrm{H} 3 \mathrm{~K} 9 \mathrm{me} 2$, respectively, but in different regions on chromosome arms (Sims et al., 2006). The authors further found that H4K20me1 and H3K9me1 were enriched in the same nucleosome (Sims et al., 2006). What role these bivalent marks play in quiescence is not known and requires additional exploration.

H4K20 methylation status is cell cycle dependent (Pesavento et al., 2008; Oda et al., 2009; Abbas et al., 2010; Centore et al., 2010; Adikes et al., 2020), at least in part because PR-Set7, the enzyme that generates H4K20mel (Fang et al., 2002; Nishioka et al., 2002b; Beck et al., 2012), is actively targeted for proteasome-mediated degradation in $\mathrm{S}$ phase (Rice et al., 2002; Julien and Herr, 2004; Jorgensen et al., 2007; Abbas et al., 2010; Tardat et al., 2010; Wu et al., 2010). Consistent with these previous reports, in primary human fibroblasts, unmodified H4K20 was most abundant in S phase, less abundant in G2/M cells, and present at low levels in G1 and cells that entered quiescence by contact inhibition for 14 days (Evertts et al., 2013a). H4K20me1 was present at low levels in $S$ phase, increased in G2/M, and increased further in G1 (Evertts et al., 2013a). H4K20me3 represented a small fraction of all of the histones, and was strongly induced with quiescence compared with all other cell cycle phases (Evertts et al., 2013a) (Table 3).

Boonsanay and colleagues investigated the levels of different histone marks in quiescent mouse MuSCs, proliferating MuSCs and differentiated myotubes (Boonsanay et al., 2016). Quiescent MuSCs contained a lower level of H4K20me1, but comparable levels of H4K20me2 to that present in proliferating MuSCs. The levels of $\mathrm{H} 4 \mathrm{~K} 20 \mathrm{me} 3$ were in the order: differentiated myotubes $>$ quiescent MuSCs > proliferating MuSCs (Boonsanay et al., 2016) (Table 3). In contrast, H3K9me3 and H3K27me3 and euchromatin marker H3K9ac did not change between proliferating and quiescent MuSCs (Boonsanay et al., 2016). Without ChIP-seq data, the distribution of histone H4K20 methylation marks, and the extent of overlap with other histone marks in these different cells is not known.

In mammals, H4K20me1 is catalyzed by PR-SET-7 (Nishioka et al., 2002a) and the methyltransferases KMT5B/Suv4-20h1 and KMT5C/Suv4-20h2, and possibly KMT3E/SMYD3, generate H4K20me2 and H4K20me3 (Rice et al., 2002; Schotta et al., 2004, 2008) (Figures 1, 2, Table 4). Loss of both SUV4$20 \mathrm{H}$ enzymes leads to strongly elevated levels of H4K20me1 (Schotta et al., 2008). Electron micrographs of MuSC nuclei with inactivation of Suv4-20h1 revealed a reduction in condensed heterochromatin (Boonsanay et al., 2016). Loss of Suv4-20h1 lead to a reduced population of quiescent cells and increased population of differentiated cells expressing MyoD (Boonsanay et al., 2016). In Suv4-20h1-abrogated quiescent MuSCs, there was a reduction in $\mathrm{H} 4 \mathrm{~K} 20 \mathrm{me} 2$ and nucleosome density, and an increase in $\mathrm{H} 3 \mathrm{~K} 4 \mathrm{me} 3$, at the distal regulatory region (DRR) that controls MyoD expression (Boonsanay et al., 2016). This indicates that DRR is more accessible in Suv4-20h1 knockout quiescent cells and this may allow expression of differentiationrelated gene, MyoD. Thus, Suv4-20h1 reduces expression from the $M y o D$ locus, resulting in the maintenance and preservation of stem cells in a quiescent state (Boonsanay et al., 2016). Further research will be required to determine whether this is a role for H4K20 methylation exclusively in MuSCs, or whether similar changes occur in other stem cells as well.

The H4K20 monomethyltransferase Pr-set-7 was discovered to regulate NSC quiescence in Drosophila (Huang et al., 2021). Targeted DNA adenine methyltransferase identification $(\mathrm{TaDa})$ was used to determine genomic loci where Pr-set7 binds. This analysis revealed Pr-set-7 binds to the promoter and transcriptional start sites of Wnt pathway coactivator earthbound1 (Ebd1) and cyclin-dependent kinase 1 (Cdk1) (Huang et al., 2021). The mRNA levels of Ebd1 and Cdk1 were depleted in pr-set7 mutant brains (Huang et al., 2021). Thus, by increasing expression of Cdk1 and Ebd1 in NSCs, Pr-set7 modulates the cell cycle and Wnt signaling, and thereby promotes NSC reactivation from quiescence (Huang et al., 2021). In these studies, The presence or absence of H4K20me1 in Ebd1 and $C d k 1$ promoters was not determined in this study (Huang et al., 2021).

In primary human dermal fibroblasts, mass spectrometrybased analysis of histone tails revealed that the histone lysine that showed the strongest change in methylation levels with quiescence was H4K20 (Evertts et al., 2013a). H4K20me2, and especially H4K20me3, were highly induced in quiescent cells when compared with proliferating fibroblasts as well as the fibroblasts that were specifically in the G1 phase of the cell cycle and contained the same DNA content as quiescent fibroblasts (Evertts et al., 2013a). In contrast, H4K20me1 levels were reduced in quiescent compared with proliferating fibroblasts. Further knockdown of Suv4-20h1 and Suv4-20h2 methyltransferases that catalyze formation of di and tri-methylated H4K20 with both small hairpin RNAs and small interfering RNAs (siRNAs) resulted in less chromatin compaction, consistent with a potential role for $\mathrm{H} 4 \mathrm{~K} 20$ trimethylation in chromatin conformation (Evertts et al., 2013a). Knockdown of Suv4-20h2 specifically, with siRNAs, resulted in increased proliferation and more cells in $\mathrm{S}$ phase (Evertts et al., 2013a). These findings support a role for Suv4-20h2 in both the regulation of the quiescence-proliferation transition and chromatin compaction with quiescence. Whether there is a direct link between these two activities, and whether they are mediated through $\mathrm{H} 4 \mathrm{~K} 20$ methylation will require additional studies.

Altogether, these studies highlight the critical role of H4K20 methylation, and in particular, $\mathrm{H} 4 \mathrm{~K} 20 \mathrm{me} 3$, in regulating the transition between quiescence and proliferation. The consistent upregulation of $\mathrm{H} 3 \mathrm{~K} 20 \mathrm{me} 3$ in multiple different quiescent models indicates it might play a larger role in establishing the functional state of chromatin in quiescence and may regulate specific gene expression changes necessary for quiescence entry, exit, and maintenance. Given the available data, it is possible that the H4K20 methylation marks act in cooperation with other marks, for instance it has been detected as part of bivalent promoters in combination with $\mathrm{H} 3 \mathrm{~K} 4 \mathrm{me} 3$ 
and H3K36me3 (Xu and Kidder, 2018), and as part of heterochromatin in combination with $\mathrm{H} 3 \mathrm{~K} 9 \mathrm{me} 3$ (Schotta et al., 2004). Taken together, the data support the possibility that H4K20me3 represents one part of a combinatorial code that regulates quiescence.

\section{HISTONE ACETYLATION WITH QUIESCENCE}

\section{General Properties of Histone Acetylation}

An array of conserved lysine residues is present in the N-terminal tails of the four histones forming the nucleosome and these positively charged lysines interact with the DNA and the negatively charged patch formed by $\mathrm{H} 2 \mathrm{~A} / \mathrm{H} 2 \mathrm{~B}$ residues of the nearby nucleosome. The tail of histone $\mathrm{H} 4$ has the strongest effect on chromatin compaction, followed by the tail of histone $\mathrm{H} 3$, which is followed by the tails of histones H2A and H2B (Ghoneim et al., 2021). Histone acetylation weakens the interactions of tails with the DNA and the negative patch, thus making the chromatin more accessible to RNA Pol II (Park and Kim, 2020). In addition to affecting the structural state of the chromatin, acetylation can also affect the proteins bound to chromatin. Lysine acetylation marks on histone tails can be recognized by bromodomaincontaining reader proteins (such as chromatin remodelers) that are generally associated with transcriptional activation (Agalioti et al., 2002; Barnes et al., 2019). The removal of acetyl groups by histone deacetylases can modulate the chromatin state to make the chromatin more compact. Further, in some cases, an individual lysine residue can be acetylated, methylated or ubiquitinated, and this establishes a potential for competition among these different lysine modifications.

The N-terminal tail of histone $\mathrm{H} 3$ is mainly acetylated at residues $\mathrm{K} 9, \mathrm{~K} 14, \mathrm{~K} 18$, and $\mathrm{K} 23$, while the corresponding region of $\mathrm{H} 4$ is acetylated at residues $\mathrm{K} 5, \mathrm{~K} 8, \mathrm{~K} 12$, and $\mathrm{K} 16$. Acetylation on H4K16 is particularly linked to unpacking of the chromatin and transcriptional activation-mainly due to diminished interactions between the $\mathrm{H} 4$ tail and the $\mathrm{H} 2 \mathrm{~A} / \mathrm{H} 2 \mathrm{~B}$ acidic patch (Shogren-Knaak et al., 2006). The periodic nature of the amino acid spacing between the acetylatable lysines in the $\mathrm{H} 3$ and $\mathrm{H} 4$ tails suggests a potential for cooperative behavior among these amino acids (Strahl and Allis, 2000). In particular, this spacing has been noted to be reminiscent of the 3.6 residues per turn of an $\alpha$-helix, raising the possibility that these acetyl marks may act as part of a combinatorial code that provides information about which proteins should bind to chromatin at a specific genomic region (Strahl and Allis, 2000).

The combined presence of histone acetyl marks and other histone modifications have been shown to result in defined outcomes (Winter et al., 2008; Zippo et al., 2009). As one example of this combinatorial effect, Bromodomain PHD Finger Transcription Factor (BPTF), an ATP-dependent chromatin remodeling protein, has increased affinity for histones with two different marks. The presence of H3K4me3 and H4K16ac together results in a 2 -fold stronger BPTF binding affinity than either H3K4me3 or H4K16ac alone (Ruthenburg et al., 2011; Rando, 2012). This effect was not limited to H4K16ac as peptide microarray studies showed an increase in binding of PHD-Bromodomain constructs to histones when H3K4me3 was combined with any of multiple different $\mathrm{H} 3$ acetyl states (Fuchs et al., 2011; Rando, 2012). As another example, some proteins bind preferentially when a single epigenetic mark is found by itself, in the absence of another mark (Rando, 2012). This is exemplified by a PHD-Bromo domain chromatin regulator TRIpartite-Motif containing 24 (TRIM24) as this protein binds to $\mathrm{H} 3 \mathrm{~K} 23 \mathrm{ac}$ to activate estrogen-responsive genes, but this binding is inhibited if H3K4 is also methylated (Tsai et al., 2010; Rando, 2012). Taken together, these reports suggest that a histone acetylation-dependent combinatorial histone code may encode information through the presence of individual histone marks, combinations of marks, their spacing, and the specific readers that recognize the marks. In the sections below, we focus on acetylation of histones $\mathrm{H} 3$ and $\mathrm{H} 4$ as these have been studied the most in relation to cellular quiescence.

\section{H3 Acetylation With Quiescence}

In budding yeast $S$. cerevisiae, a global decrease in acetylation levels was observed after quiescence entry that parallels the repression of transcriptional activity in quiescence (McKnight et al., 2015). Upon entry into quiescence, the budding yeast cells have lower levels of histone $\mathrm{H} 3$ acetylation compared with log phase cells. Immunoblotting for histone $\mathrm{H} 3 \mathrm{~K} 9 \mathrm{ac}, \mathrm{H} 3 \mathrm{~K} 23 \mathrm{ac}$, and pan-acetyl histone $\mathrm{H} 3$ revealed a significant reduction in the levels of these marks in quiescent compared with proliferating yeast (McKnight et al., 2015). In a complementary set of studies, using mass spectrometry, Mews et al. showed that when quiescent yeast cells reentered the cell cycle upon nutrient replenishment, there was a burst of histone acetylation, specifically at $\mathrm{H} 3 \mathrm{~K} 9$ and $\mathrm{H} 3 \mathrm{~K} 14$, immediately upon cell cycle entry (Mews et al., 2014). In contrast, de novo histone methylation occurred at a later cell cycle stage after the acetylation burst. As compared to histone methylation, histone acetylation was more closely correlated with the transcriptional changes that took place soon after the cell cycle entry. Western blot analysis revealed that levels of acetylated histones $\mathrm{H} 4 \mathrm{~K} 5 \mathrm{ac}$, $\mathrm{H} 4 \mathrm{~K} 8 \mathrm{ac}$, and $\mathrm{H} 3 \mathrm{~K} 9 \mathrm{ac}$ drop during quiescence and then robustly increase over a 240-min time course after nutrient refeeding. Using ChIP-seq, Mews and colleagues found that when yeast enter stationary phase, $\mathrm{H} 3 \mathrm{~K} 9 \mathrm{ac}$ levels decreased at genes identified by microarrays as growth genes and increased at genes expressed when yeast initiated quiescence following nutrient exhaustion (Mews et al., 2014). After the nutrients were replenished, acetylation of $\mathrm{H} 3 \mathrm{~K} 9$ increased at growth genes and decreased at stress response genes (Mews et al., 2014). Histone acetylation rapidly responded to changes in metabolic state, while histone methylation levels were largely constant (Mews et al., 2014). Thus, S. cerevisiae undergo a dramatic increase in acetylation, and not methylation, when they re-enter the cell cycle from quiescence as nutrients are re-introduced (Mews et al., 2014; McKnight et al., 2015; Young et al., 2017).

The histone lysine deacetylase Rpd3 has been identified as an important regulator of quiescence entry and maintenance in 
S. cerevisiae in a study by McKnight and colleagues (McKnight et al., 2015). When the yeast entered quiescence, motifs associated with transcription factors inactivated by nutrient exhaustion were associated with more repressive chromatin structure including more nucleosomes positioned over the motif and lower levels of histone acetylation (McKnight et al., 2015). Motifs for transcriptional activators that function in stress conditions had more open chromatin structure in the quiescent cells (McKnight et al., 2015). A large fraction of transcription factors with binding motifs that exhibit changes in chromatin structure with quiescence function by recruiting Rdp3 lysine deacetylase (McKnight et al., 2015). Deleting Rpd3 did not affect growth in the log phase and Rdp3-deleted cells maintained high viability in log phase (McKnight et al., 2015). Rpd3-deficient cells arrest after glucose exhaustion similarly to wild-type cells. However, fewer quiescent cells are formed in an $r p d 3 \Delta$ mutant and the quiescent cells that are formed show reduced long-term survival (McKnight et al., 2015). Analysis of chromatin structure at gene promoters revealed that $\mathrm{Rpd} 3$ has a significant role in establishing the transcriptional profile of quiescent cells by affecting the density of histone $\mathrm{H} 3$ and the acetylation of histone $\mathrm{H} 4$ at the promoters of genes regulated with quiescence (McKnight et al., 2015). The findings, taken together, support histone lysine acetylation as an important regulator of gene expression and viability during quiescence in S. cerevisiae (McKnight et al., 2015).

Studies in mouse NIH 3T3 embryonic fibroblasts that were serum starved to induce quiescence and then restimulated with serum addition revealed changes in histone acetylation (Knosp et al., 1991). Using electrophoretic and fluorographic techniques, in 1991, Knosp et al. reported that addition of serum resulted in an increase in the acetylation rate of all core histones within 15 min (Knosp et al., 1991). The sharp increase in acetylation rate was followed by a gradual decline in acetylation rate that continued until $8 \mathrm{~h}$ post serum stimulation (Knosp et al., 1991). At 10-12 h after serum stimulation, there was a strong increase in the acetylation rate of all core histones, detected based on increased incorporation of tritium into histone $\mathrm{H} 3$ from labeled acetate, a methodology that doesn't distinguish between acetylation of different lysine residues. This increase in acetylation was followed by an increase in histone synthesis (Knosp et al., 1991). The pattern differed among histones: $\mathrm{H} 3>\mathrm{H} 2 \mathrm{~A} \sim \mathrm{H} 2 \mathrm{BB}>\mathrm{H} 4$ (Knosp et al., 1991). In response to $24 \mathrm{~h}$ of serum withdrawal, there was a decrease in DNA synthesis, histone synthesis and histone acetylation (Knosp et al., 1991).

In a more recent study, proliferating and quiescent primary human fibroblasts, were incubated in ${ }^{13} \mathrm{C}$-labeled acetate and the rate of histone lysine acetylation was monitored using mass spectrometry (Evertts et al., 2013b). The quiescent fibroblasts accumulated labeled acetylated histones more slowly than proliferating fibroblasts (Evertts et al., 2013b) and differential labeling rates were observed for the acetylation of H3K9, H3K14 and histone H4 (Evertts et al., 2013b). For histone H4, mass spectrometry was used to monitor the extent of acetylation of a peptide that contained lysines K5, K8, K12 and K16 was monitored. Levels of unmodified peptide, peptide with one acetyl group and peptides with two acetyl groups were determined (Evertts et al., 2013b). Incorporation of ${ }^{13} \mathrm{C}$ in acetyl groups in quiescent cells was approximately half of that for proliferating cells. Even though the rate of acetylation was faster in proliferating fibroblasts, steady state levels of histone acetylation were similar in proliferating and quiescent fibroblasts (Evertts et al., 2013a,b).

\section{H4 Acetylation With Quiescence}

In yeast, $\mathrm{H} 4$ acetylation correlates with transcriptional activation and plays an important role in chromatin decompaction (discussed in more detail in the later section). Using immunoblotting, the overall levels of $\mathrm{H} 4 \mathrm{~K} 5 \mathrm{ac}$ and $\mathrm{H} 4 \mathrm{~K} 8 \mathrm{ac}$ were found to decrease sharply during quiescence in budding yeast $S$. cerevisiae. This was followed by a rapid increase of these histone marks during cell cycle reentry when nutrients were reintroduced (Mews et al., 2014). Also using immunoblotting, a reduction in histone $\mathrm{H} 4 \mathrm{~K} 12 \mathrm{ac}$ was observed in quiescent S. cerevisiae (McKnight et al., 2015). Similarly, by mass spectrometry and western blot analysis, two separate studies found that during stationary phase in $S$. cerevisiae, histone acetylation dropped dramatically at H4K5, H4K8, H4K12, and H4K16 compared to their levels in exponential growth phase (Sandmeier et al., 2002; Ngubo et al., 2011).

In mammals, reduced histone acetylation has been associated with a transition to quiescence in pluripotent cells (Khoa et al., 2020). Embryonic stem cells with pluripotent potential are characterized by high levels of histone acetylation, high chromatin accessibility and an active pluripotency transcriptional network. Mouse embryonic stem cells (ESCs) can exist in a proliferative, naïve ground state achieved by maintenance with a MAPK/ERK Kinase (MEK) inhibitor and a Glycogen Synthase Kinase 3 (GSK3) inhibitor (Boroviak et al., 2014). Deletion of histone acetyltransferase Males absent On the First (MOF), which acetylates histone H4 lysine 16 (Finley et al., 2018; Atlasi et al., 2019), resulted in quiescence in mouse ESCs (Figures 1, 2, Table 4). Among the $>200$ histone posttranslational modifications that were monitored in these MOFdeleted cells, only H4K16ac was significantly decreased (Khoa et al., 2020). Comparing RNA-seq gene expression data with global H4K16ac distribution obtained by ChIP-seq revealed that many genes associated with metabolic processes were regulated in a MOF-dependent manner, especially $\beta$-oxidation of fatty acids (Khoa et al., 2020). The degradation of fatty acids provided metabolites for oxidative phosphorylation and energy production in the proliferative state (Khoa et al., 2020). Inhibiting fatty acid oxidation was also sufficient to induce the proliferative ESCs into a quiescent state (Khoa et al., 2020). Taken together, these studies highlight an important role for histone $\mathrm{H} 4$ acetylation in regulating the proliferation-quiescence transition.

While addition of $\mathrm{H} 4$ acetyl groups is associated with the transition from quiescence to proliferation, the removal of $\mathrm{H} 4$ acetyl groups by Sitruins, a class of histone deacetylases (HDACs), has also been associated with the proliferation-quiescence transition (Ryall et al., 2015) (Figure 1). When mouse MuSCs exit quiescence to begin proliferating, there is a decrease in $\mathrm{NAD}^{+}$ levels and activity of $\mathrm{NAD}^{+}$-dependent sirtuin 1 (SIRTS), an HDAC (Michan and Sinclair, 2007). This reduction in SIRT1 activity results in increased $\mathrm{H} 4 \mathrm{~K} 16$ acetylation, activation of 
muscle gene transcription, premature myogenic differentiation, reduced myofiber size, impaired muscle regeneration, and derepression of muscle developmental genes (Ryall et al., 2015).

These studies taken together support a role for acetylation in modulating transcriptional activation at important genes in different quiescence models. Loss of acetylation marks at genes critical to cell cycle and cell growth define the functional state of the chromatin during quiescence. In yeast and MuSCs, the alterations in acetylation have been functionally linked to quiescence (McKnight et al., 2015; Ryall et al., 2015).

\section{RNA-MEDIATED ADDITION OF HISTONE MARKS}

The mechanisms that dictate where histone marks are deposited are not well-understood. There is an emerging literature that suggests that in some instances, long non-coding RNAs (lncRNAs) can help to direct the deposition of histone epigenetic marks (Batista and Chang, 2013; Hanly et al., 2018). LncRNAs can act as "address-codes" by directing the writers of histone marks to specific chromosomal locations (Batista and Chang, 2013; Hanly et al., 2018). The deposited marks can then affect chromatin conformation, nucleosome positioning and transcription at nearby genes (Faghihi and Wahlestedt, 2009; Guttman et al., 2011). The lncRNA Xist, for example, interacts with polycomb repressive complexes PRC1 and PRC2, which are responsible for the addition of the $\mathrm{H} 3 \mathrm{~K} 27 \mathrm{me} 3$ mark, and recruiting these complexes is one part of the process by which Xist induces transcriptional silencing of the $\mathrm{X}$ chromosomes in female mammals (Kohlmaier et al., 2004; Bousard et al., 2019). Another lncRNA termed HOTAIR represses the HoxD gene locus by recruiting PRC2 for $\mathrm{H} 3 \mathrm{~K} 27 \mathrm{me} 3$ addition (Rinn et al., 2007). LncRNAs have been confirmed to play critical roles in the establishment and maintenance of heterochromatic regions (Deng et al., 2009).

LncRNAs including $\mathrm{H} 19$ are emerging as critical regulators of quiescence and proliferation in HSCs (Venkatraman et al., 2013; Yildirim et al., 2013; Luo et al., 2015). The H19-Igf2 locus is an imprinted region that affects organism growth (DeChiara et al., 1991). The differentially methylated region (DMR) upstream of H19 is the imprinting control region that enforces the expression of $\mathrm{H} 19$ from the maternal allele only while Igf2 is expressed from the paternal allele (Bartolomei, 2009). Deletion of the maternal, but not the paternal, H19 DMR in adult mouse HSCs resulted in a activation of quiescent HSCs and reduced function of the HSCs (Venkatraman et al., 2013). When maternal H19 DMR was deleted, the Igf2-Igflr pathway was activated, the FoxO3 transcription factor translocated from the nucleus to the cytoplasm, and quiescent HSCs were activated to proliferate, resulting in their exhaustion (Venkatraman et al., 2013).

PAPAS lncRNAs have been studied in the context of cell quiescence (Figure 3A). PAPAS, or "promoter and pre-rRNA antisense," is a heterogeneous group of lncRNAs that are generated when ribosomal DNA (rDNA) is transcribed in the antisense direction and localize to the pre-rRNA coding region and the rDNA promoter (Bierhoff et al., 2010). PAPAS interacts with Suv-20h2, the methyltransferase that generates H4K20me3, and mediates deposition of this mark at rDNA during quiescence (Bierhoff et al., 2010). PAPAS and H4K20me3 were found to be upregulated in quiescent breast cancer cell line MCF7 generated with an estrogen receptor antagonist (Bierhoff et al., 2014). PAPAS and H4K20me3 are also induced upon terminal differentiation of human colon cancer cells (Caco-2), and upon quiescence in $\mathrm{C} 2 \mathrm{C} 12$ mouse myoblasts, and mouse fibroblast-like 3T3-L1 cells (Bierhoff et al., 2014). Knockdown of endogenous PAPAS with siRNAs in MEFs decreased H4K20me3 levels (Bierhoff et al., 2014). Gain- and loss-of-function experiments, RNA-protein binding assays, and chromatin accessibility analysis revealed that PAPAS guides Suv4-20h2 to nucleolar chromatin, reinforcing quiescence-dependent transcriptional repression of ribosomal RNAs through H4K20me3-dependent chromatin compaction (Bierhoff et al., 2014).

Intracisternal A particle (IAP)-specific lncRNAs were found to be involved in H4K20me3-mediated chromatin compaction at IAP retrotransposons (Bierhoff et al., 2014). At IAP elements, both H4K20me3 and Suv4-20h2 levels increased in serumstarved MEFs, and the IAP chromatin was more compact (Bierhoff et al., 2014). Knockdown of IAP lncRNA with locked nucleic acid technology resulted in upregulation of the IAP major $7 \mathrm{~kb}$ transcript, supporting a role for the lncRNA in causing repression of the IAP gene, while transfection of IAP IncRNA sequences that interact with Suv4-20h2 resulted in increased Suv4-20h2 and H4K20me3 at IAPs, with no change in H3K9me3 levels (Bierhoff et al., 2010). These studies suggest that lncRNAs may provide another dimensionality to the histone code by potentially providing an address code that directs histone marks to specific genomic positions.

\section{HISTONE MARKS AND CHROMATIN CONFORMATION DURING QUIESCENCE}

Multiple studies have reported changes in chromatin compaction with quiescence with most, but not all studies (Kallingappa et al., 2016), reporting that when cells enter quiescence, their chromatin becomes more compact (Chiu and Baserga, 1975; Setterfield et al., 1983; Evertts et al., 2013a; Swygert et al., 2019). In S. cerevisiae budding yeast, quiescence induction was found to induce global changes in chromosomal organization (Rutledge et al., 2015) using a global chromosome conformation capture highthroughput sequencing technology called Hi-C. By monitoring the frequency of interloci interactions, the study revealed an increase in long range cis interactions and a decrease in short range interactions in quiescent yeast cells (Rutledge et al., 2015). The study further found that inter-centromeric interactions decrease during quiescence, while inter-telomeric interactions increase in quiescence, indicating that quiescence maintenance is associated with substantial topological reorganization (Rutledge et al., 2015). Another study has also shown that when yeast enter the stationary phase, the telomeres hypercluster, that is, they colocalize in a single location (Laporte et al., 2016). Mutant yeast strains that lack linker histone Hho1, or condensin, or contain mutations in histone $\mathrm{H} 4$ lysine 16 are unable to form these 

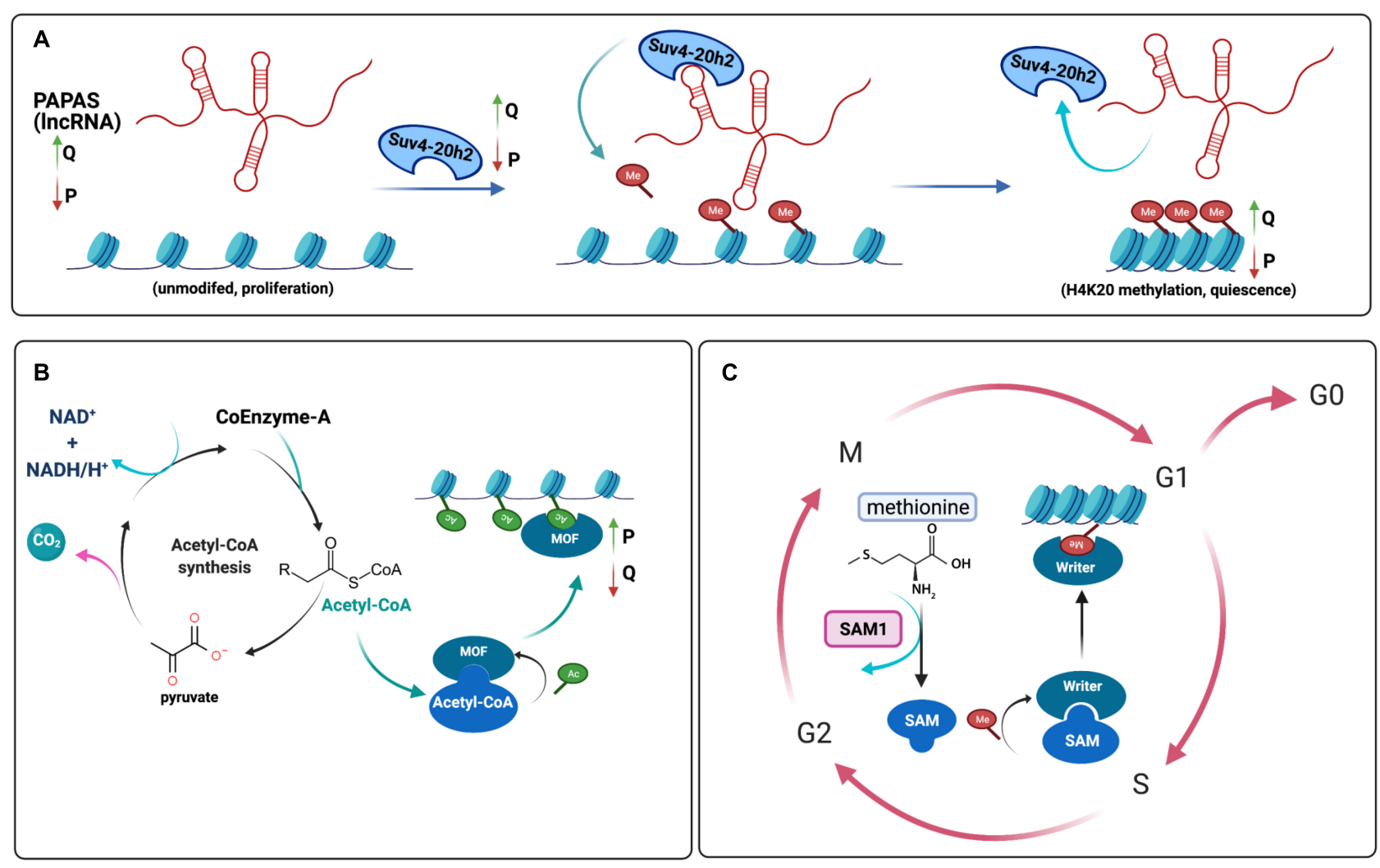

FIGURE 3 | Histone Modifications and Metabolism | (A) During quiescence, the writer Suv420h2 adds methyl groups to H4K20 via mediation with the IncRNA PAPAS. PAPAS, Suv4-20h2, and H4K20 methylation levels all increase with quiescence (Q) compared to proliferation (P), as indicated by the arrows (Bierhoff et al., 2014). (B) Acetyl-CoA acts as an acetyl group donor for histone acetyltransferases, including MOF, which is responsible for H4K16 acetylation during proliferation (Khoa et al., 2020). (C) In fission yeast, synthesis of S-adenosylmethionine (SAM) from methionine with the help of S-Adenosylmethionine synthetase (Sam1) is implicated in histone methylation. SAM acts as a methyl donor for methyltransferases; thus, Sam1 is necessary for proper cell growth and proliferation, as well as quiescence maintenance (Hayashi et al., 2018) (Figure made in BioRender).

telomere hyperclusters (Laporte et al., 2016). A contraction of the nucleolus (Wang et al., 2016) has also been observed in quiescent yeast cells as well.

A study in human diploid fibroblasts investigated changes in chromatin compaction with quiescence (Criscione et al., 2016). Using Formaldehyde Assisted Isolation of Regulatory Elements (FAIRE) to investigate global DNAse I sensitivity and chromatin accessibility, quiescent cells were found to be more resistant to DNAse I treatment, indicating more compact chromatin (Criscione et al., 2016). This study used $\mathrm{Hi}-\mathrm{C}$ to show genes switching between $\mathrm{A}$ and $\mathrm{B}$ compartments with quiescence (Criscione et al., 2016). The A-type compartment has a more open chromatin structure and is enriched for activating marks such as H3K36me3, H3K79me2, H3K27ac, and H3K4me1 (Lieberman-Aiden et al., 2009; Rao et al., 2014). The B-type compartment, on the other hand, is characterized by more densely packed chromatin and correlates with repressive marks such as H3K27me3, H3K9me3, and H4K20me3 (Lieberman-Aiden et al., 2009; Rao et al., 2014). Genes associated with cell proliferation were enriched in the group of genes switching from $\mathrm{A}$ to $\mathrm{B}$ compartments as cells entered quiescence (Criscione et al., 2016).

$\mathrm{HP} 1 \beta$ is a dimeric protein that binds to the $\mathrm{H} 3 \mathrm{~K} 9 \mathrm{me} 3$ mark in constitutive heterochromatin and can bridge two H3K9me3-containing nucleosomes (Machida et al., 2018). Both HP1 $\beta$ and H3K9me3 localized to constitutive heterochromatin regions in proliferating $\mathrm{B}$ lymphocytes, while in quiescent B lymphocytes they did not (Baxter et al., 2004). These findings suggest that the overall structure of DNA may be altered in quiescent B lymphocytes in a way that affects the accessibility of histone writers and readers, especially in constitutive heterochromatin.

One possible mechanism through which the histone code could affect chromatin state during quiescence involves the histone methyltransferase Suv4-20h2 that generates H4K20me3. As mentioned before, H4K20me3 is involved in heterochromatin formation and induces chromatin compaction (Evertts et al., 2013a; Hahn et al., 2013). Suv4-20h2 activity and the H4K20me3 mark are upregulated with quiescence (Evertts et al., 2013a; Bierhoff et al., 2014). A fluorescence in situ hybridization (FISH) analysis performed in primary human dermal fibroblasts 
found that contact-inhibited quiescent fibroblasts had more compact chromatin than their proliferating counterparts (Evertts et al., 2013a). Furthermore, knockdown of Suv20h2 resulted in decreased compaction (Evertts et al., 2013a). As described above, crystal structures of nucleosomes reconstituted with histones containing the H4K20me3 mark had alterations in higher order structure (Lu et al., 2008). Fluorescence Recovery After Photobleaching (FRAP) analysis revealed that Suv4$20 \mathrm{~h} 2$ binds tightly to heterochromatin (Hahn et al., 2013). Other studies have shown that Suv4-20h2 associates with pericentric heterochromatin through multiple, independent interaction sites on its C-terminal domain that directly bind to multiple heterochromatin protein 1 (HP1) molecules (Schotta et al., 2004, 2008; Watanabe et al., 2018). The HP1 protein family consists of three members: $\mathrm{HP} 1 \alpha, \mathrm{HP} 1 \beta$, and $\mathrm{HP} 1 \gamma$. HP $1 \alpha$ localizes to heterochromatin, HP1 $\beta$ is found in both heterochromatic and euchromatic regions and HP1 $\gamma$ is associated with actively transcribed genes (Vakoc et al., 2005; Lomberk et al., 2006). Dimeric HP1 $\alpha$ binds two H3K9me3 marks in adjacent nucleosomes and forms a bridge between them, thereby compacting the chromatin (Watanabe et al., 2018). Consequently, the combinatorial effects of the H3K9me3 and H4K20me3 marks together represent an opportunity for a quiescence combinatorial histone code that affects chromatin conformation and induces chromosomal compaction.

Chromatin-bound Suv4-20h2 also recruits the cohesin complex (Hahn et al., 2013), which is composed of rings of Smc1-Smc3 dimers connected by Scc1/Rad21 (Nasmyth, 2011). The cohesin complex can contribute to establishment of the chromatin loop domains at specific DNA regions, thereby inducing chromatin compaction (Maya-Miles et al., 2019). In Suv4-20h1/Suv4-20h2 double-knockout cells, cohesin was absent from heterochromatic regions in G0 phase, which showed that Suv4-20h enzymes are required for loading or maintaining cohesin at heterochromatin (Hahn et al., 2013). Reintroducing Suv4-20h2 or only the non-enzymatic clamp domain of Suv4$20 \mathrm{~h} 2$ rescued the loss of heterochromatin-associated cohesin suggesting the effects of Suv4-20h2 may be mediated independent of its effects on H4K20me3 (Hahn et al., 2013). This ability of Suv4-20h2 to recruit cohesin and compact chromatin may be critical for chromatin compaction with quiescence, as Suv420h2-deficient MEFs synchronized in $\mathrm{G}_{0}$, contained virtually no cohesin in regions of heterochromatin (Hahn et al., 2013). Additional experiments will be required to understand the functional consequences of a lack of cohesin in heterochromatin in Suv4-20h2-deficient quiescent cells.

\section{CROSS-TALK BETWEEN HISTONE MARKS AND METABOLISM}

An important emerging theme in epigenetic regulation is the close association between histone marks and metabolism. In yeast, metabolic signals such as the presence or absence of glucose can determine whether cells proliferate or arrest (Laporte et al., 2011), and therefore, histone marks that signal the relative abundance of glucose can potentially transmit information about nutrient abundance in a locus-specific manner to affect gene regulation. The metabolite acetyl-CoA serves as the substrate for histone acetyltransferase enzymes that generate acetylated histones (Kaelin and McKnight, 2013) (Figure 3B). Acetyl CoA is formed in mitochondria when pyruvate generated by glycolysis is committed to the TCA cycle (Martinez-Reyes and Chandel, 2020). Citrate formed in the mitochondria can be exported and converted in the cytoplasm to acetyl CoA (Martinez-Reyes and Chandel, 2020). In proliferating yeast and mammalian cells, higher levels of glycolysis and increased export of acetyl CoA from the mitochondria have been observed in proliferating compared with quiescent cells (Frauwirth and Thompson, 2004; Vander Heiden et al., 2009; Lemons et al., 2010). Thus, the metabolic profiles of proliferating cells may facilitate the generation of histone acetylation, and the formation of more open chromatin (Frauwirth and Thompson, 2004; Lemons et al., 2010). The role of histone acetylation in S. pombe was investigated with a strain that exhibited a temperature-sensitive mutation in the catalytic region of phosphopantothenoylcysteine synthetase (designated Ppc1) (Nakamura et al., 2012), an enzyme in the biosynthetic pathway for acetyl-CoA. S. pombe with mutations that inactivate the ability to synthesize acetylCoA fail to acetylate histones and are unable to re-enter the cell cycle after initiating $G_{0}$ following nitrogen withdrawal (Nakamura et al., 2012).

In fibroblasts, the oncogene c-MYC has been identified as a transcription factor that can affect global chromatin remodeling (Morrish et al., 2010). In rat fibroblasts, MYC activity increased glucose metabolism and acetyl-CoA production (Morrish et al., 2010). The presence of MYC caused a forty percent increase in ${ }^{13} \mathrm{C}$-labeled acetyl-CoA on H4-K16 during cell cycle entry with serum stimulation during the $G_{0}$ to $S$ transition (Morrish et al., 2010). Metabolic tracing revealed that in MYC-stimulated cells, MYC increases acetylCoA levels (Morrish et al., 2010). Further, the GCN5 histone acetylase enzyme, an enzyme that is important for histone acetylation in response to nutrients in yeast (McMahon et al., 2000; Cai et al., 2011), is a target of MYC (Morrish et al., 2010).

In addition to a connection between metabolism and histone acetylation, there is also a connection between metabolism and histone methylation. S-adenosylmethionine (SAM) is a metabolite that acts as a donor of methyl groups, which are transferred by methyltransferase enzymes to histones (Kaelin and McKnight, 2013) (Figure 3C). In fission yeast, the enzyme responsible for synthesizing SAM, S-adenosylmethionine synthase 1 (Sam1), is required for proper cell growth, proliferation, and quiescence entry and exit (Hayashi et al., 2018). Loss of Sam 1 results in reduced levels of H3K4me2 and $\mathrm{H} 3 \mathrm{~K} 4 \mathrm{me}$, and a significant decrease in cell growth and defects in G2 cell cycle arrest (Hayashi et al., 2018). Yeast with mutations in Sam 1 cannot survive in quiescence initiated following nitrogen starvation, and once released from $\mathrm{G}_{0}$, they are unable to increase in cell size and restart DNA replication in proliferative conditions (Hayashi et al., 2018).

Taken together, these studies exploring the crosstalk between metabolism and histone marks highlight the close association 
between nutrient uptake, proliferation and histone posttranslational modifications. How this crosstalk is established and maintained in quiescence is an important area for further exploration.

\section{GAPS IN THE FIELD AND FUTURE STUDIES}

The decision whether to proliferate or exit the proliferative cell cycle requires cells to integrate multiple types of information and execute a complex series of molecular changes that impact many of the cell's activities. Transitioning between a proliferative and quiescent state is associated with many alterations including changes in the expression and activity of specific genes, changes in the conformation of chromatin, and changes in the subnuclear localization of chromosomes. The molecular mechanisms that cells use to make these decisions are actively being investigated and there are likely levels of regulation that have yet to be uncovered. Here we explored the literature to find evidence that histone post-translational modifications serve as a code that interprets information about the activity of signaling pathways and transmits that information to enable the commitment to a proliferative or quiescent state and the functional changes required for this transition.

So, is there a histone code for cellular quiescence? As highlighted in this review, there are multiple lines of evidence that suggest that specific histone modifications alone and in combination are added or removed as cells transition between proliferation and quiescent in multiple model systems. Histone $\mathrm{H} 3 \mathrm{~K} 4 \mathrm{me} 3$, for instance, is found at the promoters of genes that are activated when cells become quiescent. H3K36 methylation is important for establishment and maintenance of the quiescent state in HSCs as inactivation of the SETD2 methyltransferase results in depletion of quiescent HSCs (Wagner and Carpenter, 2012). In quiescent mouse MuSCs, a combination of H3K9 and H3K27 marks was found to regulate cyclin A2 expression and proliferation (Cheedipudi et al., 2015). As another example, H4K20me3 levels increase in quiescent cells and knockdown of Suv4-20h2 results in a more rapid cell cycle (Evertts et al., 2013a). Finally, changes in the levels of histone acetylation have been observed with the transition between proliferation and quiescence (Ryall et al., 2015), and the close association between nutrient availability and acetyl CoA levels suggests histone acetylation as a possible link between nutrient availability and proliferation (Cai et al., 2011). For each of the marks described, there is evidence that the mark plays a functional role in some aspect of quiescence: quiescence entry, quiescence exit, quiescence maintenance, or quiescence depth. In some cases, functional studies have shown a causative role for a specific reader, writer or eraser. However, in many studies, and for many of the histone PTMs described, it is not clear whether the role of the histone marks is correlative or causative. Also, the contribution of histone marks seems to be context- and cell type-dependent as indicated by our survey of different quiescence models and conditions. For many of the marks, the direction of change was not consistent in different model systems. For instance, H3K27me3 was induced in some quiescence models and repressed in others (Baxter et al., 2004; Evertts et al., 2013a; Kallingappa et al., 2016; Maki et al., 2021). Other histone marks appear to be regulated with quiescence in some species, but are absent in others, such as H3K27me3 which is absent from yeast (Jamieson et al., 2013). Furthermore, quiescence studies have usually focused on one or a few histone marks at a time. Additional studies will be needed to determine whether a well-defined system-dependent or system-independent combinatorial histone code exists for cellular quiescence and how this histone code varies among species and tissues.

The findings in this review show that certain histone marks, and even combinations of histone marks, are altered with quiescence and some of these changes are consistent among model systems. Future studies will be needed that systematically determine the genomewide deposition of histone marks and combinations of histone marks in proliferating and quiescent cells in multiple model systems. These investigations would cover both traditional and non-traditional histone marks in multiple quiescent states. Beyond just comparing proliferating and quiescent cells, these inquiries would look into histone marks in cells that initiate quiescence in response to different signals in the same cell type and cells that have been quiescent for different durations of time to achieve different depths of quiescence (Rodgers et al., 2014; Kwon et al., 2017). While many of the studies we review have not discovered a clear relationship between changes in individual histone marks and altered gene expression (Liu et al., 2013; Lee et al., 2016), a careful analysis of combinations of marks might determine if the changes in the combinatorial pattern of histone marks is a better indicator of gene expression changes with quiescence.

Many questions remain when studying histone marks in quiescence. What triggers the deposition of these marks? In particular, how do different histone writers and readers coordinate to establish marks at the appropriate time? In some cases, establishment and maintenance of histone marks associated with an open chromatin structure and active gene transcription may be achieved through positive feedback loops (Zhang et al., 2015). These positive feedback loops can be formed when proteins that write histone marks also read the same mark (Zhang et al., 2015). For instance, SETD1 complexes not only catalyze the formation of $\mathrm{H} 3 \mathrm{~K} 4 \mathrm{me} 3$ marks, but may also recognize the same $\mathrm{H} 3 \mathrm{~K} 4 \mathrm{me} 3$ mark, bind to it, and continue to generate additional $\mathrm{H} 3 \mathrm{~K} 4 \mathrm{me} 3$ modifications (Shi et al., 2007; Murton et al., 2010; Zhang et al., 2015). Dot1, the H3K79 methyltransferase in yeast (Guan et al., 2013), recognizes modifications on the histone $\mathrm{H} 2 \mathrm{~B}$ tail and, in human, also binds phosphorylated forms of RNA polymerase II at the transcription start sites of actively transcribed genes (Kim S.K. et al., 2012). $\mathrm{H} 3 \mathrm{~K} 4 \mathrm{me} 3$ can recruit histone acetyltransferases that add acetyl groups as well as deacetylases that remove acetyl groups (Zhang et al., 2015), resulting in dynamic turnover of histone acetylation marks when H34me3, but not other marks such as H3K79me3 or H3K36me3, are present (Crump et al., 2011). For repressive 
chromatin, PRC2 not only generates $\mathrm{H} 3 \mathrm{~K} 27 \mathrm{me} 3$ but also binds to it, resulting in a positive feedback loop in which local chromatin structure allows $\mathrm{H} 3 \mathrm{~K} 27 \mathrm{me} 3$ to be deposited over chromatin regions to form domains (Hansen et al., 2008; Zhang et al., 2015). Crosstalk between H3K27me3 and monoubiquitinated $\mathrm{H} 2 \mathrm{~A}$ on lysine 119, H2AK119ul, has also been proposed as enzyme complexes that deposit each mark may recognize the other mark (Blackledge et al., 2014; Cooper et al., 2014; Kalb et al., 2014), allowing for the reinforcement of heterochromatic regions (Zhang et al., 2015). Negative feedback between histone marks also occurs as activating marks can inhibit the activity of enzymes that place repressive marks, and vice versa (Zhang et al., 2015). For instance, activating marks H3K4me $2 / 3$ and $\mathrm{H} 3 \mathrm{~K} 36 \mathrm{me} 2 / 3$ can inhibit the activity of PRC2 and prevent the deposition of $\mathrm{H} 3 \mathrm{~K} 27 \mathrm{me} 3$ repressive marks (Schmitges et al., 2011). Experiments in which the impact of modulating a specific reader and writer on the levels of multiple marks in the context of quiescence models may shed light on this question. In particular, such experiments may shed light on how positive and negative feedback loops are interrupted at proliferation-associated genes and reestablished at quiescenceassociated genes.

The development and application of new technologies will facilitate future studies investigating how combinations of histone marks coordinate. One valuable approach will be the ability to visualize proliferation and quiescence decisions in organisms in real time. Toward this end, a recent paper describes the adaptation of a biosensor for CDK activity (Spencer et al., 2013) to monitor cell division in two model organisms, Caenorhabditis elegans and zebrafish (Adikes et al., 2020). CDK activity was higher at the end of a cell division in cases in which the cell went on to divide (Adikes et al., 2020). Such biosensors could be used in conjunction with visualization of histone marks to assess whether histone marks individually or in combination can predict whether a cell will proliferate.

We anticipate that CRISPR-Cas9 will prove to be a powerful methodology for understanding the impact of histone modifications. One important challenge in understanding the impact of different histone marks and combinations of histone marks has been developing specific systems to test their functional importance. Many studies to date have focused on investigating the role of specific readers and writers with knockdown and knockout approaches. Using CRISPR-Cas9, further studies will likely allow the inactivation of specific histone modifiers using protein degradation systems that allow the proteins to be degraded in proliferating or quiescent cells with defined timing thus permitting a more detailed dissection of their role (Wu et al., 2020).

Functional dissection of histone readers and writers is sometimes complicated as they have non-histone targets as well (Cornett et al., 2019). In fact, nearly 3,000 human non-histone proteins have been reported to have a lysine that can be methylated (Hornbeck et al., 2015; Cornett et al., 2019). An alternative approach is to test for the functional consequences of modifying the histones themselves. To achieve this, CRISPR-Cas9 has been used in $S$. cerevisiae to generate yeast strains with different combinations of mutations at histone tail lysines for histone $\mathrm{H} 3$ and $\mathrm{H} 4$, allowing the investigators to assess the effects of loss of different combinations of histone marks (Fu et al., 2021). In Trypanosoma brucei, precise editing of genes in multicopy arrays was performed with CRISPR-Cas9, allowing for the replacement of histone $\mathrm{H} 4 \mathrm{~K} 4$ with $\mathrm{H} 4 \mathrm{R} 4$ to mimic the constitutively non-acetylated state. The authors achieved $90 \%$ replacement of the 43 histone $\mathrm{H} 4$ copies to H4R4 (Vasquez et al., 2018).

CRISPR/Cas9 will also be valuable for its capacity to specifically target chromatin writers and readers to specific genomic regions. As an early example of this technology, "programmable chromatin kinase" dCas9dMSK1 was generated by fusing nuclease-deficient CRISPR/Cas9 (or dCas9) to a histone H3 kinase ( $\mathrm{Li}$ et al., 2021). When this protein was targeted to specific promoters with guide RNAs, there was an increase in histone H3 serine 28 phosphorylation at the target genes' promoters and an increase in expression of the targeted gene. Such studies are likely to be valuable for defining causal connections between histone PTMs, their activity at specific genomic loci, and outcomes such as gene expression and proliferation.

We anticipate that the availability of new technologies that allow us to better visualize the relationships among histone marks and chromosomal organization on a cellby-cell basis will also benefit studies of the histone code in quiescence. A recent report built upon sequential FISH (seqFISH) and multiplexed FISH methods to target 3,660 loci in individual mouse ES cells (Takei et al., 2021). These studies revealed that nuclear zones were created by combinatorial chromatin patterns (Takei et al., 2021). Repressive histone marks H4K20me3, H3K9me3, and histone variant $\mathrm{H} 2 \mathrm{~A} 1$ were found together and colocalized with DAPI-rich regions (Takei et al., 2021). A second heterochromatic pattern of H4K20me2, H3K27me3 and H3K27me2 was also observed (Takei et al., 2021). Active histone marks, H3K9ac and H3K27ac, and RNA Polymerase II serine 5 phosphorylation localized to nuclear speckles and were excluded from heterochromatin and nuclear lamina (Takei et al., 2021). Similar studies comparing proliferating and quiescent cells could shed light on the role for a potential histone code in establishing a cell's proliferative fate. In particular, single cell analyses of proliferating and quiescent cells could reveal patterns that are consistent among cells versus those that are more variable from cell to cell.

We anticipate that with time the role of additional histone PTMs and histone variants and their roles in regulating chromatin structure and gene expression will become clearer. As one example, non-tail globular histone marks, such as H3K36 and H3K122 acetylation marks found in active gene promoters and a subset of enhancers, can contribute to the histone code and expand the possibilities for combinatorial histone PTMs that provide position-specific information to readers (Pradeepa et al., 2016). Non-enzymatic histone modifications, such as glycation, acylation and lipidation, 
generated by spontaneous chemical reactions also have the potential to alter chromatin structure and regulate genetic processes (Maksimovic and David, 2021). The non-enzymatic modifications, like the histone marks described in this review, can be "erased" by scavenger systems (Maksimovic and David, 2021). Improved mass spectrometry and chemoproteomics will likely provide important new insights into the role of these modifications in cellular decisions including the commitment to proliferation (Maksimovic and David, 2021). As another example, additional studies are likely to reveal that changes in the specific histone variants present at different positions in the chromatin cooperate with histone PTMs to alter chromatin state and reader proteins. Some histone variants such as histone $\mathrm{H} 3.1$ and histone H3.3 contain different residues, such as amino acid S31 in histone $\mathrm{H} 3.3$ and A31 in histone H3.1 that can alter the properties of the chromatin and its accessibility to the transcription apparatus (Armache et al., 2020). Linker histone H1 variants can also affect folding of nucleosome arrays and nucleosome compaction (Fyodorov et al., 2018).

Combinations of multiple distinct genome-wide, highthroughput analyses performed in models of proliferating and quiescent cells, will also be needed to allow us to dissect the role of histone modifications and other contributors to gene expression and functional changes with quiescence. Studies in which changes in the genome-wide localization of histone marks can be correlated with chromatin accessibility using ATAC-seq, DNA methylation, and $\mathrm{Hi}-\mathrm{C}$ to assess $\mathrm{A}$ and $\mathrm{B}$ compartments and topologically associating domain boundaries have the potential to yield greater insight. Combining these datasets and analyzing them with deep learning algorithms, may allow scientists to predict which combinations of marks are associated with changes in chromatin accessibility and gene expression.

\section{CONCLUSION}

Based on the findings thus far, the specific histone marks discussed in this review, methylation of $\mathrm{H} 3 \mathrm{~K} 4, \mathrm{H} 3 \mathrm{~K} 9, \mathrm{H} 3 \mathrm{~K} 27$, $\mathrm{H} 3 \mathrm{~K} 36, \mathrm{H} 3 \mathrm{~K} 79, \mathrm{H} 4 \mathrm{~K} 20$, and acetylation of $\mathrm{H} 3$ and $\mathrm{H} 4$ have been discovered to be regulated with quiescence in different model systems. Readers, writers and erasers of these marks have been found to functionally contribute to the quiescence-proliferation transition and quiescence maintenance. The model systems employed for these studies include nutrient depletion and spore formation in yeast, cell culture models in which different antiproliferative signals are employed, and models in which quiescent stem cells are visualized in situ or isolated and characterized. One of the key limitations for the field is the fact that knockout or knockdown of readers, writers and erasers can impact not just the histone marks under study, but also the PTMs of other cellular proteins as well. Also, most studies have investigated the effect of a single modification in isolation rather than the impact of several modifications together and the relationships between marks. More research with emerging technologies will be needed to determine whether there is a quiescence histone code and if so, how changes in histones are used to create a complex and context-dependent grammar that incorporates not just levels of histone marks and their readers, but also the chromatin context (in $2 \mathrm{D}$ as well as in $3 \mathrm{D}$ ). Future studies will likely address the causality of histone marks and phenotypic changes that serve as regulators of quiescence and landmarks of quiescence. These studies may define the functional consequences of these marks in terms of gene expression, chromatin conformation, and chromosomal positioning. These studies will also likely reveal the role of traditional and non-traditional histone PTMs and other changes to chromatin in the decision whether to proliferate, the mechanisms that cause cell cycle arrest, the maintenance of cells during quiescence, and the determination of quiescence depth. Altogether, these results indicate that the regulation of histone marks may help to maintain the delicate balance between quiescence, proliferation, differentiation, and cell death, with different model systems and cell types likely using both overlapping and distinct aspects of the information contained in these histone marks.

\section{AUTHOR CONTRIBUTIONS}

MM conceived the topic and design of the review. $\mathrm{KB}$ and KS prepared all the figures and tables. KB, KS, MM, and $\mathrm{HC}$ did the literature survey. $\mathrm{MM}, \mathrm{HC}, \mathrm{KB}, \mathrm{KS}$, and $\mathrm{KA}$ wrote the manuscript. MM and HC supervised the project. All authors were involved in proof-reading.

\section{FUNDING}

This work was supported by grants to HC NIGMS R01 GM081686, NIGMS R01 GM0866465, NIH R01 AR070245, 1 R01 CA221296-01A1, NCI RC1 CA 147961-02, National Cancer Institute P50 CA092131, the Cancer Research Institute CLIP grant, a Melanoma Research Alliance Team Science Award (https://doi.org/10.48050/pc.gr.80537), the Iris Cantor Women's Health Center/UCLA CTSI NIH Grant UL1TR000124, the UCLA SPORE in Prostate Cancer (P50CA092131), David Geffen School of Medicine Metabolism Theme, University of California Cancer Research Coordinating Committee, Broad Stem Cell Center Innovation Awards, and Rose Hills Foundation and Hal Gaba awards from the UCLA Broad Stem Cell Center. KA acknowledges support from 5 T32 AR 65972-5 and an MBI Whitcome Fellowship. KB acknowledges the MARC Foundation funding from NIH/NIGMS NIH MARC T34 GM008563 (PI M. M. McEvoy). HC was the Milton E. Cassel scholar of the Rita Allen Foundation (http://www.ritaallenfoundation.org).

\section{ACKNOWLEDGMENTS}

We are grateful to the entire Coller laboratory for helpful conversations. 


\section{REFERENCES}

Abbas, T., Shibata, E., Park, J., Jha, S., Karnani, N., and Dutta, A. (2010). CRL4(Cdt2) regulates cell proliferation and histone gene expression by targeting PR-Set7/Set8 for degradation. Mol. Cell 40, 9-21.

Acquaviva, L., Drogat, J., Dehe, P. M., de La Roche Saint-Andre, C., and Geli, V. (2013). Spp1 at the crossroads of H3K4me3 regulation and meiotic recombination. Epigenetics 8, 355-360. doi: 10.4161/epi. 24295

Adikes, R. C., Kohrman, A. Q., Martinez, M. A. Q., Palmisano, N. J., Smith, J. J., Medwig-Kinney, T. N., et al. (2020). Visualizing the metazoan proliferationquiescence decision in vivo. Elife 9:e63265. doi: 10.7554/eLife.63265

Agalioti, T., Chen, G., and Thanos, D. (2002). Deciphering the transcriptional histone acetylation code for a human gene. Cell 111, 381-392.

Allen, C., Büttner, S., Aragon, A. D., Thomas, J. A., Meirelles, O., Jaetao, J. E., et al. (2006). Isolation of quiescent and nonquiescent cells from yeast stationaryphase cultures. J. Cell Biol. 174, 89-100.

Allfrey, V. G., Faulkner, R., and Mirsky, A. E. (1964). Acetylation and methylation of histones and their possible role in the regulation of Rna synthesis. Proc. Natl. Acad. Sci. U.S.A. 51, 786-794.

Allis, C. D., and Jenuwein, T. (2016). The molecular hallmarks of epigenetic control. Nat. Rev. Genet. 17, 487-500.

Armache, A., Yang, S., Martinez de Paz, A., Robbins, L. E., Durmaz, C., Cheong, J. Q., et al. (2020). Histone H3.3 phosphorylation amplifies stimulation-induced transcription. Nature 583, 852-857. doi: 10.1038/s41586-020-2533-0

Atlasi, Y., Megchelenbrink, W., Peng, T., Habibi, E., Joshi, O., Wang, S. Y., et al. (2019). Epigenetic modulation of a hardwired 3D chromatin landscape in two naive states of pluripotency. Nat. Cell Biol. 21, 568-578.

Bannister, A. J., and Kouzarides, T. (2011). Regulation of chromatin by histone modifications. Cell Res. 21, 381-395.

Bannister, A. J., Zegerman, P., Partridge, J. F., Miska, E. A., Thomas, J. O., Allshire, R. C., et al. (2001). Selective recognition of methylated lysine 9 on histone H3 by the HP1 chromo domain. Nature 410, 120-124.

Barbieri, M., Xie, S. Q., Torlai Triglia, E., Chiariello, A. M., Bianco, S., de Santiago, I., et al. (2017). Active and poised promoter states drive folding of the extended HoxB locus in mouse embryonic stem cells. Nat. Struct. Mol. Biol. 24, 515-524. doi: $10.1038 / \mathrm{nsmb} .3402$

Barker, N., van Es, J. H., Kuipers, J., Kujala, P., van den Born, M., Cozijnsen, M., et al. (2007). Identification of stem cells in small intestine and colon by marker gene Lgr5. Nature 449, 1003-1007.

Barnes, C. E., English, D. M., and Cowley, S. M. (2019). Acetylation \& Co: an expanding repertoire of histone acylations regulates chromatin and transcription. Essays Biochem. 63, 97-107.

Barski, A., Cuddapah, S., Cui, K., Roh, T. Y., Schones, D. E., Wang, Z., et al. (2007). High-resolution profiling of histone methylations in the human genome. Cell $129,823-837$.

Bartolomei, M. S. (2009). Genomic imprinting: employing and avoiding epigenetic processes. Genes Dev. 23, 2124-2133. doi: 10.1101/gad.1841409

Basak, O., Krieger, T. G., Muraro, M. J., Wiebrands, K., Stange, D. E., FriasAldeguer, J., et al. (2018). Troy+ brain stem cells cycle through quiescence and regulate their number by sensing niche occupancy. Proc. Natl. Acad. Sci. U.S.A. 115, E610-E619. doi: 10.1073/pnas.1715911114

Batista, P. J., and Chang, H. Y. (2013). Long noncoding RNAs: cellular address codes in development and disease. Cell 152, 1298-1307.

Baxter, J., Sauer, S., Peters, A., John, R., Williams, R., Caparros, M. L., et al. (2004). Histone hypomethylation is an indicator of epigenetic plasticity in quiescent lymphocytes. EMBO J. 23, 4462-4472. doi: 10.1038/sj.emboj.760 0414

Beck, D. B., Oda, H., Shen, S. S., and Reinberg, D. (2012). PR-Set7 and H4K20me1: at the crossroads of genome integrity, cell cycle, chromosome condensation, and transcription. Genes Dev. 26, 325-337. doi: 10.1101/gad.177444.111

Ben Hassine, S., and Arcangioli, B. (2009). Tdp1 protects against oxidative DNA damage in non-dividing fission yeast. EMBO J. 28, 632-640.

Benetti, R., Gonzalo, S., Jaco, I., Schotta, G., Klatt, P., Jenuwein, T., et al. (2007). Suv4-20h deficiency results in telomere elongation and derepression of telomere recombination. J. Cell Biol. 178, 925-936. doi: 10.1083/jcb.200703081

Bernhart, S. H., Kretzmer, H., Holdt, L. M., Juhling, F., Ammerpohl, O., Bergmann, A. K., et al. (2016). Changes of bivalent chromatin coincide with increased expression of developmental genes in cancer. Sci. Rep. 6:37393. doi: 10.1038/ srep37393

Bernstein, B. E., Mikkelsen, T. S., Xie, X., Kamal, M., Huebert, D. J., Cuff, J., et al. (2006). A bivalent chromatin structure marks key developmental genes in embryonic stem cells. Cell 125, 315-326.

Bhattacharya, S., Levy, M. J., Zhang, N., Li, H., Florens, L., Washburn, M. P., et al. (2021). The methyltransferase SETD2 couples transcription and splicing by engaging mRNA processing factors through its SHI domain. Nat. Commun. 12:1443. doi: 10.1038/s41467-021-2 1663-w

Bierhoff, H., Dammert, M. A., Brocks, D., Dambacher, S., Schotta, G., and Grummt, I. (2014). Quiescence-induced LncRNAs trigger H4K20 trimethylation and transcriptional silencing. Mol. Cell 54, 675-682. doi: 10.1016/j.molcel.2014. 03.032

Bierhoff, H., Schmitz, K., Maass, F., Ye, J., and Grummt, I. (2010). Noncoding transcripts in sense and antisense orientation regulate the epigenetic state of ribosomal RNA genes. Cold Spring Harb. Symp. Quant. Biol. 75, 357-364. doi: $10.1101 /$ sqb.2010.75.060

Bjornson, C. R., Cheung, T. H., Liu, L., Tripathi, P. V., Steeper, K. M., and Rando, T. A. (2012). Notch signaling is necessary to maintain quiescence in adult muscle stem cells. Stem Cells 30, 232-242.

Black, J. C., Van Rechem, C., and Whetstine, J. R. (2012). Histone lysine methylation dynamics: establishment, regulation, and biological impact. Mol. Cell 48, 491-507.

Blackledge, N. P., Farcas, A. M., Kondo, T., King, H. W., McGouran, J. F., Hanssen, L. L. P., et al. (2014). Variant PRC1 complex-dependent H2A ubiquitylation drives PRC2 recruitment and polycomb domain formation. Cell 157, 14451459. doi: 10.1016/j.cell.2014.05.004

Boonsanay, V., Zhang, T., Georgieva, A., Kostin, S., Qi, H., Yuan, X., et al. (2016). Regulation of skeletal muscle stem cell quiescence by Suv4-20h1-dependent facultative heterochromatin formation. Cell Stem Cell 18, 229-242. doi: 10. 1016/j.stem.2015.11.002

Boroviak, T., Loos, R., Bertone, P., Smith, A., and Nichols, J. (2014). The ability of inner-cell-mass cells to self-renew as embryonic stem cells is acquired following epiblast specification. Nat. Cell Biol. 16, 516-528. doi: 10.1038/ncb 2965

Bousard, A., Raposo, A. C., Zylicz, J. J., Picard, C., Pires, V. B., Qi, Y., et al. (2019). The role of Xist-mediated Polycomb recruitment in the initiation of X-chromosome inactivation. EMBO Rep. 20:e48019. doi: 10.15252/embr. 201948019

Bridger, J. M., Boyle, S., Kill, I. R., and Bickmore, W. A. (2000). Remodelling of nuclear architecture in quiescent and senescent human fibroblasts. Curr. Biol. 10, 149-152. doi: 10.1016/s0960-9822(00)00 $312-2$

Cai, L., Sutter, B. M., Li, B., and Tu, B. P. (2011). Acetyl-CoA induces cell growth and proliferation by promoting the acetylation of histones at growth genes. Mol. Cell 42, 426-437. doi: 10.1016/j.molcel.2011.05.004

Carvalho, S., Raposo, A. C., Martins, F. B., Grosso, A. R., Sridhara, S. C., Rino, J., et al. (2013). Histone methyltransferase SETD2 coordinates FACT recruitment with nucleosome dynamics during transcription. Nucleic Acids Res. 41, 28812893. doi: $10.1093 /$ nar/gks 1472

Centore, R. C., Havens, C. G., Manning, A. L., Li, J. M., Flynn, R. L., Tse, A., et al. (2010). CRL4(Cdt2)-mediated destruction of the histone methyltransferase Set8 prevents premature chromatin compaction in S phase. Mol. Cell 40, 22-33. doi: 10.1016/j.molcel.2010.09.015

Champagne, K. S., and Kutateladze, T. G. (2009). Structural insight into histone recognition by the ING PHD fingers. Curr. Drug Targets 10, 432-441. doi: $10.2174 / 138945009788185040$

Chang, H. Y., Chi, J. T., Dudoit, S., Bondre, C., van de Rijn, M., Botstein, D., et al. (2002). Diversity, topographic differentiation, and positional memory in human fibroblasts. Proc. Natl. Acad. Sci. U.S.A. 99, 12877-12882.

Cheedipudi, S., Puri, D., Saleh, A., Gala, H. P., Rumman, M., Pillai, M. S., et al. (2015). A fine balance: epigenetic control of cellular quiescence by the tumor suppressor PRDM2/RIZ at a bivalent domain in the cyclin a gene. Nucleic Acids Res. 43, 6236-6256. doi: 10.1093/nar/gkv567

Cheung, T. H., and Rando, T. A. (2013). Molecular regulation of stem cell quiescence. Nat. Rev. Mol. Cell Biol. 14, 329-340. 
Cheung, T. H., Quach, N. L., Charville, G. W., Liu, L., Park, L., Edalati, A., et al. (2012). Maintenance of muscle stem-cell quiescence by microRNA-489. Nature 482, 524-528. doi: 10.1038/nature 10834

Chi, P., Allis, C. D., and Wang, G. G. (2010). Covalent histone modificationsmiswritten, misinterpreted and mis-erased in human cancers. Nat. Rev. Cancer 10, 457-469. doi: 10.1038/nrc2876

Chiu, N., and Baserga, R. (1975). Changes in template activity and structure of nuclei from WI-38 cells in the prereplicative phase. Biochemistry 14, 3126-3132. doi: 10.1021/bi00685a014

Chu, D., and Barnes, D. J. (2016). The lag-phase during diauxic growth is a tradeoff between fast adaptation and high growth rate. Sci. Rep. 6:25191. doi: 10 . $1038 /$ srep 25191

Coller, H. A. (2019a). Regulation of cell cycle entry and exit: a single cell perspective. Compr. Physiol. 10, 317-344. doi: 10.1002/cphy.c190014

Coller, H. A. (2019b). The paradox of metabolism in quiescent stem cells. FEBS Lett. 593, 2817-2839.

Coller, H. A., Sang, L., and Roberts, J. M. (2006). A new description of cellular quiescence. PLoS Biol. 4:e83. doi: 10.1371/journal.pbio.004 0083

Cooper, S., Dienstbier, M., Hassan, R., Schermelleh, L., Sharif, J., Blackledge, N. P., et al. (2014). Targeting polycomb to pericentric heterochromatin in embryonic stem cells reveals a role for H2AK119u1 in PRC2 recruitment. Cell Rep. 7, 1456-1470. doi: 10.1016/j.celrep.2014.04.012

Coppock, D. L., Kopman, C., Scandalis, S., and Gilleran, S. (1993). Preferential gene expression in quiescent human lung fibroblasts. Cell Growth Differ. 4, 483-493.

Cornett, E. M., Ferry, L., Defossez, P. A., and Rothbart, S. B. (2019). Lysine methylation regulators moonlighting outside the epigenome. Mol. Cell 75, 1092-1101. doi: 10.1016/j.molcel.2019.08.026

Cortini, R. (2016). The physics of epigenetics. Rev. Modern Phys. 88:025002.

Corvalan, A. Z., and Coller, H. A. (2021). Methylation of histone 4's lysine 20: a critical analysis of the state of the field. Physiol. Genomics 53, 22-32. doi: 10.1152/physiolgenomics.00128.2020

Cosgrove, M. S. (2012). Writers and readers: deconvoluting the harmonic complexity of the histone code. Nat. Struct. Mol. Biol. 19, 739-740. doi: 10.1038/nsmb.2350

Cosgrove, M. S., Boeke, J. D., and Wolberger, C. (2004). Regulated nucleosome mobility and the histone code. Nat. Struct. Mol. Biol. 11, 1037-1043. doi: $10.1038 / \mathrm{nsmb} 851$

Criscione, S. W., De Cecco, M., Siranosian, B., Zhang, Y., Kreiling, J. A., Sedivy, J. M., et al. (2016). Reorganization of chromosome architecture in replicative cellular senescence. Sci. Adv. 2:e1500882.

Crump, N. T., Hazzalin, C. A., Bowers, E. M., Alani, R. M., Cole, P. A., and Mahadevan, L. C. (2011). Dynamic acetylation of all lysine- 4 trimethylated histone $\mathrm{H} 3$ is evolutionarily conserved and mediated by p300/CBP. Proc. Natl. Acad. Sci. U.S.A. 108, 7814-7819. doi: 10.1073/pnas.1100099108

Cui, K., Zang, C., Roh, T. Y., Schones, D. E., Childs, R. W., Peng, W., et al. (2009). Chromatin signatures in multipotent human hematopoietic stem cells indicate the fate of bivalent genes during differentiation. Cell Stem Cell 4, 80-93. doi: 10.1016/j.stem.2008.11.011

Cutter, A. R., and Hayes, J. J. (2015). A brief review of nucleosome structure. FEBS Lett. 589, 2914-2922.

Dai, J., Itahana, K., and Baskar, R. (2015). Quiescence does not affect p53 and stress response by irradiation in human lung fibroblasts. Biochem. Biophys. Res. Commun. 458, 104-109.

Daniel, J. A., and Nussenzweig, A. (2012). Roles for histone H3K4 methyltransferase activities during immunoglobulin class-switch recombination. Biochim. Biophys. Acta 1819, 733-738.

Dardick, I., Sinnott, N. M., Hall, R., Bajenko-Carr, T. A., and Setterfield, G. (1983). Nuclear morphology and morphometry of B-lymphocyte transformation. Implications for follicular center cell lymphomas. Am. J. Pathol. 111, 35-49.

De Virgilio, C. (2012). The essence of yeast quiescence. FEMS Microbiol. Rev. 36, 306-339.

DeChiara, T. M., Robertson, E. J., and Efstratiadis, A. (1991). Parental imprinting of the mouse insulin-like growth factor II gene. Cell 64, 849-859.

Deng, Z., Norseen, J., Wiedmer, A., Riethman, H., and Lieberman, P. M. (2009). TERRA RNA binding to TRF2 facilitates heterochromatin formation and ORC recruitment at telomeres. Mol. Cell 35, 403-413. doi: 10.1016/j.molcel.2009. 06.025
DesJarlais, R., and Tummino, P. J. (2016). Role of histone-modifying enzymes and their complexes in regulation of chromatin biology. Biochemistry 55, 1584-1599.

Dhawan, J., and Laxman, S. (2015). Decoding the stem cell quiescence cyclelessons from yeast for regenerative biology. J. Cell Sci. 128, 4467-4474. doi: $10.1242 /$ jcs. 177758

Dixon, J. R., Selvaraj, S., Yue, F., Kim, A., Li, Y., Shen, Y., et al. (2012). Topological domains in mammalian genomes identified by analysis of chromatin interactions. Nature 485, 376-380.

Doil, C., Mailand, N., Bekker-Jensen, S., Menard, P., Larsen, D. H., Pepperkok, R., et al. (2009). RNF168 binds and amplifies ubiquitin conjugates on damaged chromosomes to allow accumulation of repair proteins. Cell 136, 435-446. doi: 10.1016/j.cell.2008.12.041

Duina, A. A., Miller, M. E., and Keeney, J. B. (2014). Budding yeast for budding geneticists: a primer on the Saccharomyces cerevisiae model system. Genetics 197, 33-48.

Dumont, N. A., Wang, Y. X., and Rudnicki, M. A. (2015). Intrinsic and extrinsic mechanisms regulating satellite cell function. Development 142, 1572-1581.

Dykstra, B., Kent, D., Bowie, M., McCaffrey, L., Hamilton, M., Lyons, K., et al. (2007). Long-term propagation of distinct hematopoietic differentiation programs in vivo. Cell Stem Cell 1, 218-229. doi: 10.1016/j.stem.2007. 05.015

Edwards, C. R., Dang, W., and Berger, S. L. (2011). Histone H4 lysine 20 of Saccharomyces cerevisiae is monomethylated and functions in subtelomeric silencing. Biochemistry 50, 10473-10483. doi: 10.1021/bi201120q

Egelhofer, T. A., Minoda, A., Klugman, S., Lee, K., Kolasinska-Zwierz, P., Alekseyenko, A. A., et al. (2011). An assessment of histone-modification antibody quality. Nat. Struct. Mol. Biol. 18, 91-93.

Eriksson, P. R., Ganguli, D., Nagarajavel, V., and Clark, D. J. (2012). Regulation of histone gene expression in budding yeast. Genetics 191, 7-20.

Ernst, J., and Kellis, M. (2010). Discovery and characterization of chromatin states for systematic annotation of the human genome. Nat. Biotechnol. 28, 817-825.

Evertts, A. G., Manning, A. L., Wang, X., Dyson, N. J., Garcia, B. A., and Coller, H. A. (2013a). H4K20 methylation regulates quiescence and chromatin compaction. Mol. Biol. Cell 24, 3025-3037.

Evertts, A. G., Zee, B. M., Dimaggio, P. A., Gonzales-Cope, M., Coller, H. A., and Garcia, B. A. (2013b). Quantitative dynamics of the link between cellular metabolism and histone acetylation. J. Biol. Chem. 288, 12142-12151.

Faghihi, M. A., and Wahlestedt, C. (2009). Regulatory roles of natural antisense transcripts. Nat. Rev. Mol. Cell Biol. 10, 637-643.

Fang, J., Feng, Q., Ketel, C. S., Wang, H., Cao, R., Xia, L., et al. (2002). Purification and functional characterization of SET8, a nucleosomal histone H4-lysine 20specific methyltransferase. Curr. Biol. 12, 1086-1099. doi: 10.1016/s09609822(02)00924-7

Farooq, Z., Banday, S., Pandita, T. K., and Altaf, M. (2016). The many faces of histone H3K79 methylation. Mutat. Res. Rev. Mutat. Res. 768, 46-52. doi: 10.1016/j.mrrev.2016.03.005

Farrelly, L. A., and Maze, I. (2019). An emerging perspective on 'histone code' mediated regulation of neural plasticity and disease. Curr. Opin. Neurobiol. 59, 157-163. doi: 10.1016/j.conb.2019.07.001

Farrelly, L. A., Thompson, R. E., Zhao, S., Lepack, A. E., Lyu, Y., Bhanu, N. V., et al. (2019). Histone serotonylation is a permissive modification that enhances TFIID binding to H3K4me3. Nature 567, 535-539. doi: 10.1038/s41586-0191024-7

Finley, L. W. S., Vardhana, S. A., Carey, B. W., Alonso-Curbelo, D., Koche, R., Chen, Y., et al. (2018). Pluripotency transcription factors and Tet1/2 maintain Brd4-independent stem cell identity. Nat. Cell Biol. 20, 565-574. doi: 10.1038/ s41556-018-0086-3

Foudi, A., Hochedlinger, K., Van Buren, D., Schindler, J. W., Jaenisch, R., Carey, V., et al. (2009). Analysis of histone 2B-GFP retention reveals slowly cycling hematopoietic stem cells. Nat. Biotechnol. 27, 84-90. doi: 10.1038/nbt. 1517

Frauwirth, K. A., and Thompson, C. B. (2004). Regulation of T lymphocyte metabolism. J. Immunol. 172, 4661-4665.

Frederiks, F., Tzouros, M., Oudgenoeg, G., van Welsem, T., Fornerod, M., Krijgsveld, J., et al. (2008). Nonprocessive methylation by Dotl leads to 
functional redundancy of histone H3K79 methylation states. Nat. Struct. Mol. Biol. 15, 550-557. doi: 10.1038/nsmb.1432

Freese, E. B., Chu, M. I., and Freese, E. (1982). Initiation of yeast sporulation of partial carbon, nitrogen, or phosphate deprivation. J. Bacteriol. 149, 840-851.

Fu, Y., Zhu, Z., Meng, G., Zhang, R., and Zhang, Y. (2021). A CRISPRCas9 based shuffle system for endogenous histone $\mathrm{H} 3$ and $\mathrm{H} 4$ combinatorial mutagenesis. Sci. Rep. 11:3298. doi: 10.1038/s41598-021-82 774-4

Fuchs, S. M., Krajewski, K., Baker, R. W., Miller, V. L., and Strahl, B. D. (2011). Influence of combinatorial histone modifications on antibody and effector protein recognition. Curr. Biol. 21, 53-58. doi: 10.1016/j.cub.2010.11.058

Fukada, S., Uezumi, A., Ikemoto, M., Masuda, S., Segawa, M., Tanimura, N., et al. (2007). Molecular signature of quiescent satellite cells in adult skeletal muscle. Stem Cells 25, 2448-2459.

Fyodorov, D. V., Zhou, B. R., Skoultchi, A. I., and Bai, Y. (2018). Emerging roles of linker histones in regulating chromatin structure and function. Nat. Rev. Mol. Cell Biol. 19, 192-206.

Gaertner, B., Johnston, J., Chen, K., Wallaschek, N., Paulson, A., Garruss, A. S., et al. (2012). Poised RNA polymerase II changes over developmental time and prepares genes for future expression. Cell Rep. 2, 1670-1683. doi: 10.1016/j. celrep.2012.11.024

Galdieri, L., Mehrotra, S., Yu, S., and Vancura, A. (2010). Transcriptional regulation in yeast during diauxic shift and stationary phase. OMICS 14, 629-638.

Gangloff, S., Achaz, G., Francesconi, S., Villain, A., Miled, S., Denis, C., et al. (2017). Quiescence unveils a novel mutational force in fission yeast. Elife 6:e27469. doi: 10.7554/eLife. 27469

Gangloff, S., and Arcangioli, B. (2017). DNA repair and mutations during quiescence in yeast. FEMS Yeast Res. 17:fox002.

Garza, L. A., Yang, C. C., Zhao, T., Blatt, H. B., Lee, M., He, H., et al. (2011). Bald scalp in men with androgenetic alopecia retains hair follicle stem cells but lacks CD200-rich and CD34-positive hair follicle progenitor cells. J. Clin. Invest. 121, 613-622. doi: 10.1172/JCI44478

Ghoneim, M., Fuchs, H. A., and Musselman, C. A. (2021). Histone tail conformations: a fuzzy affair with DNA. Trends Biochem. Sci. 46, 564-578. doi: $10.1016 /$ j.tibs.2020.12.012

Godfrey, L., Crump, N. T., Thorne, R., Lau, I. J., Repapi, E., Dimou, D., et al. (2019). DOT1L inhibition reveals a distinct subset of enhancers dependent on H3K79 methylation. Nat. Commun. 10:2803. doi: 10.1038/s41467-01910844-3

Godley, L. A., and Le Beau, M. M. (2012). The histone code and treatments for acute myeloid leukemia. N. Engl. J. Med. 366, 960-961.

Gray, J. V., Petsko, G. A., Johnston, G. C., Ringe, D., Singer, R. A., and Werner-Washburne, M. (2004). "Sleeping beauty": quiescence in Saccharomyces cerevisiae. Microbiol. Mol. Biol. Rev. 68, 187-206.

Greer, E. L., and Shi, Y. (2012). Histone methylation: a dynamic mark in health, disease and inheritance. Nat. Rev. Genet. 13, 343-357. doi: 10.1038/nrg3173

Greig, D. (2009). Reproductive isolation in Saccharomyces. Heredity (Edinb) 102, $39-44$.

Grigoryev, S. A., Nikitina, T., Pehrson, J. R., Singh, P. B., and Woodcock, C. L. (2004). Dynamic relocation of epigenetic chromatin markers reveals an active role of constitutive heterochromatin in the transition from proliferation to quiescence. J. Cell Sci. 117(Pt 25), 6153-6162. doi: 10.1242/cs. 01537

Guan, X., Rastogi, N., Parthun, M. R., and Freitas, M. A. (2013). Discovery of histone modification crosstalk networks by stable isotope labeling of amino acids in cell culture mass spectrometry (SILAC MS). Mol. Cell. Proteomics 12, 2048-2059. doi: 10.1074/mcp.M112.026716

Guidi, M., Ruault, M., Marbouty, M., Loiodice, I., Cournac, A., Billaudeau, C., et al. (2015). Spatial reorganization of telomeres in long-lived quiescent cells. Genome Biol. 16:206. doi: 10.1186/s13059-015-0766-2

Guttman, M., Donaghey, J., Carey, B. W., Garber, M., Grenier, J. K., Munson, G., et al. (2011). lincRNAs act in the circuitry controlling pluripotency and differentiation. Nature 477, 295-300.

Hahn, M., Dambacher, S., Dulev, S., Kuznetsova, A. Y., Eck, S., Wörz, S., et al. (2013). Suv4-20h2 mediates chromatin compaction and is important for cohesin recruitment to heterochromatin. Genes Dev. 27, 859-872. doi: $10.1101 /$ gad.210377.112
Hainer, S. J., and Fazzio, T. G. (2019). High-Resolution chromatin profiling using CUT\&RUN. Curr. Protoc. Mol. Biol. 126:e85.

Hanly, D. J., Esteller, M., and Berdasco, M. (2018). Interplay between long noncoding RNAs and epigenetic machinery: emerging targets in cancer? Philos. Trans. R. Soc. Lond. B Biol. Sci. 373:20170074. doi: 10.1098/rstb.2017.0074

Hansen, K. H., Bracken, A. P., Pasini, D., Dietrich, N., Gehani, S. S., Monrad, A., et al. (2008). A model for transmission of the H3K27me3 epigenetic mark. Nat. Cell Biol. 10, 1291-1300. doi: 10.1038/ncb1787

Hayashi, T., Teruya, T., Chaleckis, R., Morigasaki, S., and Yanagida, M. (2018). S-Adenosylmethionine synthetase is required for cell growth, maintenance of G0 phase, and termination of quiescence in fission yeast. iScience 5, 38-51. doi: $10.1016 /$ j.isci.2018.06.011

Hayashi-Takanaka, Y., Kina, Y., Nakamura, F., Becking, L. E., Nakao, Y., Nagase, T., et al. (2020). Histone modification dynamics as revealed by multicolor immunofluorescence-based single-cell analysis. J. Cell Sci. 133, doi: 10.1242/ jcs. 243444

Henikoff, S., and Shilatifard, A. (2011). Histone modification: cause or cog? Trends Genet. 27, 389-396.

Higuchi-Sanabria, R., Pernice, W. M., Vevea, J. D., Alessi Wolken, D. M., Boldogh, I. R., and Pon, L. A. (2014). Role of asymmetric cell division in lifespan control in Saccharomyces cerevisiae. FEMS Yeast Res. 14, 1133-1146.

Ho, C. H., Takizawa, Y., Kobayashi, W., Arimura, Y., Kimura, H., and Kurumizaka, H. (2021). Structural basis of nucleosomal histone H4 lysine 20 methylation by SET8 methyltransferase. Life Sci. Alliance 4:e202000919.

Ho, J. W., Jung, Y. L., Liu, T., Alver, B. H., Lee, S., Ikegami, K., et al. (2014). Comparative analysis of metazoan chromatin organization. Nature 512, 449-452.

Hornbeck, P. V., Zhang, B., Murray, B., Kornhauser, J. M., Latham, V., and Skrzypek, E. (2015). PhosphoSitePlus, 2014: mutations, PTMs and recalibrations. Nucleic Acids Res. 43, D512-D520. doi: 10.1093/nar/gku1267

Huang, J., Gujar, M. R., Deng, Q., Sook, Y. C., Li, S., Tan, P., et al. (2021). Histone lysine methyltransferase Pr-set7/SETD8 promotes neural stem cell reactivation. EMBO Rep. 2021:e50994. doi: 10.15252/embr.20205 0994

Huen, M. S., Grant, R., Manke, I., Minn, K., Yu, X., Yaffe, M. B., et al. (2007). RNF8 transduces the DNA-damage signal via histone ubiquitylation and checkpoint protein assembly. Cell 131, 901-914. doi: 10.1016/j.cell.2007. 09.041

Husmann, D., and Gozani, O. (2019). Histone lysine methyltransferases in biology and disease. Nat. Struct. Mol. Biol. 26, 880-889.

Hyun, K., Jeon, J., Park, K., and Kim, J. (2017). Writing, erasing and reading histone lysine methylations. Exp. Mol. Med. 49:e324.

Jambhekar, A., Dhall, A., and Shi, Y. (2019). Roles and regulation of histone methylation in animal development. Nat. Rev. Mol. Cell Biol. 20, 625-641.

Jamieson, K., Rountree, M. R., Lewis, Z. A., Stajich, J. E., and Selker, E. U. (2013). Regional control of histone H3 lysine 27 methylation in Neurospora. Proc. Natl. Acad. Sci. U.S.A. 110, 6027-6032.

Jenuwein, T., and Allis, C. D. (2001). Translating the histone code. Science 293, 1074-1080

Joh, R. I., Khanduja, J. S., Calvo, I. A., Mistry, M., Palmieri, C. M., Savol, A. J., et al. (2016). Survival in quiescence requires the euchromatic deployment of Clr4/SUV39H by argonaute-associated small RNAs. Mol. Cell 64, 1088-1101. doi: 10.1016/j.molcel.2016.11.020

Johnson, E. L., Robinson, D. G., and Coller, H. A. (2017). Widespread changes in mRNA stability contribute to quiescence-specific gene expression patterns in a fibroblast model of quiescence. BMC Genomics 18:123. doi: 10.1186/s12864017-3521-0

Jorgensen, S., Elvers, I., Trelle, M. B., Menzel, T., Eskildsen, M., Jensen, O. N., et al. (2007). The histone methyltransferase SET8 is required for S-phase progression. J. Cell Biol. 179, 1337-1345. doi: 10.1083/jcb.200706150

Jorgensen, S., Schotta, G., and Sorensen, C. S. (2013). Histone H4 lysine 20 methylation: key player in epigenetic regulation of genomic integrity. Nucleic Acids Res. 41, 2797-2806. doi: 10.1093/nar/gkt012

Julien, E., and Herr, W. (2004). A switch in mitotic histone H4 lysine 20 methylation status is linked to M phase defects upon loss of HCF-1. Mol. Cell 14, 713-725. doi: 10.1016/j.molcel.2004.06.008

Kaelin, W. G. Jr., and McKnight, S. L. (2013). Influence of metabolism on epigenetics and disease. Cell 153, 56-69. 
Kalakonda, N., Fischle, W., Boccuni, P., Gurvich, N., Hoya-Arias, R., Zhao, X., et al. (2008). Histone $\mathrm{H} 4$ lysine 20 monomethylation promotes transcriptional repression by L3MBTL1. Oncogene 27, 4293-4304. doi: 10.1038/onc.2008.67

Kalamakis, G., Brune, D., Ravichandran, S., Bolz, J., Fan, W., Ziebell, F., et al. (2019). Quiescence modulates stem cell maintenance and regenerative capacity in the aging brain. Cell 176, 1407-19.e14. doi: 10.1016/j.cell.2019. 01.040

Kalb, R., Latwiel, S., Baymaz, H. I., Jansen, P. W., Muller, C. W., Vermeulen, M., et al. (2014). Histone H2A monoubiquitination promotes histone H3 methylation in Polycomb repression. Nat. Struct. Mol. Biol. 21, 569-571.

Kallingappa, P. K., Turner, P. M., Eichenlaub, M. P., Green, A. L., Oback, F. C., Chibnall, A. M., et al. (2016). Quiescence loosens epigenetic constraints in bovine somatic cells and improves their reprogramming into totipotency. Biol. Reprod. 95:16. doi: 10.1095/biolreprod.115.137109

Kang, S., Long, K., Wang, S., Sada, A., and Tumbar, T. (2020). Histone H3 K4/9/27 trimethylation levels affect wound healing and stem cell dynamics in adult skin. Stem Cell Rep. 14, 34-48. doi: 10.1016/j.stemcr.2019.11.007

Kantidakis, T., Saponaro, M., Mitter, R., Horswell, S., Kranz, A., Boeing, S., et al. (2016). Mutation of cancer driver MLL2 results in transcription stress and genome instability. Genes Dev. 30, 408-420. doi: 10.1101/gad.275453.115

Kaya-Okur, H. S., Wu, S. J., Codomo, C. A., Pledger, E. S., Bryson, T. D., Henikoff, J. G., et al. (2019). CUT\&Tag for efficient epigenomic profiling of small samples and single cells. Nat. Commun. 10:1930.

Kent, D., Dykstra, B., and Eaves, C. (2007). Isolation and assessment of long-term reconstituting hematopoietic stem cells from adult mouse bone marrow. Curr. Protoc. Stem Cell Biol. Chapter 2:Unit 2A.4.

Kharchenko, P. V., Alekseyenko, A. A., Schwartz, Y. B., Minoda, A., Riddle, N. C., Ernst, J., et al. (2011). Comprehensive analysis of the chromatin landscape in Drosophila melanogaster. Nature 471, 480-485.

Khoa, L. T. P., Tsan, Y. C., Mao, F., Kremer, D. M., Sajjakulnukit, P., Zhang, L., et al. (2020). Histone acetyltransferase MOF blocks acquisition of quiescence in ground-state ESCs through activating fatty acid oxidation. Cell Stem Cell 27, 441-458.e10. doi: 10.1016/j.stem.2020.06.005

Kim, S. K., Jung, I., Lee, H., Kang, K., Kim, M., Jeong, K., et al. (2012). Human histone H3K79 methyltransferase DOT1L protein [corrected] binds actively transcribing RNA polymerase II to regulate gene expression. J. Biol. Chem. 287, 39698-39709. doi: 10.1074/jbc.M112.384057

Kim, T. D., Shin, S., Berry, W. L., Oh, S., and Janknecht, R. (2012). The JMJD2A demethylase regulates apoptosis and proliferation in colon cancer cells. J. Cell. Biochem. 113, 1368-1376. doi: 10.1002/jcb.24009

Klose, R. J., Yan, Q., Tothova, Z., Yamane, K., Erdjument-Bromage, H., Tempst, P., et al. (2007). The retinoblastoma binding protein RBP2 is an H3K4 demethylase. Cell 128, 889-900.

Knosp, O., Talasz, H., and Puschendorf, B. (1991). Histone acetylation and histone synthesis in mouse fibroblasts during quiescence and restimulation into S-phase. Mol. Cell. Biochem. 101, 51-58. doi: 10.1007/BF00238437

Kohlmaier, A., Savarese, F., Lachner, M., Martens, J., Jenuwein, T., and Wutz, A. (2004). A chromosomal memory triggered by Xist regulates histone methylation in X inactivation. PLoS Biol. 2:E171. doi: 10.1371/journal.pbio. 0020171

Kolas, N. K., Chapman, J. R., Nakada, S., Ylanko, J., Chahwan, R., Sweeney, F. D., et al. (2007). Orchestration of the DNA-damage response by the RNF8 ubiquitin ligase. Science 318, 1637-1640.

Kornberg, R. D., and Lorch, Y. (2020). Primary role of the nucleosome. Mol. Cell $79,371-375$.

Kourmouli, N., Jeppesen, P., Mahadevhaiah, S., Burgoyne, P., Wu, R., Gilbert, D. M., et al. (2004). Heterochromatin and tri-methylated lysine 20 of histone H4 in animals. J. Cell Sci. 117(Pt 12), 2491-2501.

Kurumizaka, H., Kujirai, T., and Takizawa, Y. (2021). Contributions of histone variants in nucleosome structure and function. J. Mol. Biol. 433:166678.

Kwon, J. S., Everetts, N. J., Wang, X., Wang, W., Della Croce, K., Xing, J., et al. (2017). Controlling depth of cellular quiescence by an Rb-E2F network switch. Cell Rep. 20, 3223-3235. doi: 10.1016/j.celrep.2017.09.007

Lachner, M., O'Carroll, D., Rea, S., Mechtler, K., and Jenuwein, T. (2001). Methylation of histone H3 lysine 9 creates a binding site for HP1 proteins. Nature 410, 116-120.
Lacoste, N., Utley, R. T., Hunter, J. M., Poirier, G. G., and Cote, J. (2002). Disruptor of telomeric silencing- 1 is a chromatin-specific histone $\mathrm{H} 3$ methyltransferase. J. Biol. Chem. 277, 30421-30424. doi: 10.1074/jbc.C200366200

Laporte, D., Courtout, F., Tollis, S., and Sagot, I. (2016). Quiescent Saccharomyces cerevisiae forms telomere hyperclusters at the nuclear membrane vicinity through a multifaceted mechanism involving Esc1, the Sir complex, and chromatin condensation. Mol. Biol. Cell 27, 1875-1884. doi: 10.1091/mbc.E1601-0069

Laporte, D., Lebaudy, A., Sahin, A., Pinson, B., Ceschin, J., Daignan-Fornier, B., et al. (2011). Metabolic status rather than cell cycle signals control quiescence entry and exit. J. Cell Biol. 192, 949-957. doi: 10.1083/jcb.201009028

Lauberth, S. M., Nakayama, T., Wu, X., Ferris, A. L., Tang, Z., Hughes, S. H., et al. (2013). H3K4me3 interactions with TAF3 regulate preinitiation complex assembly and selective gene activation. Cell 152, 1021-1036. doi: 10.1016/j.cell. 2013.01.052

Lavarone, E., Barbieri, C. M., and Pasini, D. (2019). Dissecting the role of H3K27 acetylation and methylation in PRC2 mediated control of cellular identity. Nat. Commun. 10:1679. doi: 10.1038/s41467-019-09624-w

Lee, H. N., Mitra, M., Bosompra, O., Corney, D. C., Johnson, E. L., Rashed, N., et al. (2018). RECK isoforms have opposing effects on cell migration. Mol. Biol. Cell 29, 1825-1838.

Lee, J., Kang, S., Lilja, K. C., Colletier, K. J., Scheitz, C. J., Zhang, Y. V., et al. (2016). Signalling couples hair follicle stem cell quiescence with reduced histone H3 K4/K9/K27me3 for proper tissue homeostasis. Nat. Commun. 7:11278. doi: 10.1038/ncomms 11278

Lee, S., Oh, S., Jeong, K., Jo, H., Choi, Y., Seo, H. D., et al. (2018). Dot1 regulates nucleosome dynamics by its inherent histone chaperone activity in yeast. Nat. Commun. 9:240. doi: 10.1038/s41467-017-02759-8

Legesse-Miller, A., Raitman, I., Haley, E. M., Liao, A., Sun, L. L., Wang, D. J., et al. (2012). Quiescent fibroblasts are protected from proteasome inhibitionmediated toxicity. Mol. Biol. Cell 23, 3566-3581. doi: 10.1091/mbc.E12-030192

Lemons, J. M., Feng, X. J., Bennett, B. D., Legesse-Miller, A., Johnson, E. L., Raitman, I., et al. (2010). Quiescent fibroblasts exhibit high metabolic activity. PLoS Biol. 8:e1000514. doi: 10.1371/journal.pbio.1000514

Lesch, B. J., Dokshin, G. A., Young, R. A., McCarrey, J. R., and Page, D. C. (2013). A set of genes critical to development is epigenetically poised in mouse germ cells from fetal stages through completion of meiosis. Proc. Natl. Acad. Sci. U.S.A. 110, 16061-16066. doi: 10.1073/pnas.131520 4110

Li, J., Mahata, B., Escobar, M., Goell, J., Wang, K., Khemka, P., et al. (2021). Programmable human histone phosphorylation and gene activation using a CRISPR/Cas9-based chromatin kinase. Nat. Commun. 12:896. doi: 10.1038/ s41467-021-21188-2

Li, L., and Bhatia, R. (2011). Stem cell quiescence. Clin. Cancer Res. 17, 4936-4941. Li, L., and Clevers, H. (2010). Coexistence of quiescent and active adult stem cells in mammals. Science 327, 542-545.

Lieberman-Aiden, E., van Berkum, N. L., Williams, L., Imakaev, M., Ragoczy, T., Telling, A., et al. (2009). Comprehensive mapping of long-range interactions reveals folding principles of the human genome. Science 326, 289-293. doi: $10.1126 /$ science. 1181369

Lien, W. H., Guo, X., Polak, L., Lawton, L. N., Young, R. A., Zheng, D., et al. (2011). Genome-wide maps of histone modifications unwind in vivo chromatin states of the hair follicle lineage. Cell Stem Cell 9, 219-232. doi: 10.1016/j.stem.2011. 07.015

Liokatis, S., Stutzer, A., Elsasser, S. J., Theillet, F. X., Klingberg, R., van Rossum, B., et al. (2012). Phosphorylation of histone H3 Ser10 establishes a hierarchy for subsequent intramolecular modification events. Nat. Struct. Mol. Biol. 19, 819-823. doi: $10.1038 / \mathrm{nsmb} .2310$

Liu, L., Cheung, T. H., Charville, G. W., Hurgo, B. M., Leavitt, T., Shih, J., et al. (2013). Chromatin modifications as determinants of muscle stem cell quiescence and chronological aging. Cell Rep. 4, 189-204. doi: 10.1016/j.celrep. 2013.05.043

Liu, Y., Chen, S., Wang, S., Soares, F., Fischer, M., Meng, F., et al. (2017). Transcriptional landscape of the human cell cycle. Proc. Natl. Acad. Sci. U.S.A. $114,3473-3478$. 
Lomberk, G., Bensi, D., Fernandez-Zapico, M. E., and Urrutia, R. (2006). Evidence for the existence of an HP1-mediated subcode within the histone code. Nat. Cell Biol. 8, 407-415. doi: 10.1038/ncb 1383

Lu, X., Simon, M. D., Chodaparambil, J. V., Hansen, J. C., Shokat, K. M., and Luger, K. (2008). The effect of H3K79 dimethylation and H4K20 trimethylation on nucleosome and chromatin structure. Nat. Struct. Mol. Biol. 15, 1122-1124. doi: $10.1038 / \mathrm{nsmb} .1489$

Luo, M., Jeong, M., Sun, D., Park, H. J., Rodriguez, B. A., Xia, Z., et al. (2015). Long non-coding RNAs control hematopoietic stem cell function. Cell Stem Cell 16, $426-438$.

Lynch, M. D., and Watt, F. M. (2018). Fibroblast heterogeneity: implications for human disease. J. Clin. Invest. 128, 26-35.

Ma, D. K., Bonaguidi, M. A., Ming, G. L., and Song, H. (2009). Adult neural stem cells in the mammalian central nervous system. Cell Res. 19, 672-682.

Machida, S., Takizawa, Y., Ishimaru, M., Sugita, Y., Sekine, S., Nakayama, J. I., et al. (2018). Structural basis of heterochromatin formation by human HP1. Mol. Cell 69, 385-397.e8.

Mailand, N., Bekker-Jensen, S., Faustrup, H., Melander, F., Bartek, J., Lukas, C., et al. (2007). RNF8 ubiquitylates histones at DNA double-strand breaks and promotes assembly of repair proteins. Cell 131, 887-900.

Maki, K., Nava, M. M., Villeneuve, C., Chang, M., Furukawa, K. S., Ushida, T., et al. (2021). Hydrostatic pressure prevents chondrocyte differentiation through heterochromatin remodeling. J. Cell Sci. 134:jcs247643.

Maksimovic, I., and David, Y. (2021). Non-enzymatic covalent modifications as a new chapter in the histone code. Trends Biochem. Sci. 46, 718-730.

Marescal, O., and Cheeseman, I. M. (2020). Cellular mechanisms and regulation of quiescence. Dev. Cell 55, 259-271.

Margaritis, T., and Holstege, F. C. (2008). Poised RNA polymerase II gives pause for thought. Cell 133, 581-584. doi: 10.1016/j.cell.2008.04.027

Marguerat, S., Schmidt, A., Codlin, S., Chen, W., Aebersold, R., and Bahler, J. (2012). Quantitative analysis of fission yeast transcriptomes and proteomes in proliferating and quiescent cells. Cell 151, 671-683. doi: 10.1016/j.cell.2012. 09.019

Margueron, R., and Reinberg, D. (2011). The Polycomb complex PRC2 and its mark in life. Nature 469, 343-349.

Margueron, R., Justin, N., Ohno, K., Sharpe, M. L., Son, J., Drury, W. J. III, et al. (2009). Role of the polycomb protein EED in the propagation of repressive histone marks. Nature 461, 762-767. doi: 10.1038/nature08398

Margueron, R., Li, G., Sarma, K., Blais, A., Zavadil, J., Woodcock, C. L., et al. (2008). Ezh1 and Ezh2 maintain repressive chromatin through different mechanisms. Mol. Cell 32, 503-518.

Marion, R. M., Schotta, G., Ortega, S., and Blasco, M. A. (2011). Suv4-20h abrogation enhances telomere elongation during reprogramming and confers a higher tumorigenic potential to iPS cells. PLoS One 6:e25680. doi: 10.1371/ journal.pone.0025680

Martens, J. H., O’Sullivan, R. J., Braunschweig, U., Opravil, S., Radolf, M., Steinlein, P., et al. (2005). The profile of repeat-associated histone lysine methylation states in the mouse epigenome. EMBO J. 24, 800-812. doi: 10.1038/sj.emboj. 7600545

Martinez, M. J., Roy, S., Archuletta, A. B., Wentzell, P. D., Anna-Arriola, S. S., Rodriguez, A. L., et al. (2004). Genomic analysis of stationary-phase and exit in Saccharomyces cerevisiae: gene expression and identification of novel essential genes. Mol. Biol. Cell 15, 5295-5305. doi: 10.1091/mbc.e03-11-0856

Martinez-Reyes, I., and Chandel, N. S. (2020). Mitochondrial TCA cycle metabolites control physiology and disease. Nat. Commun. 11:102.

Martynoga, B., Mateo, J. L., Zhou, B., Andersen, J., Achimastou, A., Urban, N., et al. (2013). Epigenomic enhancer annotation reveals a key role for NFIX in neural stem cell quiescence. Genes Dev. 27, 1769-1786. doi: 10.1101/gad.216804.113

Maurer-Stroh, S., Dickens, N. J., Hughes-Davies, L., Kouzarides, T., Eisenhaber, F., and Ponting, C. P. (2003). The Tudor domain 'royal family': Tudor, plant Agenet, chromo, PWWP and MBT domains. Trends Biochem. Sci. 28, 69-74. doi: 10.1016/S0968-0004(03)00004-5

Maya-Miles, D., Andujar, E., Perez-Alegre, M., Murillo-Pineda, M., BarrientosMoreno, M., Cabello-Lobato, M. J., et al. (2019). Crosstalk between chromatin structure, cohesin activity and transcription. Epigenet. Chromatin 12, 47. doi: 10.1186/s13072-019-0293-6

McKnight, J. N., Boerma, J. W., Breeden, L. L., and Tsukiyama, T. (2015). Global promoter targeting of a conserved lysine deacetylase for transcriptional shutoff during quiescence entry. Mol. Cell 59, 732-743. doi: 10.1016/j.molcel.2015. 07.014

McMahon, S. B., Wood, M. A., and Cole, M. D. (2000). The essential cofactor TRRAP recruits the histone acetyltransferase hGCN5 to c-Myc. Mol. Cell. Biol. 20, 556-562. doi: 10.1128/MCB.20.2.556-562.2000

Mehta, I. S., Amira, M., Harvey, A. J., and Bridger, J. M. (2010). Rapid chromosome territory relocation by nuclear motor activity in response to serum removal in primary human fibroblasts. Genome Biol. 11:R5. doi: 10.1186/gb-201011-1-r5

Meng, F., Stamms, K., Bennewitz, R., Green, A., Oback, F., Turner, P., et al. (2020). Targeted histone demethylation improves somatic cell reprogramming into cloned blastocysts but not postimplantation bovine concepti†. Biol. Reprod. 103, 114-125. doi: 10.1093/biolre/ioaa053

Mews, P., Zee, B. M., Liu, S., Donahue, G., Garcia, B. A., and Berger, S. L. (2014). Histone methylation has dynamics distinct from those of histone acetylation in cell cycle reentry from quiescence. Mol. Cell. Biol. 34, 3968-3980. doi: 10.1128/MCB.00763-14

Michan, S., and Sinclair, D. (2007). Sirtuins in mammals: insights into their biological function. Biochem. J. 404, 1-13.

Mikkelsen, T. S., Ku, M., Jaffe, D. B., Issac, B., Lieberman, E., Giannoukos, G., et al. (2007). Genome-wide maps of chromatin state in pluripotent and lineage-committed cells. Nature 448, 553-560. doi: 10.1038/nature06008

Miles, S., Bradley, G. T., and Breeden, L. L. (2021). The budding yeast transition to quiescence. Yeast 38, 30-38.

Miles, S., Li, L. H., Melville, Z., and Breeden, L. L. (2019). Ssd1 and the cell wall integrity pathway promote entry, maintenance, and recovery from quiescence in budding yeast. Mol. Biol. Cell. 30, 2205-2217. doi: 10.1091/mbc.E1904-0190

Milne, T. A., Zhao, K., and Hess, J. L. (2009). Chromatin immunoprecipitation (ChIP) for analysis of histone modifications and chromatin-associated proteins. Methods Mol. Biol. 538, 409-423.

Mitra, M., Ho, L. D., and Coller, H. A. (2018a). An in vitro model of cellular quiescence in primary human dermal fibroblasts. Methods Mol. Biol. 1686, 27-47. doi: 10.1007/978-1-4939-7371-2_2

Mitra, M., Johnson, E. L., Swamy, V. S., Nersesian, L. E., Corney, D. C., Robinson, D. G., et al. (2018b). Alternative polyadenylation factors link cell cycle to migration. Genome Biol. 19:176. doi: 10.1186/s13059-0181551-9

Mochida, S., and Yanagida, M. (2006). Distinct modes of DNA damage response in S. pombe G0 and vegetative cells. Genes Cells 11, 13-27. doi: 10.1111/j.13652443.2005.00917.x

Montoya-Durango, D. E., Liu, Y., Teneng, I., Kalbfleisch, T., Lacy, M. E., Steffen, M. C., et al. (2009). Epigenetic control of mammalian LINE-1 retrotransposon by retinoblastoma proteins. Mutat. Res. 665, 20-28. doi: 10.1016/j.mrfmmm. 2009.02.011

Morgan, M. A. J., and Shilatifard, A. (2020). Reevaluating the roles of histone-modifying enzymes and their associated chromatin modifications in transcriptional regulation. Nat. Genet. 52, 1271-1281. doi: 10.1038/s41588020-00736-4

Morris, S. A., Shibata, Y., Noma, K., Tsukamoto, Y., Warren, E., Temple, B., et al. (2005). Histone H3 K36 methylation is associated with transcription elongation in Schizosaccharomyces pombe. Eukaryot. Cell 4, 1446-1454. doi: 10.1128/EC. 4.8.1446-1454.2005

Morrish, F., Noonan, J., Perez-Olsen, C., Gafken, P. R., Fitzgibbon, M., Kelleher, J., et al. (2010). Myc-dependent mitochondrial generation of acetyl-CoA contributes to fatty acid biosynthesis and histone acetylation during cell cycle entry. J. Biol. Chem. 285, 36267-36274. doi: 10.1074/jbc.M110.14 1606

Mueller, D., Bach, C., Zeisig, D., Garcia-Cuellar, M. P., Monroe, S., Sreekumar, A., et al. (2007). A role for the MLL fusion partner ENL in transcriptional elongation and chromatin modification. Blood 110, 4445-4454.

Muhl, L., Genove, G., Leptidis, S., Liu, J., He, L., Mocci, G., et al. (2020). Single-cell analysis uncovers fibroblast heterogeneity and criteria for fibroblast and mural cell identification and discrimination. Nat. Commun. 11:3953.

Murton, B. L., Chin, W. L., Ponting, C. P., and Itzhaki, L. S. (2010). Characterising the binding specificities of the subunits associated with the KMT2/Set1 histone lysine methyltransferase. J. Mol. Biol. 398, 481-488. doi: 10.1016/j.jmb.2010. 03.036 
Nakamura, T., Pluskal, T., Nakaseko, Y., and Yanagida, M. (2012). Impaired coenzyme A synthesis in fission yeast causes defective mitosis, quiescenceexit failure, histone hypoacetylation and fragile DNA. Open Biol. 2:120117. doi: 10.1098/rsob.120117

Nakamura-Ishizu, A., Takizawa, H., and Suda, T. (2014). The analysis, roles and regulation of quiescence in hematopoietic stem cells. Development 141, 4656-4666.

Nasmyth, K. (2011). Cohesin: a catenase with separate entry and exit gates? Nat. Cell Biol. 13, 1170-1177. doi: 10.1038/ncb2349

Neiman, A. M. (2011). Sporulation in the budding yeast Saccharomyces cerevisiae. Genetics 189, 737-765.

Nelson, D. M., Jaber-Hijazi, F., Cole, J. J., Robertson, N. A., Pawlikowski, J. S., Norris, K. T., et al. (2016). Mapping H4K20me3 onto the chromatin landscape of senescent cells indicates a function in control of cell senescence and tumor suppression through preservation of genetic and epigenetic stability. Genome Biol. 17:158. doi: 10.1186/s13059-016-1017-x

Ngubo, M., Kemp, G., and Patterton, H. G. (2011). Nano-electrospray tandem mass spectrometric analysis of the acetylation state of histones $\mathrm{H} 3$ and $\mathrm{H} 4$ in stationary phase in Saccharomyces cerevisiae. BMC Biochem. 12:34. doi: 10.1186/ 1471-2091-12-34

Nguyen, A. T., and Zhang, Y. (2011). The diverse functions of Dot1 and H3K79 methylation. Genes Dev. 25, 1345-1358.

Ninova, M., Fejes Toth, K., and Aravin, A. A. (2019). The control of gene expression and cell identity by H3K9 trimethylation. Development 146:dev181180.

Nishioka, K., Rice, J. C., Sarma, K., Erdjument-Bromage, H., Werner, J., Wang, Y., et al. (2002b). PR-Set7 is a nucleosome-specific methyltransferase that modifies lysine 20 of histone $\mathrm{H} 4$ and is associated with silent chromatin. Mol. Cell 9, 1201-1213. doi: 10.1016/s1097-2765(02)00548-8

Nishioka, K., Chuikov, S., Sarma, K., Erdjument-Bromage, H., Allis, C. D., Tempst, P., et al. (2002a). Set9, a novel histone H3 methyltransferase that facilitates transcription by precluding histone tail modifications required for heterochromatin formation. Genes Dev. 16, 479-489. doi: 10.1101/gad.96 7202

Norton, V. G., Imai, B. S., Yau, P., and Bradbury, E. M. (1989). Histone acetylation reduces nucleosome core particle linking number change. Cell 57, 449-457.

Nowak, J. A., Polak, L., Pasolli, H. A., and Fuchs, E. (2008). Hair follicle stem cells are specified and function in early skin morphogenesis. Cell Stem Cell 3, 33-43. doi: 10.1016/j.stem.2008.05.009

Nurse, P., and Bissett, Y. (1981). Gene required in G1 for commitment to cell cycle and in G2 for control of mitosis in fission yeast. Nature 292, 558-560.

Obernier, K., Cebrian-Silla, A., Thomson, M., Parraguez, J. I., Anderson, R., Guinto, C., et al. (2018). Adult neurogenesis is sustained by symmetric selfrenewal and differentiation. Cell Stem Cell 22, 221-234.e8.

Oda, H., Okamoto, I., Murphy, N., Chu, J., Price, S. M., Shen, M. M., et al. (2009). Monomethylation of histone H4-lysine 20 is involved in chromosome structure and stability and is essential for mouse development. Mol. Cell. Biol. 29, 2278-2295. doi: 10.1128/MCB.01768-08

O'Geen, H., Echipare, L., and Farnham, P. J. (2011). Using ChIP-seq technology to generate high-resolution profiles of histone modifications. Methods Mol. Biol. 791, 265-286.

Oya, E., Durand-Dubief, M., Cohen, A., Maksimov, V., Schurra, C., Nakayama, J. I., et al. (2019). Leol is essential for the dynamic regulation of heterochromatin and gene expression during cellular quiescence. Epigenet. Chromatin 12:45. doi: 10.1186/s13072-019-0292-7

Park, S. Y., and Kim, J. S. (2020). A short guide to histone deacetylases including recent progress on class II enzymes. Exp. Mol. Med. 52, 204-212. doi: 10.1038/ s12276-020-0382-4

Pesavento, J. J., Yang, H., Kelleher, N. L., and Mizzen, C. A. (2008). Certain and progressive methylation of histone $\mathrm{H} 4$ at lysine 20 during the cell cycle. Mol. Cell. Biol. 28, 468-486. doi: 10.1128/MCB.01517-07

Pradeepa, M. M., Grimes, G. R., Kumar, Y., Olley, G., Taylor, G. C., Schneider, R., et al. (2016). Histone $\mathrm{H} 3$ globular domain acetylation identifies a new class of enhancers. Nat. Genet. 48, 681-686. doi: 10.1038/ng.3550

Prakash, K., and Fournier, D. (2018). Evidence for the implication of the histone code in building the genome structure. Biosystems 164, 49-59. doi: 10.1016/j. biosystems.2017.11.005

Radonjic, M., Andrau, J. C., Lijnzaad, P., Kemmeren, P., Kockelkorn, T. T., van Leenen, D., et al. (2005). Genome-wide analyses reveal RNA polymerase
II located upstream of genes poised for rapid response upon S. cerevisiae stationary phase exit. Mol. Cell 18, 171-183. doi: 10.1016/j.molcel.2005.03.010

Rando, O. J. (2012). Combinatorial complexity in chromatin structure and function: revisiting the histone code. Curr. Opin. Genet. Dev. 22, 148-155. doi: 10.1016/j.gde.2012.02.013

Rao, S. S., Huntley, M. H., Durand, N. C., Stamenova, E. K., Bochkov, I. D., Robinson, J. T., et al. (2014). A 3D map of the human genome at kilobase resolution reveals principles of chromatin looping. Cell 159, 1665-1680.

Rawlings, J. S., Gatzka, M., Thomas, P. G., and Ihle, J. N. (2011). Chromatin condensation via the condensin II complex is required for peripheral T-cell quiescence. EMBO J. 30, 263-276. doi: 10.1038/emboj. 2010.314

Rhodes, C. T., Sandstrom, R. S., Huang, S. A., Wang, Y., Schotta, G., Berger, M. S., et al. (2016). Cross-species analyses unravel the complexity of H3K27me3 and H4K20me3 in the context of neural stem progenitor cells. Neuroepigenetics 6, 10-25. doi: 10.1016/j.nepig.2016.04.001

Rice, J. C., Nishioka, K., Sarma, K., Steward, R., Reinberg, D., and Allis, C. D. (2002). Mitotic-specific methylation of histone H4 Lys 20 follows increased PRSet7 expression and its localization to mitotic chromosomes. Genes Dev. 16, 2225-2230. doi: 10.1101/gad.1014902

Rickels, R., Herz, H. M., Sze, C. C., Cao, K., Morgan, M. A., Collings, C. K., et al. (2017). Histone H3K4 monomethylation catalyzed by Trr and mammalian COMPASS-like proteins at enhancers is dispensable for development and viability. Nat. Genet. 49, 1647-1653. doi: 10.1038/ng.3965

Riddle, N. C., Minoda, A., Kharchenko, P. V., Alekseyenko, A. A., Schwartz, Y. B., Tolstorukov, M. Y., et al. (2011). Plasticity in patterns of histone modifications and chromosomal proteins in Drosophila heterochromatin. Genome Res. 21, 147-163. doi: 10.1101/gr.110098.110

Rinn, J. L., Kertesz, M., Wang, J. K., Squazzo, S. L., Xu, X., Brugmann, S. A., et al. (2007). Functional demarcation of active and silent chromatin domains in human HOX loci by noncoding RNAs. Cell 129, 1311-1323. doi: 10.1016/j. cell.2007.05.022

Rittershaus, E. S., Baek, S. H., and Sassetti, C. M. (2013). The normalcy of dormancy: common themes in microbial quiescence. Cell Host Microbe 13, 643-651. doi: 10.1016/j.chom.2013.05.012

Rodgers, J. T., King, K. Y., Brett, J. O., Cromie, M. J., Charville, G. W., Maguire, K. K., et al. (2014). mTORC1 controls the adaptive transition of quiescent stem cells from G0 to G(Alert). Nature 510, 393-396. doi: 10.1038/nature13255

Rodriguez, C. N., and Nguyen, H. (2018). Identifying quiescent stem cells in hair follicles. Methods Mol. Biol. 1686, 137-147.

Rogakou, E. P., Pilch, D. R., Orr, A. H., Ivanova, V. S., and Bonner, W. M. (1998). DNA double-stranded breaks induce histone $\mathrm{H} 2 \mathrm{AX}$ phosphorylation on serine 139. J. Biol. Chem. 273, 5858-5868.

Roudier, F., Ahmed, I., Berard, C., Sarazin, A., Mary-Huard, T., Cortijo, S., et al. (2011). Integrative epigenomic mapping defines four main chromatin states in Arabidopsis. EMBO J. 30, 1928-1938. doi: 10.1038/emboj. 2011.103

Ruthenburg, A. J., Li, H., Milne, T. A., Dewell, S., McGinty, R. K., Yuen, M., et al. (2011). Recognition of a mononucleosomal histone modification pattern by BPTF via multivalent interactions. Cell 145, 692-706. doi: 10.1016/j.cell.2011.03.053

Rutledge, M. T., Russo, M., Belton, J. M., Dekker, J., and Broach, J. R. (2015). The yeast genome undergoes significant topological reorganization in quiescence. Nucleic Acids Res. 43, 8299-8313. doi: 10.1093/nar/gkv723

Ryall, J. G., Dell'Orso, S., Derfoul, A., Juan, A., Zare, H., Feng, X., et al. (2015). The NAD(+)-dependent SIRT1 deacetylase translates a metabolic switch into regulatory epigenetics in skeletal muscle stem cells. Cell Stem Cell 16, 171-183. doi: 10.1016/j.stem.2014.12.004

Sagot, I., and Laporte, D. (2019a). Quiescence, an individual journey. Curr. Genet. 65, 695-699.

Sagot, I., and Laporte, D. (2019b). The cell biology of quiescent yeast - a diversity of individual scenarios. J. Cell Sci. 132:jcs213025. doi: 10.1242/jcs.213025

Sajiki, K., Hatanaka, M., Nakamura, T., Takeda, K., Shimanuki, M., Yoshida, T., et al. (2009). Genetic control of cellular quiescence in S. pombe. J. Cell Sci. 122(Pt 9), 1418-1429. doi: 10.1242/jcs.046466

Saksouk, N., Simboeck, E., and Dejardin, J. (2015). Constitutive heterochromatin formation and transcription in mammals. Epigenet. Chromatin 8:3. 
Sandmeier, J. J., French, S., Osheim, Y., Cheung, W. L., Gallo, C. M., Beyer, A. L., et al. (2002). RPD3 is required for the inactivation of yeast ribosomal DNA genes in stationary phase. EMBO J. 21, 4959-4968. doi: 10.1093/emboj/ cdf498

Sang, L., and Coller, H. A. (2009). Fear of commitment: Hes1 protects quiescent fibroblasts from irreversible cellular fates. Cell Cycle 8, 2161-2167. doi: 10.4161/ cc.8.14.9104

Sang, L., Roberts, J. M., and Coller, H. A. (2010). Hijacking HES1: how tumors coopt the anti-differentiation strategies of quiescent cells. Trends Mol. Med. 16, 17-26. doi: 10.1016/j.molmed.2009.11.001

Schafer, G., McEvoy, C. R., and Patterton, H. G. (2008). The Saccharomyces cerevisiae linker histone Hholp is essential for chromatin compaction in stationary phase and is displaced by transcription. Proc. Natl. Acad. Sci. U.S.A. 105, 14838-14843. doi: 10.1073/pnas.0806337105

Schmitges, F. W., Prusty, A. B., Faty, M., Stutzer, A., Lingaraju, G. M., Aiwazian, J., et al. (2011). Histone methylation by PRC2 is inhibited by active chromatin marks. Mol. Cell 42, 330-341.

Schneider, C., King, R. M., and Philipson, L. (1988). Genes specifically expressed at growth arrest of mammalian cells. Cell 54, 787-793.

Schotta, G., Lachner, M., Sarma, K., Ebert, A., Sengupta, R., Reuter, G., et al. (2004). A silencing pathway to induce H3-K9 and H4-K20 trimethylation at constitutive heterochromatin. Genes Dev. 18, 1251-1262. doi: 10.1101/gad. 300704

Schotta, G., Sengupta, R., Kubicek, S., Malin, S., Kauer, M., Callen, E., et al. (2008). A chromatin-wide transition to H4K20 monomethylation impairs genome integrity and programmed DNA rearrangements in the mouse. Genes Dev. 22, 2048-2061. doi: 10.1101/gad.476008

Setterfield, G., Hall, R., Bladon, T., Little, J., and Kaplan, J. G. (1983). Changes in structure and composition of lymphocyte nuclei during mitogenic stimulation. J. Ultrastruct. Res. 82, 264-282.

Shi, X., Kachirskaia, I., Walter, K. L., Kuo, J. H., Lake, A., Davrazou, F., et al. (2007). Proteome-wide analysis in Saccharomyces cerevisiae identifies several PHD fingers as novel direct and selective binding modules of histone $\mathrm{H} 3$ methylated at either lysine 4 or lysine 36. J. Biol. Chem. 282, 2450-2455.

Shimada, M., Niida, H., Zineldeen, D. H., Tagami, H., Tanaka, M., Saito, H., et al. (2008). Chk1 is a histone $\mathrm{H} 3$ threonine 11 kinase that regulates DNA damage-induced transcriptional repression. Cell 132, 221-232.

Shogren-Knaak, M., Ishii, H., Sun, J. M., Pazin, M. J., Davie, J. R., and Peterson, C. L. (2006). Histone H4-K16 acetylation controls chromatin structure and protein interactions. Science 311, 844-847. doi: 10.1126/science. 1124000

Sieburg, H. B., Cho, R. H., Dykstra, B., Uchida, N., Eaves, C. J., and MullerSieburg, C. E. (2006). The hematopoietic stem compartment consists of a limited number of discrete stem cell subsets. Blood 107, 2311-2316. doi: 10. 1182/blood-2005-07-2970

Sims, J. K., Houston, S. I., Magazinnik, T., and Rice, J. C. (2006). A trans-tail histone code defined by monomethylated H4 Lys-20 and H3 Lys-9 demarcates distinct regions of silent chromatin. J. Biol. Chem. 281, 12760-12766. doi: 10.1074/jbc.M513462200

Singer, M. S., Kahana, A., Wolf, A. J., Meisinger, L. L., Peterson, S. E., Goggin, C., et al. (1998). Identification of high-copy disruptors of telomeric silencing in Saccharomyces cerevisiae. Genetics 150, 613-632. doi: 10.1093/genetics/150. 2.613

Smeenk, G., and Mailand, N. (2016). Writers, readers, and erasers of histone ubiquitylation in DNA double-strand break repair. Front. Genet. 7:122. doi: 10.3389/fgene.2016.00122

So, W. K., and Cheung, T. H. (2018). Molecular regulation of cellular quiescence: a perspective from adult stem cells and its niches. Methods Mol. Biol. 1686, 1-25. doi: 10.1007/978-1-4939-7371-2_1

Sorrell, J. M., and Caplan, A. I. (2004). Fibroblast heterogeneity: more than skin deep. J. Cell Sci. 117(Pt 5), 667-675.

Soshnev, A. A., Josefowicz, S. Z., and Allis, C. D. (2016). Greater than the sum of parts: complexity of the dynamic epigenome. Mol. Cell 62, 681-694.

Spain, M. M., Swygert, S. G., and Tsukiyama, T. (2018). Preparation and analysis of Saccharomyces cerevisiae quiescent cells. Methods Mol. Biol. 1686, 125-135.

Spencer, S. L., Cappell, S. D., Tsai, F. C., Overton, K. W., Wang, C. L., and Meyer, T. (2013). The proliferation-quiescence decision is controlled by a bifurcation in CDK2 activity at mitotic exit. Cell 155, 369-383. doi: 10.1016/j.cell.2013. 08.062
Srivastava, S., Gala, H. P., Mishra, R. K., and Dhawan, J. (2018). Distinguishing states of arrest: genome-wide descriptions of cellular quiescence using ChIPSeq and RNA-Seq analysis. Methods Mol. Biol. 1686, 215-239. doi: 10.1007/ 978-1-4939-7371-2_16

Steele-Perkins, G., Fang, W., Yang, X. H., Van Gele, M., Carling, T., Gu, J., et al. (2001). Tumor formation and inactivation of RIZ1, an Rb-binding member of a nuclear protein-methyltransferase superfamily. Genes Dev. 15, 2250-2262. doi: 10.1101/gad. 870101

Stender, J. D., Pascual, G., Liu, W., Kaikkonen, M. U., Do, K., Spann, N. J., et al. (2012). Control of proinflammatory gene programs by regulated trimethylation and demethylation of histone H4K20. Mol. Cell 48, 28-38. doi: 10.1016/j. molcel.2012.07.020

Strahl, B. D., and Allis, C. D. (2000). The language of covalent histone modifications. Nature 403, 41-45.

Stucki, M., Clapperton, J. A., Mohammad, D., Yaffe, M. B., Smerdon, S. J., and Jackson, S. P. (2005). MDC1 directly binds phosphorylated histone H2AX to regulate cellular responses to DNA double-strand breaks. Cell 123, 1213-1226.

Su, S. S., Tanaka, Y., Samejima, I., Tanaka, K., and Yanagida, M. (1996). A nitrogen starvation-induced dormant G0 state in fission yeast: the establishment from uncommitted G1 state and its delay for return to proliferation. J. Cell Sci. 109(Pt 6), 1347-1357.

Suh, E. J., Remillard, M. Y., Legesse-Miller, A., Johnson, E. L., Lemons, J. M., Chapman, T. R., et al. (2012). A microRNA network regulates proliferative timing and extracellular matrix synthesis during cellular quiescence in fibroblasts. Genome Biol. 13:R121. doi: 10.1186/gb-2012-13-12-r121

Sun, D., and Buttitta, L. (2017). States of $\mathrm{G}(0)$ and the proliferation-quiescence decision in cells, tissues and during development. Int. J. Dev. Biol. 61, 357-366. doi: $10.1387 / \mathrm{ijdb} .160343 \mathrm{LB}$

Svensson, V., Vento-Tormo, R., and Teichmann, S. A. (2018). Exponential scaling of single-cell RNA-seq in the past decade. Nat. Protoc. 13, 599-604. doi: 10. 1038/nprot.2017.149

Swygert, S. G., Kim, S., Wu, X., Fu, T., Hsieh, T. H., Rando, O. J., et al. (2019). Condensin-Dependent chromatin compaction represses transcription globally during quiescence. Mol. Cell 73, 533-546.e4.

Swygert, S. G., Lin, D., Portillo-Ledesma, S., Lin, P.-Y., Hunt, D. R., Kao, C.F., et al. (2021). Chromatin fiber folding represses transcription and loop extrusion in quiescent cells. bioRxiv [preprint] doi: 10.1101/2020.11.24.39 6713

Takeda, K., and Yanagida, M. (2010). In quiescence of fission yeast, autophagy and the proteasome collaborate for mitochondrial maintenance and longevity. Autophagy 6, 564-565.

Takei, Y., Yun, J., Zheng, S., Ollikainen, N., Pierson, N., White, J., et al. (2021). Integrated spatial genomics reveals global architecture of single nuclei. Nature 590, 344-350. doi: 10.1038/s41586-020-03126-2

Tang, G. B., Zeng, Y. Q., Liu, P. P., Mi, T. W., Zhang, S. F., Dai, S. K., et al. (2017). The histone H3K27 demethylase UTX regulates synaptic plasticity and cognitive behaviors in mice. Front. Mol. Neurosci. 10:267. doi: 10.3389/fnmol. 2017.00267

Tardat, M., Brustel, J., Kirsh, O., Lefevbre, C., Callanan, M., Sardet, C., et al. (2010). The histone H4 Lys 20 methyltransferase PR-Set7 regulates replication origins in mammalian cells. Nat. Cell Biol. 12, 1086-1093. doi: 10.1038/ncb2113

Terzi, M. Y., Izmirli, M., and Gogebakan, B. (2016). The cell fate: senescence or quiescence. Mol. Biol. Rep. 43, 1213-1220.

Tesio, M., Tang, Y., Mudder, K., Saini, M., von Paleske, L., Macintyre, E., et al. (2015). Hematopoietic stem cell quiescence and function are controlled by the CYLD-TRAF2-p38MAPK pathway. J. Exp. Med. 212, 525-538. doi: 10.1084/jem.20141438

Tessarz, P., and Kouzarides, T. (2014). Histone core modifications regulating nucleosome structure and dynamics. Nat. Rev. Mol. Cell Biol. 15, 703-708.

Tie, G., Yan, J., Khair, L., Tutto, A., and Messina, L. M. (2020). Hypercholesterolemia accelerates the aging phenotypes of hematopoietic stem cells by a Tet1-dependent pathway. Sci. Rep. 10:3567. doi: 10.1038/s41598-020-60403-w

Tokuyasu, K., Madden, S. C., and Zeldis, L. J. (1968). Fine structural alterations of interphase nuclei of lymphocytes stimulated to grwoth activity in vitro. J. Cell Biol. 39, 630-660. doi: 10.1083/jcb.39.3.630

Torres, I. O., Kuchenbecker, K. M., Nnadi, C. I., Fletterick, R. J., Kelly, M. J., and Fujimori, D. G. (2015). Histone demethylase KDM5A is regulated by its 
reader domain through a positive-feedback mechanism. Nat. Commun. 6:6204. doi: $10.1038 /$ ncomms7204

Tripputi, P., Emanuel, B. S., Croce, C. M., Green, L. G., Stein, G. S., and Stein, J. L. (1986). Human histone genes map to multiple chromosomes. Proc. Natl. Acad. Sci. U.S.A. 83, 3185-3188.

Trojer, P., and Reinberg, D. (2007). Facultative heterochromatin: is there a distinctive molecular signature? Mol. Cell 28, 1-13. doi: 10.1016/j.molcel.2007. 09.011

Trojer, P., Li, G., Sims, R. J. III, Vaquero, A., Kalakonda, N., Boccuni, P., et al. (2007). L3MBTL1, a histone-methylation-dependent chromatin lock. Cell 129, 915-928. doi: 10.1016/j.cell.2007.03.048

Tsai, W. W., Wang, Z., Yiu, T. T., Akdemir, K. C., Xia, W., Winter, S., et al. (2010). TRIM24 links a non-canonical histone signature to breast cancer. Nature 468, 927-932. doi: 10.1038/nature09542

Tumpel, S., and Rudolph, K. L. (2019). Quiescence: good and bad of stem cell aging. Trends Cell Biol. 29, 672-685. doi: 10.1016/j.tcb.2019. 05.002

Turner, B. M. (2002). Cellular memory and the histone code. Cell 111, 285-291.

Urbán, N., and Cheung, T. H. (2021). Stem cell quiescence: the challenging path to activation. Development 148, doi: 10.1242/dev.165084

Vakoc, C. R., Mandat, S. A., Olenchock, B. A., and Blobel, G. A. (2005). Histone H3 lysine 9 methylation and HPlgamma are associated with transcription elongation through mammalian chromatin. Mol. Cell 19, 381-391.

Valcourt, J. R., Lemons, J. M., Haley, E. M., Kojima, M., Demuren, O. O., and Coller, H. A. (2012). Staying alive: metabolic adaptations to quiescence. Cell Cycle 11, 1680-1696. doi: 10.4161/cc.19879

van Leeuwen, F., Gafken, P. R., and Gottschling, D. E. (2002). Dot1p modulates silencing in yeast by methylation of the nucleosome core. Cell 109, 745-756. doi: 10.1016/s0092-8674(02)00759-6

van Velthoven, C. T. J., de Morree, A., Egner, I. M., Brett, J. O., and Rando, T. A. (2017). Transcriptional profiling of quiescent muscle stem cells in vivo. Cell Rep. 21, 1994-2004.

Vander Heiden, M. G., Cantley, L. C., and Thompson, C. B. (2009). Understanding the Warburg effect: the metabolic requirements of cell proliferation. Science 324, 1029-1033.

Vasquez, J. J., Wedel, C., Cosentino, R. O., and Siegel, T. N. (2018). Exploiting CRISPR-Cas9 technology to investigate individual histone modifications. Nucleic Acids Res. 46:e106. doi: 10.1093/nar/gky517

Venezia, T. A., Merchant, A. A., Ramos, C. A., Whitehouse, N. L., Young, A. S., Shaw, C. A., et al. (2004). Molecular signatures of proliferation and quiescence in hematopoietic stem cells. PLoS Biol. 2:e301. doi: 10.1371/journal. pbio.0020301

Venkatraman, A., He, X. C., Thorvaldsen, J. L., Sugimura, R., Perry, J. M., Tao, F., et al. (2013). Maternal imprinting at the H19-Igf2 locus maintains adult haematopoietic stem cell quiescence. Nature 500, 345-349. doi: 10.1038/ nature 12303

Vizán, P., Gutiérrez, A., Espejo, I., García-Montolio, M., Lange, M., Carretero, A., et al. (2020). The Polycomb-associated factor PHF19 controls hematopoietic stem cell state and differentiation. Sci. Adv. 6:eabb2745. doi: 10.1126/sciadv. abb2745

Voigt, P., Tee, W. W., and Reinberg, D. (2013). A double take on bivalent promoters. Genes Dev. 27, 1318-1338. doi: 10.1101/gad.219 626.113

Volker-Albert, M. C., Schmidt, A., Forne, I., and Imhof, A. (2018). Analysis of histone modifications by mass spectrometry. Curr. Protoc. Protein Sci. 92:e54.

Wagner, E. J., and Carpenter, P. B. (2012). Understanding the language of Lys36 methylation at histone H3. Nat Rev. Mol. Cell Biol. 13, 115-126. doi: 10.1038/ nrm3274

Walter, D., Matter, A., and Fahrenkrog, B. (2014). Loss of histone $\mathrm{H} 3$ methylation at lysine 4 triggers apoptosis in Saccharomyces cerevisiae. PLoS Genet. 10:e1004095. doi: 10.1371/journal.pgen.100 4095

Wang, D., Mansisidor, A., Prabhakar, G., and Hochwagen, A. (2016). Condensin and Hmol mediate a starvation-induced transcriptional position effect within the ribosomal DNA array. Cell Rep. 17:624.

Wang, G. G., and Allis, C. D. (2009). "Misinterpretation" of a histone mark is linked to aberrant stem cells and cancer development. Cell Cycle 8, 1982-1983.
Wang, Z., Gerstein, M., and Snyder, M. (2009). RNA-Seq: a revolutionary tool for transcriptomics. Nat. Rev. Genet. 10, 57-63.

Wang, Z., Zang, C., Rosenfeld, J. A., Schones, D. E., Barski, A., Cuddapah, S., et al. (2008). Combinatorial patterns of histone acetylations and methylations in the human genome. Nat. Genet. 40, 897-903.

Watanabe, S., Mishima, Y., Shimizu, M., Suetake, I., and Takada, S. (2018). Interactions of HP1 bound to $\mathrm{H} 3 \mathrm{~K} 9 \mathrm{me} 3$ dinucleosome by molecular simulations and biochemical assays. Biophys. J. 114, 2336-2351. doi: 10.1016/j. bpj.2018.03.025

Wei, Y., Yu, L., Bowen, J., Gorovsky, M. A., and Allis, C. D. (1999). Phosphorylation of histone $\mathrm{H} 3$ is required for proper chromosome condensation and segregation. Cell 97, 99-109.

Werner-Washburne, M., Braun, E. L., Crawford, M. E., and Peck, V. M. (1996). Stationary phase in Saccharomyces cerevisiae. Mol. Microbiol. 19, 1159-1166.

Wiles, E. T., and Selker, E. U. (2017). H3K27 methylation: a promiscuous repressive chromatin mark. Curr. Opin. Genet. Dev. 43, 31-37. doi: 10.1016/j.gde.2016. 11.001

Wilson, A., Laurenti, E., Oser, G., van der Wath, R. C., Blanco-Bose, W., Jaworski, M., et al. (2008). Hematopoietic stem cells reversibly switch from dormancy to self-renewal during homeostasis and repair. Cell 135, 1118-1129. doi: 10.1016/ j.cell.2008.10.048

Winter, S., Simboeck, E., Fischle, W., Zupkovitz, G., Dohnal, I., Mechtler, K., et al. (2008). 14-3-3 proteins recognize a histone code at histone $\mathrm{H} 3$ and are required for transcriptional activation. EMBO J. 27, 88-99. doi: 10.1038/sj. emboj.7601954

Wu, S., Wang, W., Kong, X., Congdon, L. M., Yokomori, K., Kirschner, M. W., et al. (2010). Dynamic regulation of the PR-Set7 histone methyltransferase is required for normal cell cycle progression. Genes Dev. 24, 2531-2542. doi: $10.1101 /$ gad.1984210

Wu, T., Yoon, H., Xiong, Y., Dixon-Clarke, S. E., Nowak, R. P., and Fischer, E. S. (2020). Targeted protein degradation as a powerful research tool in basic biology and drug target discovery. Nat. Struct. Mol. Biol. 27, 605-614.

Xu, J., and Kidder, B. L. (2018). H4K20me3 co-localizes with activating histone modifications at transcriptionally dynamic regions in embryonic stem cells. BMC Genomics 19:514. doi: 10.1186/s12864-0184886-4

Xu, J., Ma, H., Jin, J., Uttam, S., Fu, R., Huang, Y., et al. (2018). Super-Resolution imaging of higher-order chromatin structures at different epigenomic states in single mammalian cells. Cell Rep. 24, 873-882.

Xu, M., Soloveychik, M., Ranger, M., Schertzberg, M., Shah, Z., Raisner, R., et al. (2012). Timing of transcriptional quiescence during gametogenesis is controlled by global histone H3K4 demethylation. Dev. Cell 23, 1059-1071. doi: 10.1016/ j.devcel.2012.10.005

Yan, H., Evans, J., Kalmbach, M., Moore, R., Middha, S., Luban, S., et al. (2014). HiChIP: a high-throughput pipeline for integrative analysis of ChIP-Seq data. BMC Bioinformatics 15:280. doi: 10.1186/1471-210515-280

Yang, K., and Chi, H. (2018). Investigating cellular quiescence of T lymphocytes and antigen-induced exit from quiescence. Methods Mol. Biol. 1686, 161-172. doi: 10.1007/978-1-4939-7371-2_12

Yildirim, E., Kirby, J. E., Brown, D. E., Mercier, F. E., Sadreyev, R. I., Scadden, D. T., et al. (2013). Xist RNA is a potent suppressor of hematologic cancer in mice. Cell 152, 727-742. doi: 10.1016/j.cell.2013.01.034

Yin, H., Price, F., and Rudnicki, M. A. (2013). Satellite cells and the muscle stem cell niche. Physiol. Rev. 93, 23-67.

Young, C. P., Hillyer, C., Hokamp, K., Fitzpatrick, D. J., Konstantinov, N. K., Welty, J. S., et al. (2017). Distinct histone methylation and transcription profiles are established during the development of cellular quiescence in yeast. BMC Genomics 18:107. doi: 10.1186/s12864-0173509-9

Yuan, W., Xu, M., Huang, C., Liu, N., Chen, S., and Zhu, B. (2011). H3K36 methylation antagonizes PRC2-mediated H3K27 methylation. J. Biol. Chem. 286, 7983-7989.

Zahedi, Y., Durand-Dubief, M., and Ekwall, K. (2020). High-Throughput flow cytometry combined with genetic analysis brings new insights into the understanding of chromatin regulation of cellular quiescence. Int J Mol Sci. 21:9022. doi: $10.3390 /$ ijms21239022 
Zhang, T., Cooper, S., and Brockdorff, N. (2015). The interplay of histone modifications - writers that read. EMBO Rep. 16, 1467-1481.

Zhou, K., Gaullier, G., and Luger, K. (2019). Nucleosome structure and dynamics are coming of age. Nat. Struct. Mol. Biol. 26, 3-13.

Zhou, Y., Yan, X., Feng, X., Bu, J., Dong, Y., Lin, P., et al. (2018). Setd2 regulates quiescence and differentiation of adult hematopoietic stem cells by restricting RNA polymerase II elongation. Haematologica 103, 1110-1123. doi: 10.3324/haematol.2018.187708

Zhu, C., Zhang, Y., Li, Y. E., Lucero, J., Behrens, M. M., and Ren, B. (2021). Joint profiling of histone modifications and transcriptome in single cells from mouse brain. Nat. Methods 18, 283-292. doi: 10.1038/s41592-021-01060-3

Zippo, A., Serafini, R., Rocchigiani, M., Pennacchini, S., Krepelova, A., and Oliviero, S. (2009). Histone crosstalk between H3S10ph and H4K16ac generates a histone code that mediates transcription elongation. Cell 138, 1122-1136. doi: 10.1016/j.cell.2009.07.031
Conflict of Interest: The authors declare that the research was conducted in the absence of any commercial or financial relationships that could be construed as a potential conflict of interest.

Publisher's Note: All claims expressed in this article are solely those of the authors and do not necessarily represent those of their affiliated organizations, or those of the publisher, the editors and the reviewers. Any product that may be evaluated in this article, or claim that may be made by its manufacturer, is not guaranteed or endorsed by the publisher.

Copyright (c) 2021 Bonitto, Sarathy, Atai, Mitra and Coller. This is an open-access article distributed under the terms of the Creative Commons Attribution License (CC BY). The use, distribution or reproduction in other forums is permitted, provided the original author(s) and the copyright owner(s) are credited and that the original publication in this journal is cited, in accordance with accepted academic practice. No use, distribution or reproduction is permitted which does not comply with these terms. 